\title{
The Influence of Instructional Design Decisions on Student Motivation in Online Courses
}

\author{
Robin E. Youger
}

Follow this and additional works at: https://researchrepository.wvu.edu/etd

\section{Recommended Citation}

Youger, Robin E., "The Influence of Instructional Design Decisions on Student Motivation in Online Courses" (2018). Graduate Theses, Dissertations, and Problem Reports. 7011.

https://researchrepository.wvu.edu/etd/7011

This Dissertation is protected by copyright and/or related rights. It has been brought to you by the The Research Repository @ WVU with permission from the rights-holder(s). You are free to use this Dissertation in any way that is permitted by the copyright and related rights legislation that applies to your use. For other uses you must obtain permission from the rights-holder(s) directly, unless additional rights are indicated by a Creative Commons license in the record and/ or on the work itself. This Dissertation has been accepted for inclusion in WVU Graduate Theses, Dissertations, and Problem Reports collection by an authorized administrator of The Research Repository @ WVU.

For more information, please contact researchrepository@mail.wvu.edu. 


\title{
The influence of instructional design decisions on student motivation in online courses
}

\author{
Robin E. Youger \\ Dissertation submitted to the College of Education and Human Services \\ at West Virginia University \\ in partial fulfillment of the requirements for the Degree of \\ Doctor of Education in \\ Instructional Design and Technology
}

Terence C. Ahern, Ph.D., Chair

Ugur Kale, Ph.D.

Jiangmei Yuan, Ph.D.

D.J. Hendricks, Ed.D.

John Oughton, Ed.D.

Department of Learning Sciences and Human Development

Morgantown, WV

2018

Keywords: motivation; motivational design; Quality Matters; quality; value; worth; online learning; retention

Copyright (C) Robin E. Youger 


\title{
ABSTRACT \\ The influence of instructional design decisions on student motivation in online courses
}

\author{
Robin E. Youger
}

The goal of higher education is to educate, train, and motivate people (Hunt, 1998). Typically, best practices and accepted design strategies are used to develop online courses that fulfill the needs of the university, faculty, and student stakeholders. This study examines two methods of instructional design - the Quality Matters (QM) process, and Keller's ARCS motivational design process - to understand if instructional design decisions have influence on student motivation in online courses. Quality Matters (QM) offers a well-researched process of designing online courses based on nationally-recognized standards. The QM format provides an ideal objectives-based course design; however, it does not account for the learning experience itself. Alternately, Keller's model of motivational design (2010) provides a series of planning activities course designers can use to capture and retain student attention, reveal or strengthen content relevance, instill student confidence, and create satisfaction with the overall learning experience. Student motivation has been directly linked to attrition (Chen \& Jang, 2010). Design decisions can be implemented to enhance motivation, critical to student success and retention. Perhaps the real quality of a course only matters if the course has value and is worthwhile to students. 


\section{Dedication and Acknowledgements}

To Mike and Joe: you have always been my motivation!

Thank you, Mom, for your encouragement!

I love you! Always Twice...

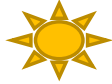

Thank you to my outstanding committee members who made this work so much better.

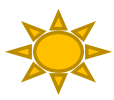

I would like to acknowledge the lessons taught to me by all the students I have had the privilege to teach. Each class was unique, despite course content being equal between sessions. My students taught me many valuable lessons on presentation and materials, but most importantly, they helped me learn techniques and tricks confirmed by this research that can make learning both easy and fun for all involved. I hope readers find something of value here. 


\section{Table of Contents}

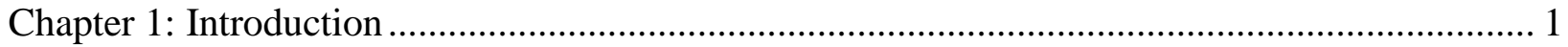

Significance of the Study ……………………………….............................................. 2

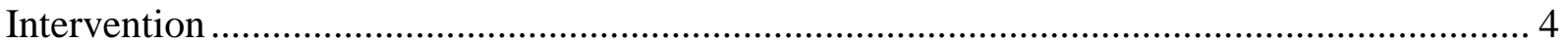

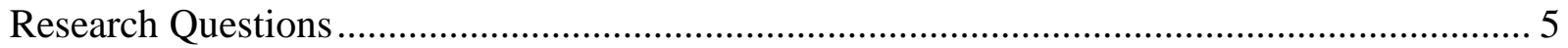

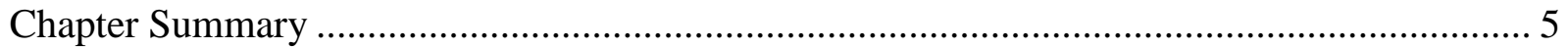

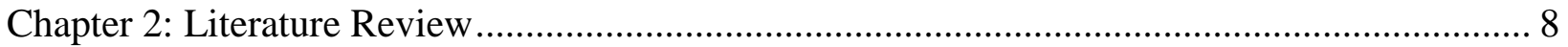

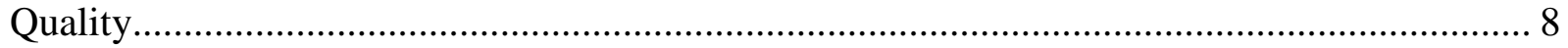

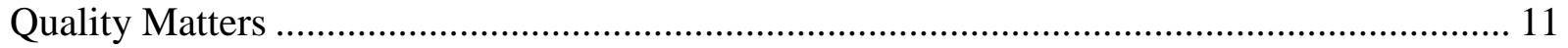

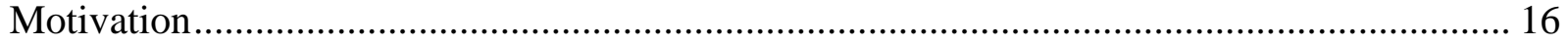

Keller's Motivational Design Theory ………………...................................................... 19

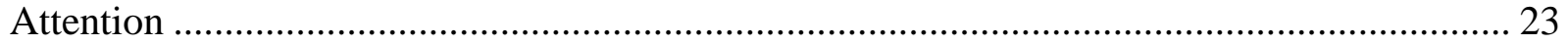

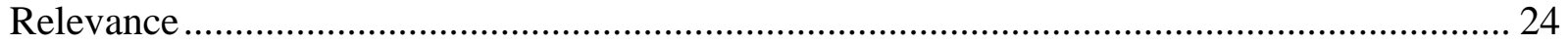

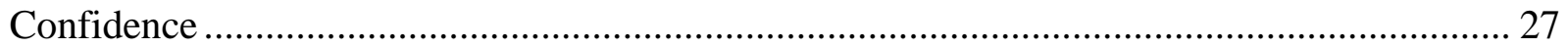

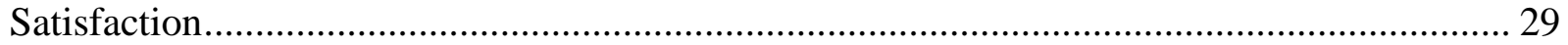

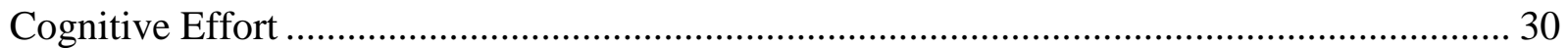

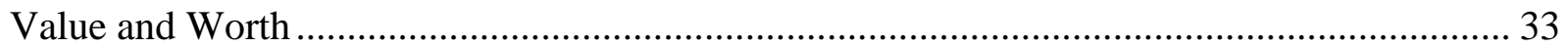

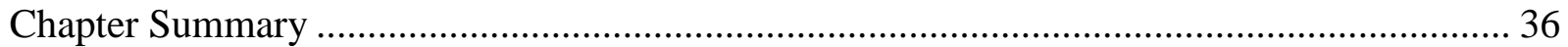

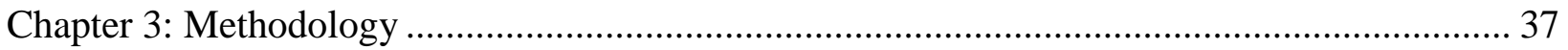

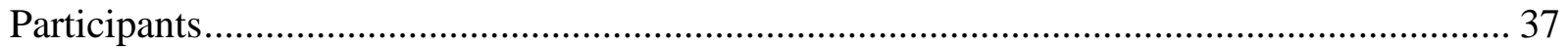

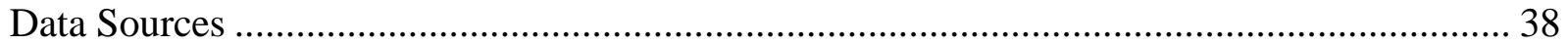

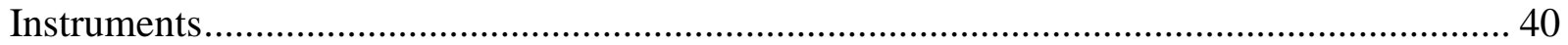

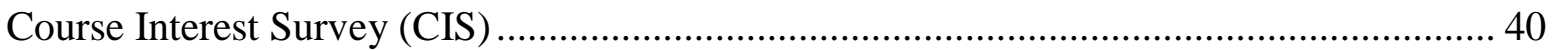

Instructional Materials Motivation Scale (IMMS) ………............................................... 41

Course Syllabus Comparison Chart ............................................................................. 42

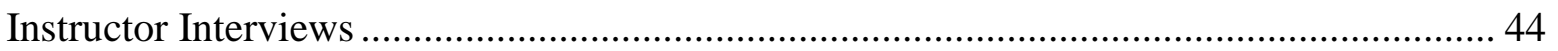

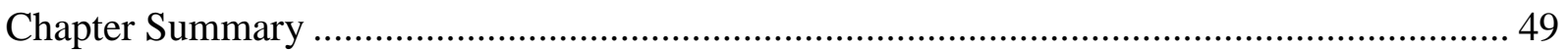

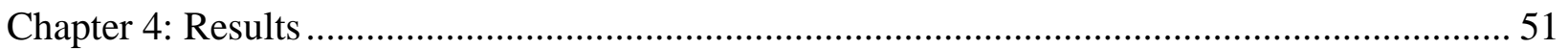

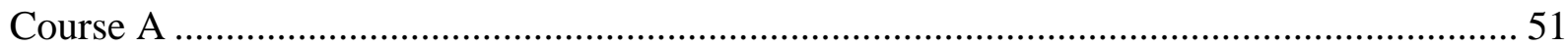

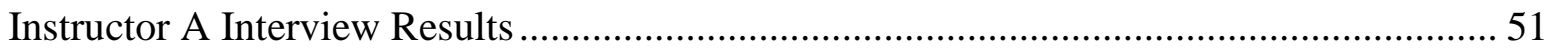

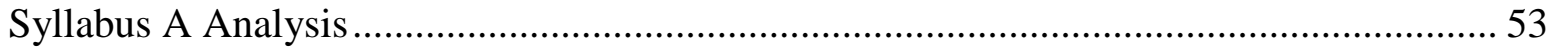

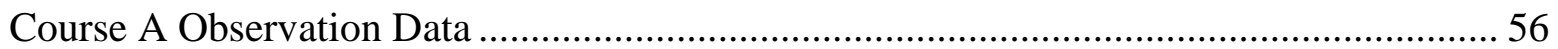

Course A Student Ratings of Motivation: CIS Survey ………………................................. 58

Course A Student Ratings of Motivation: IMMS Survey.................................................... 63

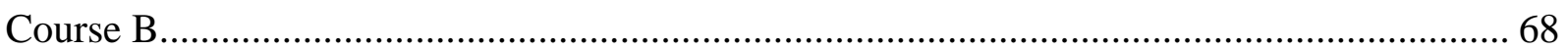




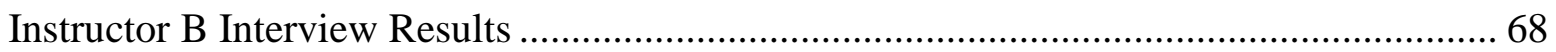

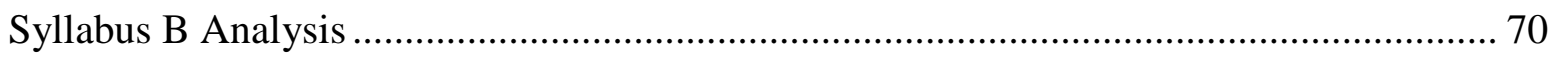

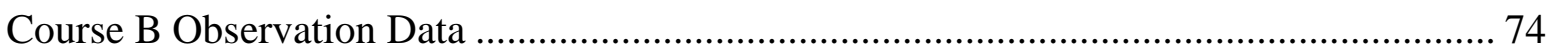

Course B Student Ratings of Motivation: CIS Survey ………………………………….... 75

Course B Student Ratings of Motivation: IMMS Survey ....................................................... 79

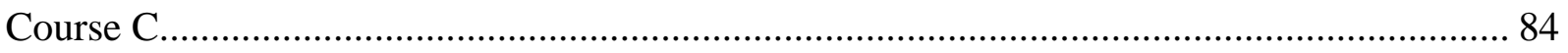

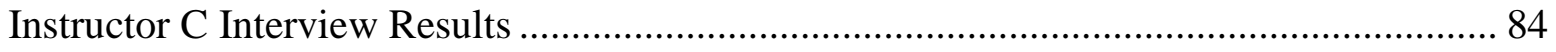

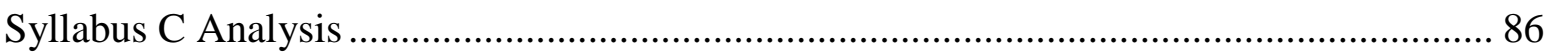

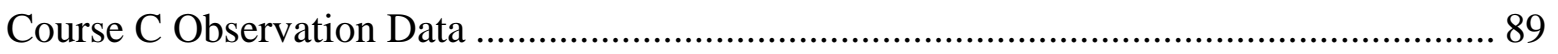

Course C Student Ratings of Motivation: CIS Survey ……………………………............. 91

Course C Student Ratings of Motivation: IMMS Survey................................................... 96

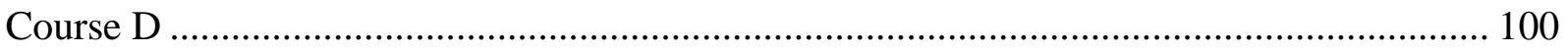

Instructor D Interview Results .................................................................................... 100

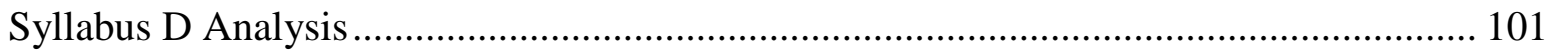

Course D Observation Data ........................................................................................... 105

Course D Student Ratings of Motivation: CIS Survey ......................................................... 107

Course D Student Ratings of Motivation: IMMS Survey.................................................. 111

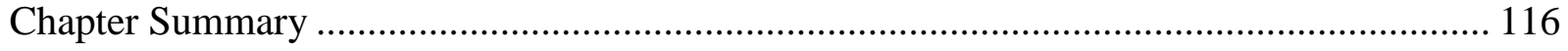

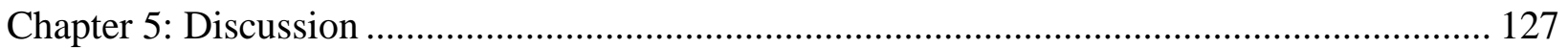

Limitations ........................................................................................................... 133

Recommendations for Future Research ............................................................................... 134

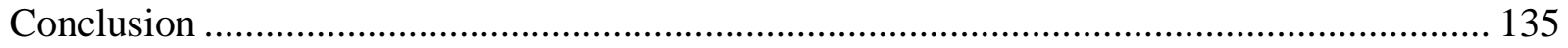

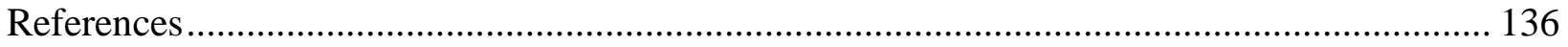

\section{Appendices}

Appendix A: Course Interest Survey (CIS)

Appendix B: Instructional Materials Motivational Scale (IMMS) 


\section{Table of Tables}

Table 1: ARCS Model Categories, Definitions, and Process Questions (Keller, 2010).............. 20

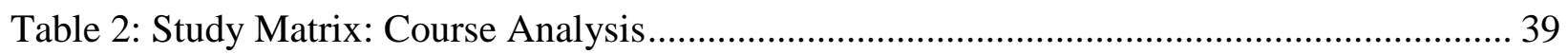

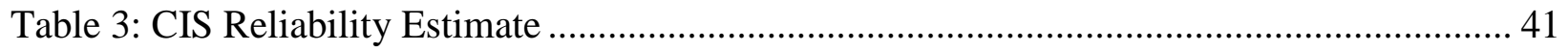

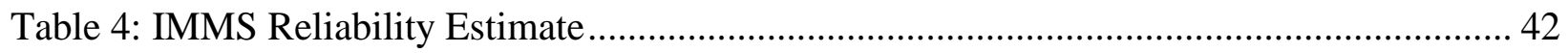

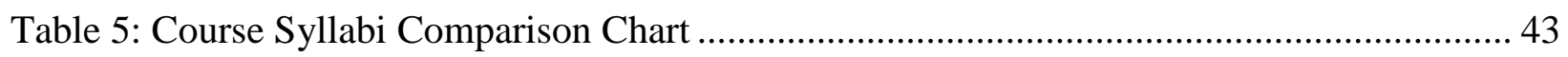

Table 6: Summary of Motivational Design in Relation to Instructional Design ........................ 45

Table 7: Data Sources, Collection, and Analysis Procedures................................................... 47

Table 8: Scoring Guide for the Course Interest Survey (CIS) ................................................ 48

Table 9: Scoring Guide for the Instructional Materials Motivational Survey (IMMS) ............... 48

Table 10: Course A Scoring Results - Course Interest Survey (CIS) ....................................... 60

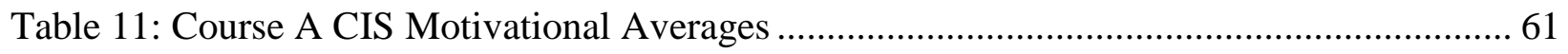

Table 12: Course A Scoring Results - Instructional Materials Motivational Scale (IMMS)........ 65

Table 13: Course A IMMS Motivational Averages................................................................ 66

Table 14: Course B Scoring Results - Course Interest Survey (CIS) ....................................... 77

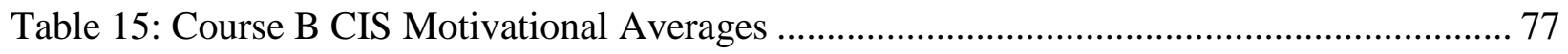

Table 16: Course B Scoring Results - Instructional Materials Motivational Scale (IMMS)........ 82

Table 17: Course B IMMS Motivational Averages ............................................................... 82

Table 18: Course C Scoring Results - Course Interest Survey (CIS) ...................................... 93

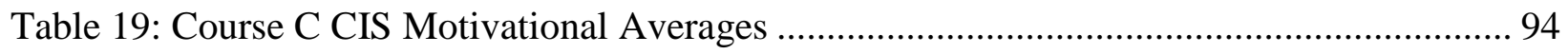

Table 20: Course C Scoring Results - Instructional Materials Motivational Scale (IMMS)........ 98

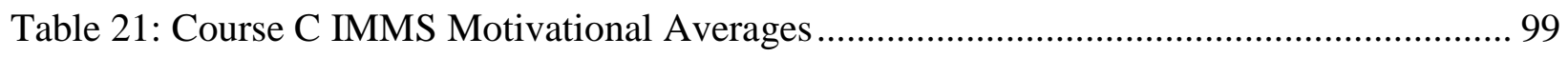

Table 22: Course D Scoring Results - Course Interest Survey (CIS) .................................... 109

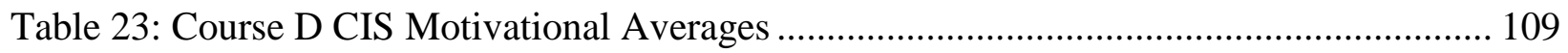

Table 24: Course D Scoring Results - Instructional Materials Motivational Scale (IMMS)...... 114

Table 25: Course D IMMS Motivational Averages.............................................................. 114

Table 26: Course Syllabi Comparison Chart (Completed) ...................................................... 118

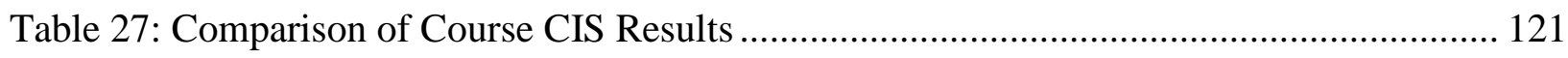

Table 28: Comparison of Course IMMS Results................................................................. 124

Table 29: Analysis of Course Interest Survey (CIS) Results............................................... 125

Table 30: Analysis of Instructional Materials Motivational Scale (IMMS) Results ................. 125 


\section{Chapter 1: Introduction}

College students are demanding more online education opportunities than ever before. Online-only students represent $49.9 \%$ of all new college enrollments, while online course offerings provide 32\% of total enrollment in degree-granting post-secondary institutions (Allen \& Seaman, 2013). Increased demand for online education has colleges and universities firmly committed to improving the design and delivery of their online instruction; however, this has proved to be a difficult task. The many factors that combine to determine course success can be elusive (Smyth, 2014), dependent on a confluence of key elements such as course structure, instructional strategies, learner considerations, and learning tasks (Koohang, 2004). After the course is developed, it must be successfully deployed and made available for seamless interaction between students and instructors.

Courses, whether online or face-to-face, do not exist in a vacuum. In most institutions, there are four primary stakeholders, each with a vested interest in the success or failure of the instruction: administrators, instructional designers, faculty, and students. Administrators provide the central resources to develop and deliver a course. Instructional designers, often faculty, create the course using accepted design techniques and tools, including content provided by subjectmatter experts. Faculty also serve as subject-matter experts specialized in the delivery of the education to students, who are consumers of the instruction. Each course is multidimensional as stakeholder groups each see it from a different perspective and for a different purpose (Harvey \& Green, 1993; Shelton, 2011; Tam, 2001). Consequently, it is difficult to create successful, highquality instruction that is motivating and valuable to learners. Because student retention is essential to the success of higher education institutes, a model of prediction is much-needed to advance student persistence (Boston, Ice, \& Gibson, 2011). 
The ultimate goal is to design education experiences that make students want to log in, want to participate, and want to feel challenged by the content and assessment measures. Reality is slightly different, however: studies indicate a direct connection between attrition rates and lack of motivation (Chen \& Jang, 2010). Motivation, related to the amount of effort that a person puts forth to reach a goal, is vital to successful adult learning. This, in turn, is critical to retention and, therefore, to the fulfillment of all stakeholder interests. This study examines two methods of instructional design - the Quality Matters (QM) process, and Keller’s ARCS motivational design process - to understand if instructional design decisions influence student motivation in online courses. This study seeks to determine whether choices made in the instructional design process have an impact on student motivation to complete the online course and effectively utilize the course materials.

\section{Significance of the Study}

To meet the growing demand for online courses, administrators, instructional designers, and faculty must understand the impact of student motivation on the learning process. The need for this study on student motivation and the influence of instructional design is both significant and timely. High attrition has been directly attributed to low motivation (Chen \& Jang, 2010), making it crucial to understand whether design decisions can influence student motivation and increase the desire to participate in online courses that are seen as relevant and engaging. Understanding how instructional design choices influence student motivation in online learning may result in higher retention through the creation of more engaging education opportunities.

In 2008, nearly $40 \%$ of all adult learners in higher education, defined as those over the age of 24, were enrolled in online institutions (Boston, Ice, \& Gibson 2011). Effective instructional design is paramount to successful online adult education where it is necessary to 
accommodate the different learning styles and needs of a varied student population, particularly nontraditional students. The U.S. Department of Education has defined non-traditional students as meeting at least one of the following criteria: delayed enrollment (one or more years after high school graduation); attend part-time; work full-time; financially independent; have dependents other than a spouse; is a single parent; or does not have a high school diploma (Gilardi \& Gugliemetti, 2011). Adult learners want to know how new knowledge will enhance their own lives, evidenced by several studies which found that relevance to work or personal goals is an effective motivator for learning (Gorges \& Kandler, 2012; Hodges, 2004; Means, Jonassen \& Dwyer, 1997). An examination of student motivation elements may encourage instructional designers or faculty to use specific, targeted design strategies that demonstrate course relevance and increase student satisfaction with the overall learning experience.

In 2010, more than 4.6 million students were enrolled in online courses in the United States (Boston, Ice, \& Gibson, 2011). The National Center for Educational Statistics (2011) reported that between 2000 and 2009, college enrollment increased across all age-ranges: young adults ages 18-19 increased from 45 to 50\%; adults ages 20-24 increased from 32 to 39\%; adults ages 25-29 increased from 11 to 13\%, and adults ages 30-34 increased from 7 to 8\% (U.S. Department of Education, 2011, p. 2). College enrollment continues to rise. Today’s students are faced with multiple commitments in addition to their academic pursuits, making online courses even more desirable.

An online course has many components in addition to subject-matter content that can be enhanced by the use of motivational design strategies. For example, many design issues are dependent on the delivery medium of a course and the learning management system (LMS) chosen by the university to grant access and deliver online education courses to students and 
faculty. It is important that both students and instructors are able to successfully navigate around the learning environment. The general format and overall layout of the course should be usable and intuitive for both students and instructors, and should accommodate class, group, and individual discussion and interaction. An online course should have a comprehensive but userfriendly repository that allows seamless access to all course resources and materials. Online course design should offer intuitive communication and assignment submission procedures to avoid student confusion and error. Before the course is released and made available to students, attention must be given to the smallest detail: all hyperlinks must function properly; all readable files must work; all dates must be accurate, or students quickly become overwhelmed or anxious.

The concept of quality in online learning provides both a means of accountability and a route to improvement, yet is as complex as online learning itself (Smyth, 2014). O'Neill and Palmer (2004) defined quality in higher education as "the difference between what a student expects to receive and his/her perceptions of actual delivery” (p. 42). Some propose the quality of any course can be developed through "best practice,” measurable against a process (Harvey \& Green, 1993). Keller's ARCS model suggests motivational strategies can be incorporated into the traditional instructional design process to result in more meaningful online learning experiences. Motivation to learn can be increased when students have confidence in their ability to complete a task (Hodges, 2004).

\section{Intervention}

An intervention was designed to determine whether student motivation is influenced by instructional design decisions. Four case studies were developed using data from instructor interviews, observation research, and syllabi analysis to reveal instructional design choices within each course. Keller’s two survey instruments were administered to determine student 
ratings of motivation in each course. Student data were analyzed for overall course motivation rating. Scores in each of the four ARCS categories of attention, relevance, confidence, and satisfaction, were also analyzed to determine if specific instructional design choices influenced student motivation.

Data from the comprehensive case studies provide insight about the influence of instructional design decisions on student motivation in online courses, and greatly contribute to the existing literature on instructional design, QM, and student motivation. This study sought to determine if motivational design strategies such as those suggested by Keller can help course designers capture and hold learner attention, and provide a perception of relevance, confidence and satisfaction about learning the content. The development of motivating educational courses may in turn lead to enhanced cognitive performance (Keller, 1987a, 1987b, 2006, 2010; Means, et al., 1997) and increased course success for all stakeholders. It was the final goal of this study to present proven strategies that instructional designers and instructors can implement to create more motivating online educational experiences.

\section{Research Questions}

This research study is driven by following question with two sub-questions:

RQ\#1: Do instructional design decisions influence student motivation in online courses? RQ\#1a: What motivational elements are present in QM vs non-QM designed courses? RQ\#1b: Do motivational elements differ in QM vs non-QM designed courses?

\section{Chapter Summary}

The continuing demand for and expansion of online course offerings makes it urgent to research effective instructional design techniques, even as designers struggle to keep pace with viable technology options available for creating and delivering high-value online course content 
for students. Today’s course designers have at their disposal sophisticated technologies to design and deliver a truly remarkable learning experience; yet as Churches (2008) points out, it’s not about the tools, it's about effectively using those tools to facilitate learning. As educational technologies continue to evolve and improve, online instructional design remains inconsistent and varied (Shelton, 2011; Youger \& Ahern, 2015). Methods to assess “quality” in online courses also vary across institutes and may be inadequate due to a lack of consistent and ongoing quality assurance measures (Shelton, 2011).

A motivational design process as suggested by Keller’s ARCS -- attention, relevance, confidence, and satisfaction -- model (1987a; 1987b; 2006; 2010) may enrich the traditional instructional design process and supplement existing quality measures such as those of Quality Matters (QM). The value and worth of a course is constantly being reevaluated as each group of students bring their own set of needs and wants to the learning experience. This study seeks to also determine if motivational techniques subsequently add value and worth to an online course. Online instructional design is a complex task of assembling resources and content into a course, which then conforms to and compliments the overall curriculum while achieving student learning objectives (Horton, 2006).

This study examines two methods of instructional design -- the Quality Matters (QM) process, and Keller’s ARCS motivational design process -- to understand if instructional design decisions influence student motivation in online courses.

The QM nonprofit organization offers well-researched, nationally-recognized methods for effective online learning creation through customized rubrics and trainings for higher education, K-12 education, continuing and professional education, and educational publishing (QM, 2014a). Peer-reviewers trained in the QM evaluation procedure use the applicable rubric to 
assess and certify online courses. The QM higher education rubric contains 40 individual standards organized into eight categories: course overview, learner objectives, assessment and measurement, resources and materials, learner engagement, course technology, learner support, and accessibility (QM, 2014a). This standardized framework is ideal for designing objectivesbased online courses. However, this approach does not account for the value and worth of the learning experience (Youger R. \& Ahern, T., 2015), nor does it address the process of learning itself (Swan, K., Matthews, D., Bogle, L., Boles, E., \& Day, S., 2012).

Keller's motivational design theory provides another process approach that seeks to increase student motivation in an online course by incorporating design elements that promote attention, relevance, confidence, and satisfaction. Motivational design is defined as "the process of arranging resources and procedures to bring about changes in people’s motivation” (Keller, 2010, p. 22). A series of ten worksheets allow instructors and instructional designers to analyze existing course structure and develop an online class that can capture and retain student attention, reveal content relevance, instill confidence, and create satisfaction with the overall learning experience. (Keller, 2010). Two survey instruments, the Course Interest Survey (CIS) and the Instructional Materials Motivation Score (IMMS), were designed to assess student motivation ratings of an online course.

A thorough analysis of these two process approaches to online course development is required to meet the need for research into designing high-quality learning experiences that can motivate today’s diverse online student population and increase retention. 


\section{Chapter 2: Literature Review}

Effective course design that fulfills the needs of all stakeholder groups is a complex, multidimensional process dependent on many factors. This inquiry begins with an exploration of “quality,” a simple term for a complex, multidimensional concept. The elusiveness of a consistent definition for the term as related to instructional design may underlie the inconsistent quality-assessment practices of online course design.

\section{Quality}

There is a great need for more research into what constitutes "quality" in online education (Ozdemir \& Loose, 2014). Admitting a definition is complex and elusive, the Online Learning Consortium (OLC), the former Sloan Consortium, states that "quality" is a key component in online education (OLC, 2015b). Perceptions of quality are strongly tied to satisfaction and are said to be the result of a consumer's comparison of expectations to actual performance (Malik, 2012). O'Neill and Palmer (2004) defined quality in higher education as "the difference between what a student expects to receive and his/her perceptions of actual delivery” (p. 42). Another perspective holds that the quality of a course can be developed through best-practice, measurable against a process (Harvey \& Green, 1993). The many nuances of the term itself have resulted in the use of varied methods to identify and define quality in online courses and programs (Shelton, 2011).

OLC, a nonprofit organization created with funding from the Alfred P. Sloan Foundation (Moore, 2005), is dedicated to “advancing quality online learning by providing professional development, instruction, best practice publications, and guidance to educators, online learning professionals and organizations around the world” (OLC, 2015a). OLC offers community and professional memberships that can provide faculty training, leadership development, and access 
to subject-matter experts (OLC, 2015a). OLC members are part of a global community that includes hundreds of corporations and institutions from more than 14 countries (OLC, 2015a).

OLC has developed several instruments and resources, including a quality framework, the Five Pillars of Quality Online Education (Moore, 2005; OLC, 2015b). This framework can be used in either academic or corporate training environments to assess and demonstrate the quality of online learning through five interconnected areas: learning effectiveness, scale, access, faculty satisfaction, and student satisfaction (Moore, 2005; OLC, 2015b.). OLC has defined these areas as the main components that support online learning since a thorough analysis enables the identification of goals, measurement of progress, and performance of ongoing improvements (Moore, 2005; OLC, 2015b.). Moore (2005) states that "the business of education to improve learning while achieving capacity enrollment” can only be accomplished by continuous quality improvement (p. 2). The Five Pillars framework provides education entities flexibility in achieving this ongoing quality improvement by allowing them to determine the importance of factors in each category as best reflected by their individual standards of operation (Moore, 2005).

To encourage networking and community involvement, member submissions to the OLC online knowledge center are eligible for annual awards when approved for effective practices in innovation, replicability, potential impact, supporting documentation, and scope (Moore, 2005). The 2010 Sloan-C Effective Practice Award was presented to Dr. Kaye Shelton (OLC, 2015c) for her work in developing a Quality Scorecard for administration of online education programs, a simplified method to “measure and quantify elements of quality” (OLC, 2015b). Shelton used the Institute for Higher Education Policy study, Quality on the Line: Benchmarks for Success in 
Internet-Based Distance Educations (2000) to establish the original 24 quality indicators as a starting point in her study (OLC, 2015c).

The Quality Scorecard evolved through a collaboration of experienced online education administrators who developed 70 "quality indicators” (OLC, 2015c) that are organized into eight categories: institutional support; technology support; course development/instructional design; course structure; teaching and learning; social and student engagement; student support, and evaluations and assessment (OLC, 2015b). The Scorecard, revised in 2014, can be used by administrators to identify, evaluate, and improve elements of quality within the online program, as well as to demonstrate overall quality of their online course offerings to accreditation entities.

A scoring method was devised where each indicator is assigned a value between 0-3 points, with zero meaning the criteria was not observed and three points signifying the indicator "meets criteria completely" (OLC, 2015c). The highest possible score is 210 points, with score rationales as follows: 90-99\% (189-209), Exemplary, little improvement needed; 80-89\% (168188), Acceptable, some improvement is recommended; 70-79\% (147-167), Marginal, significant improvement is needed in multiple areas; 60-69\% (126-146), Inadequate, many areas of improvement are needed throughout the program, and 0-59\% (0-125), Unacceptable (OLC, 2015c).

Evidence suggests the Quality Scorecard is an effective measure that has become an industry standard in determining the quality of online education programs (OLC, 2015c; Shelton, 2011). This study, however, focuses on identifying motivational factors within the individual course design rather than the entire online program: courses must have quality for the program to have quality. Quality Matters (QM) was selected as an instructional design format to analyze for 
student motivation factors because it uses a standardized rubric and peer review process to evaluate quality in online course materials.

\section{Quality Matters}

Quality Matters (QM) was developed by MarylandOnline, part of the University of Maryland, with funding provided by the Fund for the Improvement of Postsecondary Education (FIPSE), a unit within the Office of Postsecondary Education, U.S. Department of Education (QM, 2014a). Incorporated as its own nonprofit in the summer of 2014, the goal of QM is to provide tools and training for the quality assurance of online courses that will improve student learning (QM, 2014a). In April, 2015, QM claimed over 900 subscribing institutions and more than 150 individual subscribers (QM, 2014a; 2015a).

Over the last decade, QM has developed nationally-recognized standards for online course assessment, based on continuous scholarly research and presented through customized rubrics and trainings for higher education, K-12 education, continuing/professional education, and educational publishing (QM, 2014a). Peer-reviewers trained in the QM evaluation procedure use the applicable rubric to assess, certify, and offer recommendations for the improvement of online courses. More than 23,000 faculty and instructional designers have been trained as QM peer-reviewers (QM, 2014a).

The QM higher education rubric contains 40 individual standards organized into eight categories: course overview, learning objectives, assessment and measurement, instructional materials, learner interaction and engagement, course technology, learner support, and accessibility (MarylandOnline, 2011; QM, 2014a).

The Course Overview section, the largest in the rubric, includes eight standards that ensure students receive a proper introduction to the course, including instructions for getting 
started, a clear explanation of the purpose and structure of the course, class expectations and policies, etiquette, prerequisite knowledge, minimum technical skills, and creating/accessing introductions from students and instructors (MarylandOnline, 2011).

The Learning Objectives section of the QM rubric includes five standards that determine if learning objectives are appropriate for the course and for each unit, have measurable outcomes, and are clearly written with adequate instructions (MarylandOnline, 2011).

Five Assessment and Measurement standards determine if the types of assessments measure stated learning objectives, are consistent with learning activities and resources, whether grading policy is clearly stated and explained for each assessment measure, and if students have multiple opportunities to assess their own learning progress (MarylandOnline, 2011).

Six standards focus on Instructional Materials and the degree to which they are current, appropriate in meeting learning objectives, clearly explained regarding purpose and whether the resource is required or optional, appropriately cited, and whether materials present course content from different perspectives (MarylandOnline, 2011).

The Learner Interaction and Engagement section contains only four standards: requirements for student interaction are clearly explained; learning activities help students achieve stated learning objectives while providing opportunities for interaction and active learning, and policies on assignment response-time and instructor feedback are clearly explained (MarylandOnline, 2011).

The five Course Technology standards seek to determine if tools and media support learning objectives, student engagement, and active learning, are current and readily accessible, and provide consistent, logical, and efficient navigation (MarylandOnline, 2011). 
Learner Support has four standards that assess instructions for accessing technical, academic, and student support services, and articulate or link to the institution's accessibility policies and services (MarylandOnline, 2011).

Finally, four Accessibility standards evaluate accessibility, readability, availability of assistive technology options such as auditory and visual content alternatives, and information on accessibility and obtaining accommodation (MarylandOnline, 2011).

Online courses designed to use the QM design process can be submitted for peer-review evaluation. Reviews, conducted using a student perspective, do not evaluate course delivery and are intended for previously-taught or fully-developed online or blended courses where reviewers can evaluate course components (QM, 2014d). To prepare faculty and promote best outcomes, it is recommended the Self-Review Tool in the Course Review Management System (CRMS) is used prior to requesting a Course Review (QM, 2014d). QM notes that the Learning Objectives standard, specifically standards dealing with both course- and unit-level objectives, is most often in need of improvement (2014d).

The Course Review process (QM, 2014d) has three steps: pre-review; review period, and post-review. During the pre-review phase, an application is submitted in the CRMS and the QM Coordinator instructs the Course Representative to complete an online Course Worksheet. All review participants are notified of required actions through the CRMS, and the QM Coordinator ensures the review team has appropriate access to the course. The actual review lasts four to six weeks, allowing for pre- and post-conference calls and three weeks review time. Each course is measured against the QM rubric and point-values are assigned for the 40 individual standards. Reviewers may make recommendations for improvement, the Team Chair will submit the final report, and the Course Representative is informed of the review outcome. During post-review, 
the Course Representative informs QM whether the course will be recognized for meeting QM standards or, if the course was found lacking, modifications will be made. When all standards have been met, the Course Representative receives QM recognition and the course is registered as an approved course on the QM web site (QM, 2014d), which listed 277 recognized courses for 2015 on May 22, 2015 (QM, 2015b).

To ensure the process remains current and effective, a comprehensive literature review of instructional design and QM-focused research is performed in advance of rubric updates to discover emergent themes and issues, then presented to the Rubric Review Committee (Shattuck, 2013). The 2011-2013 review of research literature, available online through the QM web site, contained more than 500 citations drawn from 21 peer-reviewed journals and five academic databases (Shattuck, 2013). An independent Google Scholar search on May 5, 2015 presented 508 article results for the specific keyword search of “Quality Matters” in conjunction with the QM abbreviation. The ongoing literature review process guides the Rubric Review Committee and also provides direction for future QM-related research: over 60 new-research presentations were featured at the $6^{\text {th }}$ Annual QM Conference in Baltimore, MD on September 30, 2014 (QM, 2014c).

Nine themes were highlighted in the 2011-2013 literature review (Shattuck, 2013). The first theme discusses the frequent use of the Community of Inquiry (CoI) framework as a guide to designing and assessing the quality of online learning experiences. CoI uses a constructivist theoretical perspective to define a learning experience in terms of three overlapping circles of “presence” required to achieve deeper levels of learning: social presence, teaching presence, and cognitive presence (Shattuck, 2013). Shattuck specifically notes a 2013 study that tied social presence to motivation and the use of learner support (2013, p. 3). Many aspects within the CoI 
conceptual framework can be explored that would greatly contribute to motivation studies. For example, cognitive presence uses the Practical Inquiry (PI) model based on Dewey's theory that educational experiences have more worth if based in reflective thought (Garrison, Anderson \& Archer, 2010). The PI model consists of four phases: triggering event, exploration, integration, and resolution (Garrison, et al., 2010). The CoI research revealed students were not adequately reaching the integration and resolution phases because the design and facilitation of the course did not require them to do so (Garrison, et al., 2010). Design techniques that promote motivation to integrate the new knowledge to solve a learning challenge can help address this learning issue (Garrison, et al., 2010). Other emerging themes discovered by the 2011-2013 QM literature review are also relevant to motivation studies, including the importance of developing online learning communities and collaborative learning endeavors, learner-centered course design evaluation, pedagogy as a determinant for technology choice, gaming and immersive activities to increase cognitive engagement, and the need for further research into mobile learning, cognitive load, accessibility and inclusivity (Shattuck, 2013).

QM has explored student satisfaction for many years, beginning in 2005 with a QMfunded study that showed increased student satisfaction following course design improvements suggestions by QM peer reviewers (Shattuck, 2012). To further address this important issue, QM initiated an online student satisfaction study during the 2014-2015 academic term (QM, 2014b; Ralston-Berg \& Nath, 2011). The research project, titled “Quality Matters for Online Students: A national, inter-institutional study on the impact of QM on online student priorities and satisfaction,” allows QM subscribing institutes to confidentially analyze student priorities and satisfaction using the QM-aligned Priorities Survey for Online Learners (PSOL) to determine if 
differences exist between programs that use or do not use QM standards to design their online courses (QM, 2014b).

Student satisfaction is vital to a successful course; however, it is only one element of student motivation. The standardized QM process is ideal for designing objectives-based online courses; however, this approach does not account for the value and worth of the learning experience (Youger \& Ahern, 2015), nor does it address the process of learning itself (Swan, et al., 2012). Quality, as measured by the QM rubric, is more a production issue than an assessment of the learning experience. It measures a course against a set of standards where quality becomes an institutional matter defined objectively through the rubric. This inquiry into the influence of instructional design decisions on student motivation in online courses will contribute to the QMfocused research.

\section{Motivation}

Motivation can be defined as the direction and intensity of behavior, defining the goals people choose to pursue and how much effort is expended to achieve those goals (Keller, 2010). Motivation accounts for between 16\% and 38\% variance in student achievement (Means, et al., 1997). As noted, attrition has been directly attributed to low motivation (Chen \& Jang, 2010), making it vital for online course designers to seek out and employ strategies that may increase both student effort and retention (Hodges, 2004). Determining common motivational factors that make people want to learn may be an important step in meeting this challenge.

Learning is an individualized activity. The motivation and personality theory proposed by Maslow in 1954 remains relevant to modern research since it accounts for many factors that are important to successful online learning, including varied learner abilities, socioeconomic factors, motivation by achievement versus affiliation (church, family, peer expectations), and anxiety tied 
to self-efficacy or confidence (Knowles, 2005). Maslow also draws a parallel relationship between motives and values in terms of how some long-range goals may affect short-term activities. For example, students may put more effort into courses relevant to their major than into unrelated electives unless they are intrinsically motivated to excel (Beesley, Clark, Barker, Germeroth \& Apthorp, 2010; Hodges, 2004; Knowles, 2005; Liao, 2006). Student expectations and values work together to form goals and can predict outcomes such as engagement, continued interest, and academic achievement (Belland, Kim \& Hannafin, 2013; Wigfield \& Eccles, 2000). Self-efficacy, personal belief in one's ability to complete a task and reach goals, is cited by Hodges (2004) as the most important aspect of motivation. Keller (2010) states that this selfbelief, expectancy in the Expectancy-Value theory, may be linked to actual task engagement, as one is more likely to engage in something they are confident they can complete (Beesley, et al., 2010; Gorges \& Kandler, 2012). Eccles and Wigfield (2002) state that people who have this selfconfidence “perform better and are motivated to select more challenging tasks” (p.110).

Another study names relevance as the primary motivational factor in learning. Conducted with 100 upper-level undergraduate students enrolled in either a statistics course or a course on human physiology, this study sought to determine if relevance has a positive influence on student learning (Means, et al., 1997). Students in each course were paid to participate in the study by completing a lesson on the human heart. Half of each class received materials that used ARCS relevance-enhancing strategies, including goal orientation and familiarity, which researchers predicted would produce higher motivation and increased performance (Means, et al., 1997). Results found all students who received enhanced materials performed better than those who did not (Means, et al., 1997). Students in the physiology class had higher motivation scores than the students in the statistics course; however, motivation scores were higher for learners in the 
irrelevant (statistics) course who received the enhanced lesson design strategies (Means, et al., 1997). Confidence was found to be the greatest predictor of motivation and appeared to have a strong relationship to achievement, while relevance was found to influence terminology and comprehension scores (Means, et al., 1997).

While relevance and self-efficacy are important, other aspects of motivation such as achievement goals, intrinsic and extrinsic influences, and challenge preference are equally important. Covered primarily in psychological literature (Beesley, et al., 2010; Gorges \& Kandler, 2012), these aspects work together to form a clearer picture of what drives some students to put in the extra effort needed to produce high-quality work that demonstrates deep learning while others are content to merely pass the class and earn the credits.

Achievement goals are conscious decisions to complete an academic task, and include both mastery and performance goals (Beesley, et al., 2010; Wigfield \& Eccles, 2000). Mastery goals reflect the student interest in mastering the learning tasks necessary to succeed, while performance goals are more closely linked to avoiding failure and proving competence to others (Beesley, et al., 2010; Lund \& Haugen, 2000; Wigfield \& Eccles, 2000). Achievement goals can be either general, such as completing college, or very task-specific, such as getting an A on the Algebra midterm exam (Beesley, et al., 2010). Both achievement goals and outcomes may be indirectly influenced by external factors such as demographic characteristics, stereotypes, prior experience, and perception of others' beliefs and behaviors (Beesley, et al., 2010; Wigfield \& Eccles, 2000).

Intrinsic motivation describes the internal drive to succeed for the mere interest and enjoyment of the task itself, tied closely to mastery goals and challenge preference (Beesley, et al., 2010; Gorges \& Kandler, 2012). Intrinsic motivation factors such as feelings of self-esteem, 
respect and positive interaction with others, as well as mastering challenges that increase feelings of competence, are extremely powerful and often overlooked motivators (Keller, 2010). Extrinsic motivation is driven by perceived reward external to the task, such as grades, opportunities for advancement, or praise (Beesley, et al., 2010; Gorges \& Kandler, 2012; Keller, 2010).

Each learning experience is a unique event centered on a designed “course.” Just as a course will change in some ways when a new instructor takes over, course dynamics conform to the students who make up each section (Youger \& Ahern, 2015). The individuals within each learning event have different motivators and background knowledge (Atkinson, 1981); therefore, exchanges and ideas will vary within class sections (Youger \& Ahern, 2015). If something is interesting and engaging, students will want to learn and will be intrinsically motivated to produce higher-quality assignments, which can foster an increased sense of achievement and a desire to learn more (Beesley et. al, 2010; Hodges, 2004; Liao, 2006; Wigfield \& Eccles, 2000).

\section{Keller's Motivational Design Theory}

Keller (2010) defines motivational design as "the process of arranging resources and procedures to bring about changes in people’s motivation” (p. 22). The ARCS Model of Motivational Design provides a proven strategy to account for learning differences by focusing on attention, relevance, confidence, and satisfaction (Chen \& Jang, 2010; Hodges, 2004; Keller, 1987a, 1987b, 2010). The ARCS design model uses system theory to address relationships between four categories of motivation concepts which he describes as having shared attributes within motivational literature (Keller, 2010). When these components are properly addressed within a course, learners can be motivated to succeed while the worth and value of that course can be increase for all stakeholders (Youger \& Ahern, 2015). 
The expectancy-value theory, originally developed by John W. Atkinson in the 1950s to understand achievement motivation then expanded to include education by Jacquelynne Eccles in the 1980s, provides a basic background for Keller’s work (Eccles \& Wigfield, 2002). Keller (2010) states his theory takes a perspectivalist position, “a philosophical position which posits that truth tends to be contextualized and relative” (p. 5). Indeed, motivation is an individualized activity that occurs within a specific context, dependent on many factors that include personality or character, values, and the perceived value of the achievement (Atkinson, 1981; Keller, 2010; Knowles, 2005). If a learner's motivation to succeed is strong enough, little can be done to keep them from persisting until the goal is achieved (Keller, 2006, 2010).

Keller (2010) provides Table 1 to summarize the ARCS category definitions and process questions instructional designers should ask when designing education (p. 45):

\begin{tabular}{|clll|}
\hline Table 1 & & \\
ARCS Model Categories, Definitions, and Process Questions
\end{tabular}

Table 1: ARCS Model Categories, Definitions, and Process Questions (Keller, 2010)

Keller (1987a) states the instructional design process focuses on how well a learner can gain, remember, and use new knowledge and skills. The ARCS design process can be used to supplement traditional instructional design by systematically addressing problems of human 
motivation in learning activities (Keller, 1987a). To successfully apply the ARCS model, the instructional designer must first understand and be able to identify motivation elements that are conducive to learning. Second, the audience is analyzed to determine potential motivators. Once these have been determined, instructional resources, materials, and procedures that stimulate motivation are identified. Finally, designers will select and apply the appropriate motivational tactics needed to create a quality learning experience (Keller, 1987a). Ongoing evaluation is necessary to ensure that all stakeholder interests continue to be met.

Audience analysis is a complex process yet must be completed to design a truly effective learning experience. Various factors can impact student learning and performance, including cultural and socioeconomic issues, family or work obligations, even health. Many of these issues can be identified by assigning students to create an introduction or brief biography during the first few days of class. Specific instructions can include student identification of school and online learning experience level, outside employment status, and goals for the course (Youger \& Ahern, 2015). Understanding these self-identified learning conflicts can help determine which instructional and motivational tactics may be most effective in the particular course setting.

Technology has both complicated and enhanced the identification of instructional resources, materials, and procedures that will be used to develop the course (Ozdemir \& Loose, 2014). Once restricted to text-based materials, instructional designers can now also choose from web-based, audio, or video resources. Learning activities can be accomplished either on- or offline, independently or in groups. Procedures for delivery of the education have also been enhanced and complicated by technology: nearly all LMS allow real-time text, audio, or video interaction yet adequate technology-literacy skills are paramount to student success. 
Once these methods are identified and implemented within the learning environment, student performance is evaluated to determine if the measures are effective in creating an engaging and thorough educational experience. Keller (1987a) states that inclusion of the ARCS design process results in the creation of a learning environment where carefully-chosen tactics and activities will have a predictable influence on learner behavior and will impact how much effort they are willing to put forth to achieve the goal of successfully completing the course.

Keller developed two survey instruments based on the motivational concepts and theories of the ARCS model: the Course Interest Survey (CIS) and the Instructional Materials Motivation Scale (IMMS). The two surveys, reproduced in Appendix A and Appendix B respectively, are designed for use by undergraduate and graduate students, adults in non-collegiate settings, or with secondary students as self-report instruments that measure student motivation in a particular course (Keller, 2010).

Keller (1987a, 2010) cites numerous research reports, including studies by NaimeDiffenbach (1991) and Small and Gluck (1994), that confirm the usability and validity of the ARCS model and survey instruments, stating this process has been used worldwide in virtually every type of education setting. A 2008 study on motivation and usability by Yu is cited by Keller (2010) as confirming "the internal consistency and empirical validity of the IMMS” (p. 286). Chen \& Jang (2010) cite several studies that have used the ARCS survey instruments, including studies by Gabrielle (2003) and Lee (2002), which found the surveys were "significant predictors of online student satisfaction and performance” (p. 741). Keller (2010) states because these instruments measure situation-specific attitudes and not psychological constructs, it is difficult to apply traditional factor analysis to the instruments because the four subcategories of attention, relevance, confidence, and satisfaction “can have high intercorrelations” (p. 286). 
When instructional designers are successful in capturing attention, revealing relevance, and promoting confidence, students will be motivated to learn, while feelings of satisfaction produced by intrinsic or extrinsic motivators will result in a desire to learn more (Keller, 2010). Course design elements that allow for some flexibility in resources, presentation, and assessment can address some factors that predetermine student learning effectiveness and satisfaction, thus allowing students to develop a deeper sense of value about a course (Youger \& Ahern, 2015).

\section{Attention}

Capturing student attention is the first step in encouraging motivation. Specific design techniques, such as variety and inquiry activities, can help maintain attention throughout the course. Keller (2010) defines three general categories of attention-getting strategies: perceptual arousal, inquiry arousal, and variability. Perceptual arousal is a type of curiosity that refers to reflexive reactions to stimuli, a technique most employed by headline writers, and the first step in the attention process (Keller, 2010). The perception arousal concept should be immediately followed by inquiry arousal, an activity that stimulates a deeper level of curiosity that can be initiated by the creation of a problem that can only be resolved by knowledge-seeking behavior (Keller, 2010). This provides a basis for audience analysis (Keller, 2010) that can be useful in selecting and implementing appropriate, effective design strategies for each course.

Motivation requires that the learner's attention be stimulated and sustained, while learning requires student attention be directed through cues, prompts, and resources toward the concepts necessary to ensure a successful learning experience (Keller, 2010). Curiosity is a natural state since we all seek to make sense of our world. The desire to remove uncertainty motivates us to find causes for inconsistencies, thus arousing our curiosity when confronted with new, strange or mysterious elements (Keller, 2010). In discussing curiosity, Keller describes an 
experiment conducted by Berlyne (1950) that definitively demonstrated rats will investigate new objects introduced into their environment while ignoring items they were accustomed to having there. Berlyne concluded that novelty creates curiosity that leads to exploratory behavior until familiarity is established (Keller, 2010). This pattern is also evidenced by humans, amply demonstrated by the intense desire we feel to upgrade our technology gadgets. Driven by curiosity as soon as "the next new thing” becomes available, we feel a sense of achievement or pride obtaining the newest cell phone or gaming system before anyone else we know. Required course content that is presented in a novel or unusual manner can generate curiosity, while cues and prompts are useful strategies for directing attention and stimulating recall. Answering questions leads to a deeper understanding and increased competence, yet can also lead to more questions, thus perpetuating the learning cycle (Keller, 2010).

Variability of instruction style and presentation techniques can help maintain attention throughout the course (Knowles, 2005). For example, wording strategies can be used to direct student attention to new concepts by asking them to recall past lessons: "Remember last week when we explored ...” Textual strategies like this can also be used to convey relevance, while text blocks or color choices can also be used to highlight salient points and drawn attention.

\section{Relevance}

Several studies have found relevance to work or personal goals is an effective motivator in adult learning (Gorges \& Kandler, 2012; Hodges, 2004; Means, et al., 1997). Establishing relevance can allow students to see future value of course content and may increase the course worth and motivation to excel (Keller, 2010; Means, et al., 1997; Youger \& Ahern, 2015). Keller (2006, 2010) defines relevance as meeting the personal needs or goals of the learner to effect a positive attitude. 
Relevance can be linked to task value, how important, useful, or enjoyable a task is perceived to be, in the Expectancy-Value theory (Keller, 2010). Task value consists of four elements: attainment value, intrinsic value, utility value, and cost (Belland, et al., 2013; Eccles \& Wigfield, 2002). Attainment value, the personal importance attached to completion, has been linked to theories of identity and helps explain engagement as a method of reinforcing beliefs held about one's self. Intrinsic value references the level of interest associated with a task or the level of personal satisfaction or enjoyment that arises from performing the task. Utility value is a determination of the usefulness of a task to current or future goals. Cost was determined to be a critical factor in establishing task value since it is most often seen as a synthesis of the negative factors that result from engaging in the task, including anticipated time and effort, as well as performance anxiety and lost opportunity issues (Belland, et al., 2013; Eccles \& Wigfield, 2002).

Today we understand that adults learn differently than children. Andragogy is a $20^{\text {th }}$ century term popularized by Knowles in the late-1960s (Smith, 2002). Interest in the topic of adult learning greatly increased during that time, thanks to advanced studies in clinical psychology, developmental psychology, gerontology, sociology, and anthropology (Knowles, 1970). Knowles (1970) credits Cyril O. Houle for publishing the seminal study on the internal processes of adult learning in his 1961 publication, The Inquiring Mind, which proposed adult learners fall into three categories: goal-oriented, activity-oriented, and learning-oriented.

The primary difference between adult and child learning is that adult learning is based on life-experience (Knowles, 2005). Unlike children whose self-identity is largely defined by external factors like family or community, adults view their identity through their experiences (Knowles, 2005). Knowles (2004) states if adult experiences are ignored or devalued, they feel they, as well as their experiences, are being rejected; therefore, the most effective adult teaching 
and instructional design techniques will connect the experience of the learner to the new material.

Goal orientation, motive matching, and familiarity are three strategies used to produce the relevance (Keller, 2010; Means, et al., 1997). Goal orientation, setting goals and working to achieve them, is perhaps the most influential strategy in establishing relevance because it helps students understand the connection between learning and application (Keller, 2010; Means, et al., 1997). Adults want to know why they should spend time on learning. Goal orientation techniques can be used to demonstrate the logical progression of the course and reveal the relevance of the overall learning experience to individual students.

Motive matching strategies employ a mix of independent and cooperative assignments to meet the needs of students motivated by competition as well as those more comfortable with collaborative learning activities (Keller, 2010). Students who perceive learning as important and relevant will put in more effort to succeed, and, if given a choice, will choose contexts for assignments that best meet their personal needs (Means, et al., 1997). People value their efforts, and if a task is seen as irrelevant or unimportant, it may be discounted, deemed unworthy of their cognitive efforts (Westbrook, Kester \& Braver, 2013). One strategy that can be used to promote relevance through motive-matching is to design open-ended assignments that enable students to make connections between the class topic and their own interest areas (Belland, et al., 2013).

Familiarity strategies, such as the use of personal pronouns in lesson activities or correspondence, help students feel more connected to the learning and help build a sense of comradery within the course (Means, et al., 1997; R.E. Youger, personal communication, 2014). Content can be intrinsically relevant to learners with a personal interest in the topic, causing them to be more motivated to increase their knowledge despite the material having no extrinsic 
relevance, such as usefulness in their careers or future studies (Pintrich, 2002). Learning opportunities that are intrinsically relevant will help connect the instruction to the learner, and increase academic performance and meaningfulness (Means, et al., 1997).

\section{Confidence}

The relationship between motivation and achievement has been directly tied to student confidence (Means, et al., 19997). Everyone wants to feel competent, and drawing on existing knowledge or experience can boost feelings of confidence in students. Students must have confidence in their ability to complete all tasks and objectives needed to complete the course, as well as in their ability to successfully communicate within the course environment (Beesley, et al., 2010; Keller, 2010). Conversely, excess confidence in their abilities or existing knowledge may negatively impact motivation, resulting in failure to see the relevance of further instruction, which can cause students to miss important learning activity details because of biases against new perspectives and ideas (Keller, 2010; Knowles, 2005).

Students new to the higher education setting or to online courses are vulnerable to anxiety created by lack of confidence (Shea, Li, Swan, \& Pickett, 2005; West, 2010); therefore, it is important to provide opportunities for success early in each course (Keller, 2010; Youger \& Ahern, 2015). Anxiety or lack of confidence will have a detrimental effect on learning (Shea, et al., 2005), and may manifest in the form of absenteeism, procrastination, and negativity (Keller, 2010). Providing early opportunities for success allows students to develop positive expectations by demonstrating they have some control of their learning outcomes, causing them to perhaps develop a sense of optimism that was not present initially (Keller, 2010).

Self-efficacy, the belief that one will succeed, is a major contributory factor in adult learning (Gorges \& Kandler, 2012; Schunk, 1991). Inherent in the expectancy-value model of 
motivation are two conflicting achievement motives: the motive to seek success and the motive to avoid failure (Lund \& Haugen, 2000). If a specific challenge has an unknown outcome, those who are success-oriented expect that engaging in the task will result in success, while the failureavoidance learner has a general expectation of failure (Lund \& Haugen). These achievement motives can be tied to the concept of locus of control, outcomes tied to either internal or external forces (Keller, 2010; Sarwar \& Ashrafi, 2014). For example, Sara expects to receive an A on her project but instead receives a B, causing her to immediately blame the instructor (external locus of control) for being unclear or unfair. Robert also expects an A and upon receiving a B, immediately assumes he himself (internal locus of control) either did not put forth enough effort or did not properly follow instruction (Keller, 2010). Students with internal locus of control have higher motivation for achievement, which results in higher achievement than occurs in those with external locus of control who believe their success is most dependent upon luck or other factors beyond their control (Keller, 2010; Sarwar \& Ashrafi, 2014).

Establishing clear learning requirements, opportunities for success, and options for personal control over success are three techniques used to enhance student confidence (Keller, 2010). The syllabus is typically the first contact students have with a new course; therefore, establishing clearly defined prerequisite knowledge and learning requirements is a very effective method to develop learner confidence early in any course. Heightened personal control can be established by using projects or essays instead of more traditional types of assessment measures like quizzes and tests (Keller, 2010; Youger \& Ahern, 2015). Ongoing feedback and positive reinforcement are essential to instilling confidence in students, and while corrective feedback is necessary, this can be presented in positive language that points out accomplishments or effort as well as errors (Keller, 2010; Youger \& Ahern, 2015). 


\section{Satisfaction}

Motivated learners experience higher performance and productivity, as well as an enhanced sense of self-actualization brought about by these achievements (Keller, 2010; Lin, Lin \& Laffey, 2008; Youger \& Ahern, 2015). Satisfaction is listed as one of the "Five Pillars of Online Education” developed to improve online learning experiences by the Online Learning Consortium (OLC), formerly the Sloan Consortium (OLC, 2015b). The OLC defines student satisfaction as a reflection of course rigor and fairness, instructor and peer interaction, and effectiveness of support services (2015b.).

Instructor support is vital to ensuring student satisfaction, which reflects the overall effectiveness of all aspects of the educational experience (OLC, 2015b; Shea, et al., 2005; West, 2010). Online instructors who use current resources and communication technologies to support individualized, engaged, constructive learning are most effective in helping students achieve learning goals (OLC, 2015b). As consumers of education, student satisfaction is highly dependent on their perceptions of the effectiveness of academic and administrative services, technology and infrastructure support, and learning resources being timely, responsive, and personalized (OLC, 2015b).

Student satisfaction, the final step in the ARCS motivation design process, has the overall goal of fostering a continued motivation to learn, and features three strategies: natural consequences, positive consequences, and equity (Keller, 2010). A natural consequence is the intrinsic fulfillment attained when a student successfully completes a challenging task not possible at the beginning of the course or receives praise that focuses on specific aspects of their performance (Keller, 2010). Awards, certificates, and trophies are examples of positive consequences, and are useful when learning is inherently monotonous or highly competitive, or 
if students are not intrinsically motivated to excel (Keller, 2010). Student preference for challenge (Keller, 2010) and group atmosphere (competition vs. cooperation) will directly affect satisfaction and learning products (Knowles, 2005). Equity is best achieved when course outcomes genuinely reflect student efforts and task completion since students often compare their scores and progress with others (Keller, 2010).

While studies conducted during the late-1990s and early-2000s indicated students were more satisfied with face-to-face courses (Lin, et al., 2008), recent studies show that advances in technology, communication, and interactive elements have helped increase student satisfaction in online courses (Marmon, Vanscoder \& Gordesky, 2014). Active participation and meaningful interaction with content, faculty, and peers remain vital in sustaining student satisfaction, helping to reduce feelings of isolation, particularly in asynchronous online courses (Marmon, et al., 2014; West, 2010). Several studies suggest the development of online learning communities will help students establish and build trust with peers and faculty, resulting in greater achievement, engagement, and satisfaction (Boston, Ice \& Gibson, 2011; Marmon, et al., 2014; Shea, et al., 2005; West, 2010).

\section{Cognitive Effort}

Motivation is driven by incentive, the rationale for putting forth the mental or physical effort to achieve a goal. Biological evidence (Schmidt, Lebreton, Clery-Melin, Daunizeau \& Pessiglione, 2012) has provided substance to the educational theory of cognitive effort, defined as intentionally engaging cognitive resources to achieve a particular end (Cognitive Atlas, 2013). Cognitive effort was mapped in human subjects using neuroimaging techniques as the Schmidt study (2012) investigated neural activity in conjunction with incentive motivation, seeking variations between mental and physical effort that may support a central motivational system 
within the human brain. Neuroimaging data was gathered during both the cognitive effort and the motor effort, which was manipulated for the following parameters: expected reward for incentive display; performance level, and motor and cognitive demand (Schmidt, et al., 2012). Behavioral data results found no significant interaction between incentive and task difficulty, and no difference in motivation or performance based on whether the task was cognitive or motor (Schmidt, et al., 2012). Best performance occurred when monetary incentive was larger and both physical and mental tasks were easy, while the worst performance occurred when both tasks were hard (Schmidt, et al., 2012). MRI results indicated that brain activity predicted performance variations not explained by task difficulty, and provided evidence in support of cognitive effort by demonstrating that different areas of the ventral striatum region of the brain become engaged depending on whether the task is cognitive or motor (Schmidt, et al., 2012).

Brain chemistry, including genetics and environmental factors, can impact learning and cognitive effort (Frank \& Fossella, 2011). Dopamine, a chemical that works in the striatum region of the brain, plays a vital role in learning and motivation since it is required for incentivebased actions and higher cognitive processes (Frank \& Fossella, 2011). Pharmacological studies on performance conducted by inducing or blocking dopamine have shown dopamine-releasing stimulants improve cognitive function in healthy individuals, as well as those diagnosed with ADHD (Frank \& Fossella, 2011). The good news for instructional designers is that dopamine is released when we get pleasure from something: intrinsic fulfillment. Learning activities that are structured to have relevance and presented in a logical, intuitive manner should be enjoyable for students, thus promoting intrinsic fulfillment, stimulating dopamine activity and cognitive effort. This instructional design strategy is motivating and may improve the overall learning experience, which could, in turn, lead to ongoing participation in life-long learning activities. 
Greater cognitive effort results in better recall (Tyler, Hertel, McCallum \& Ellis, 1979). The human cognitive structure consists of long-term memory and working memory (Sweller, Van Merrienboer \& Paas, 1998). Long-term memory works as a storehouse for our accumulated life-knowledge, categorized as schemas, connections and pathways between concepts (Sweller, 1988, 1994; Sweller, et al., 1998). Working memory is temporary storage used to process pieces of information in some way, such as organizing, comparing, or contrasting (Sweller, 1988, 1994; Sweller, et al., 1998). Schemas held in long-term memory reduce the strain on working memory, which can only hold about seven pieces of information at any one time - once we learn something, it is transferred from working memory to the appropriate schema within the longterm memory structure (Koohang, 2004; Sweller, 1994; Sweller, et al., 1998). Interaction between information bits held in working memory will decrease capacity further, implying people can only deal with two or three bits of information simultaneously if they must process versus simply hold that information (Sweller, et al., 1998). Greater cognitive efforts lead to stronger schematic connections between concepts, thus producing more accurate recall results (Tyler, et al., 1979).

The terms cognitive effort and cognitive load are often used interchangeably; however, cognitive effort is learner-centered, while cognitive load is more relevant to instructional design (T.C. Ahern, personal communication, 2015). The cognitive load theory, proposed by Sweller in 1988 while researching learning and problem-solving, refers to working memory constraints that can determine the effectiveness of instructional design (Sweller, 1994). Schemas are constructed not only to organize and store information in long-term memory, but also to reduce the load on working memory (Sweller, et al., 1998). A schema may contain a huge amount of information but is treated as a single entity by working memory regardless of its content complexity (Sweller, 
et al., 1998). Complex learning tasks limit the bits of information that working memory can hold since it must simultaneously manipulate the information to complete the overall task process. Complicated learning activities can also lead to an increased probability of error due to decreased working memory capacity, required to adequately process the various information and procedure steps necessary to complete the task and achieve, as an end result, a solid schematic connection between new and existing knowledge structures (Sweller, 1988).

Confidence and satisfaction are directly related to the amount of cognitive effort required to complete a task (Kock, 2004; Marmon, et al., 2014). Cognitive effort, the amount of mental work required to achieve a goal, has a direct impact on motivation and task completion (Kock, 2004; Marmon, et al., 2014; Schmidt, et al., 2012), which is dependent on confidence and selfefficacy: students will be motivated to perform better if they believe they can do all the learning tasks required to successfully complete a course (Beesley, et al., 2010; Belland, et al., 2013; Chen \& Jang, 2010; Keller, 2010). The usability of instruction components and interface should be examined to insure students do not become overwhelmed by the method of course delivery, allowing learners to devote their cognitive efforts to the subject matter (Koohang, 2004). When students have difficulty navigating the learning environment or determining how to submit assignments, they are required to use a large amount of cognitive effort to make sense of the delivery medium and can quickly lose the confidence and motivation needed to successful learn course content (Kock, 2004; Marmon, et al., 2014).

\section{Value and Worth}

Value, like "quality," is a simple word with multiple meanings, highly-dependent on the context in which it is used. Synonyms include: benefit; importance; meaning; power; profit; 
purpose; quality; significance (thesaurus.com/value). A base definition as required for this study is provided by Merriam-Webster as, “usefulness or importance (“Value,” 2015).

The process for determining the value and worth of an online course is complex and multidimensional. Determining the "value" of an online course is an individual decision that varies depending on the stakeholder (Youger \& Ahern, 2015). At their core, all courses are valuable to students in degree programs for the credits earned through completion. Many courses are popular for their intrinsic or extrinsic attributes: perhaps the subject matter is interesting or the course is required to complete a program of study. Here, quality is inconsequential, although its presence or absence will certain impact the overall learning experience. A low-quality course can have high value simply because the course is required for the program of study or perceived as relevant to future success (Gorges \& Kandler, 2012; Youger \& Ahern, 2015). Conversely, even the highest-quality course will hold no value for a student with no reason to take it. Online availability itself can provide value to a student or instructor facing a long commute to campus, again, regardless of “quality” (Youger \& Ahern, 2015). Similarly, asynchronous online course availability can be highly valuable to a student with time obligations that conflict with a more traditional class schedule. Instructional designers have many options available to help students build an increased sense of value about a course. Keller's ARCS Model provides a process with strategies that can be incorporated into traditional instructional design practices to accomplish this complex task (Chen \& Jang, 2010; Keller, 2010).

Student beliefs about the value, interest factor, and relevance of the educational content is referred to as task value (Belland, et al., 2013; Lin, et al., 2008). Those with higher levels of task value are cited as having better academic outcomes, possibly through the use of increased critical thinking skills (Lin, et al., 2008). People are motivated to participate in activities that fulfill 
personal needs and from which they have a reasonable chance of successful completion (Keller, 1987b; Lund \& Haugen, 2000). Activities that allow students to meet performance-based mastery goals can promote expectations of success and self-direction (Belland, et al., 2013). Instructional designers can develop learning activities that establish task value and promote confidence and interest by allowing opportunities for success, social interaction, and selfdirection that may increase their sense of value about the course (Belland, et al., 2013).

Like value and quality, it is difficult to find a precise definition of "worth" as related to education. Of the four full definitions provided by Merriam-Webster, the second best suits the purposes of this study: "the value of something measured by its qualities or by the esteem in which it is held" (“Worth," 2015).

The value of a course is subjective to the audience perception of "worth.” Value causes a student to enroll in the course but "worth" determines the effort they put forth to be successful in the course: the greater the value, the higher the worth (Youger \& Ahern, 2015; Keller, 2010). For example, an Art History course may be extremely worthwhile to an Art major, regardless of the course quality. They may learn new knowledge critical to future courses and careers, and will therefore, sustain their effort in assignments and assessment measures. Even an undeclared major may find great worth in an Art History course if the content or course design stimulates their interest (Keller, 2010; Youger \& Ahern, 2015). In contrast, this same Art History course might hold value for a Business major by fulfilling a Humanities requirement for their degree program but will have no worth if the content is unappealing or irrelevant. Unless they are intrinsically interested in the content, that Business major has little motivation to excel in such a course, and may exert only the minimal effort required to "pass" the class in fulfillment of the degree and credit requirements. 
The value and worth of a course is constantly being reevaluated as each group of students brings their own set of needs and wants to the learning experience. Effective design requires some level of customization and tailoring to provide quality learning experiences that have value and worth (Ahern, 2002; Youger \& Ahern, 2015). By exploring motivation and its contributory factors, course designers have the opportunity to create learning experiences that are valuable to students and faculty, while also contributing to the value of the university and overall program of study.

\section{Chapter Summary}

Although exact definitions for the terms, “quality," “value,” and "worth” as related to online learning remain elusive, studies such as this are needed to explore connections in thought and practice that can help education professionals create and delivery motivating, relevant online learning experiences that satisfy the diverse demands of all stakeholders. The resources explored for this study span nearly 100 years of education research, at times offering obviously-dated perspectives that retain tenets still applicable to our computerized, always-connected society. The availability of online courses continues to grow, attempting to meet the increasing demands of adult learners driven by multiple priorities. This investigation into student motivation and the factors that affect this complex concept seeks to provide solid evidence of strategies that can be incorporated into the instructional design process that result in richer, more meaningful learning experiences. 


\section{Chapter 3: Methodology}

Four online summer education-based graduate courses were chosen to examine the influence that instructional design decisions has on student motivation. The instructional design of each course was explored through content analysis of the syllabus, instructor interviews, and online observation. Student ratings of motivation quality were determined utilizing Keller's Course Interest Survey (CIS) and Instructional Materials Motivation Scale (IMMS), which were administered online via Qualtrics survey software during Week 5. Data from the investigation of the course instructional design were compared with student survey data, then analyzed for connections between student motivation and course design elements. Four comprehensive case studies resulted and were utilized to investigate the influence that instructional design decisions have on student motivation and course value and worth. The following research question guides this qualitative study of student motivation in online learning:

RQ 1: Do instructional design decisions influence student motivation in online courses? Sub-question \#1: What motivational elements are present in QM vs non-QM designed courses? Sub-question \#2: Do motivational elements differ in QM vs non-QM designed courses?

\section{Participants}

Courses for this study were purposively chosen from a mid-Atlantic university, based on use or non-use of the QM higher education rubric in the course design. All courses were 6-week online graduate courses held during the summer 2015 semester, and each was required for available degree programs.

Participating instructors consented to an email interview and provided a copy of the course syllabus for motivational design analysis. 
Instructors added this researcher to their respective online course as an observer, to verify that the course experience matched the motivational design expectations of the syllabus. This observation analysis functioned as expected, enhancing results and contributing insights in the review of each overall course survey.

Survey participants were a convenience sampling of adult graduate students enrolled in one of the four online graduate credit courses at West Virginia University (WVU), listed as a subscribing institution with QM (QM, 2015a). Based on pre-registration and prior semester enrollment, it was estimated there would be 15-25 students in each course. Actual course enrollment was as follows: Course A, 12; Course B, 10; Course C, 14; and Course D, 17.

\section{Data Sources}

This study explored two QM-designed graduate courses and two non-QM-designed graduate courses conducted during the summer of 2015 to determine the impact of instructional design decisions on student ratings of motivation in an online course. Three data sources were analyzed to determine instructional design features and motivational design elements: the course syllabus, instructor interview, and observation research of each course. Student motivation data was derived from the results of two online surveys that had been designed by Keller as part of the motivational design framework. A study matrix was created to demonstrate how individual data sources were combined to create the four course case studies (Table 2) and answer the guiding research question on the influence of instructional design choices on student motivation in online courses: 


\begin{tabular}{|cccccc|}
\hline Table 2 & & \\
Study Matrix: Course Analysis \\
RQ: Do Instructional design decisions influence student motivation in online courses? \\
RQ1a: What motivational elements are present in QM vs non-QM designed courses? \\
RQ1b: Do motivational elements differ in QM vs non-QM designed courses?
\end{tabular}

Table 2: Study Matrix: Course Analysis

Instructors provided the course syllabus, which was measured against the Course Syllabus Comparison Chart (Table 5), described on page 43 in the Instruments section.

An email interview was conducted with each instructor to discover perspectives about the characteristics of their course, as well as teaching and instructional design experience.

Finally, instructors added this researcher to their course as an observer to verify that course experience matched the motivational design expectations on the syllabus.

Comparison data on student motivation were drawn from two (2) online surveys, made available through an anonymous web-link to the Qualtrics online survey software and website. Observation research of the courses provided additional insight that was useful in reviewing overall student motivation survey results. 


\section{Instruments}

The ARCS model and survey instruments have been validated by numerous research projects and by other indicators of validity (Chen \& Jang, 2010). Keller (2010) states:

“The practical utility of the ARCS Model has been supported in a field test (Keller, 1984), and by research studies in a variety of settings (Shellnut, Knowlton, \& Savage, 1999)... Over time, the strategies have been modified for specific kinds of instructional settings such as textual material (Keller \& Kopp, 1987), computer-based instruction (Keller \& Suzuki, 1988), and online instruction (Keller, 1999)” (p. 46).

The surveys have been designed for use by undergraduate and graduate students, adults in non-collegiate settings, or with secondary students. The goal of these self-report instruments is to measure student motivation in a particular course. As situation-specific measures, there are no expectations of a normal distribution of responses (Keller, 2010).

\section{Course Interest Survey (CIS)}

This survey instrument, designed to correspond with the theoretical foundation of the ARCS Model, can be used in face-to-face or online courses, either synchronous or asynchronous, which are instructor-facilitated. The CIS (Appendix A) has 34 items, featuring eight (8) each for the Attention and Confidence subscales, and nine (9) each for the Relevance and Satisfaction subscales. Internal consistency estimates based on the Cronbach’s alpha (Table 3) were satisfactory (Keller, 2010): 


\begin{tabular}{|cc|}
\hline $\begin{array}{l}\text { Table } 3 \\
\text { CIS Reliability Estimate }\end{array}$ \\
\hline Scale & Reliability Estimate (Cronbach a) \\
\hline Attention & .84 \\
Relevance & .84 \\
Confidence & .81 \\
Satisfaction & .88 \\
Total Score & .95 \\
\hline
\end{tabular}

Instructional Materials Motivation Scale (IMMS)

The Instructional Materials Motivation Scale (IMMS) (Appendix B), designed to correspond with the theoretical foundation of the ARCS Model, can be used in print-based selfdirected learning, computer-based instruction, or online courses, either synchronous or asynchronous, which are primarily self-directed. This instrument is appropriate to all courses being analyzed due to the accelerated schedule of a 6-week summer course in which the instructor is available but students are primarily responsible for their own learning and performance.

The IMMS has 36 items, with 12 for the Attention subscale, nine (9) items each for the Relevance and Confidence subscales, and six (6) items for the Satisfaction subscale. Keller attributes the higher number of items that examine Attention elements to a prevailing educational notion that text-based instructional materials contribute to boredom and lack of stimulation, while the lower number of Satisfaction items reflects that this motivational element has fewer connections to printed materials than the other subcategories do (Keller, 2010). Keller designed a 
Motivational Tactics Checklist that can be useful in developing and evaluating instructional materials for motivation (2010, p. 286-292).

Internal consistency estimates based on the Cronbach’s alpha (Table 4) were satisfactory (Keller, 2010):

\begin{tabular}{|ll|}
\hline Table 4 & \\
\hline IMMS Reliability Estimate & Reliability Estimate (Cronbach a) \\
\hline Scale & .89 \\
Attention & .81 \\
Relevance & .90 \\
Confidence & .92 \\
Satisfaction & .96 \\
Total Score & \\
\hline
\end{tabular}

Table 4: IMMS Reliability Estimate

\section{Course Syllabus Comparison Chart}

Content analysis was performed by this researcher to identify specific motivational design elements and strategies within each course syllabus. Syllabi for the surveyed courses were analyzed to identify motivational design elements that could affect attention, relevance, confidence and satisfaction. Attention elements include arouse or capture interest, variability, and inquiry. Relevance elements include goal orientation, motive-matching, choice, and familiarity. Confidence elements include clear learning requirements, opportunities for success, and personal control options. Satisfaction elements include natural consequences, positive consequences, and equity. The Course Syllabus Comparison Chart (Table 5) was developed based on ARCS Model categories, definitions, and strategies: 


\begin{tabular}{|c|c|c|c|c|}
\hline \multicolumn{5}{|c|}{$\begin{array}{l}\text { Table } 5 \\
\text { Course Syllabi Comparison Chart }\end{array}$} \\
\hline $\begin{array}{c}\text { ARCS } \\
\text { Elements }\end{array}$ & Course A (ID) & Course B (ID) & Course C (QM) & Course D (QM) \\
\hline $\begin{array}{l}\text { Attention- } \\
\text { getting or } \\
\text { sustaining } \\
\text { features }\end{array}$ & $\begin{array}{l}\text { Arouse/capture } \\
\text { interest } \\
\text { Variability } \\
\text { Inquiry }\end{array}$ & $\begin{array}{l}\text { Arouse/capture } \\
\text { interest } \\
\text { Variability } \\
\text { Inquiry }\end{array}$ & $\begin{array}{l}\text { Arouse/capture } \\
\text { interest } \\
\text { Variability } \\
\text { Inquiry }\end{array}$ & $\begin{array}{l}\text { Arouse/capture } \\
\text { interest } \\
\text { Variability } \\
\text { Inquiry }\end{array}$ \\
\hline $\begin{array}{l}\text { Relevance- } \\
\text { generating } \\
\text { features }\end{array}$ & $\begin{array}{l}\text { Goal orientation } \\
\text { Motive- } \\
\text { matching/choice } \\
\text { Familiarity }\end{array}$ & $\begin{array}{l}\text { Goal orientation } \\
\text { Motive- } \\
\text { matching/choice } \\
\text { Familiarity }\end{array}$ & $\begin{array}{l}\text { Goal orientation } \\
\text { Motive- } \\
\text { matching/choice } \\
\text { Familiarity }\end{array}$ & $\begin{array}{l}\text { Goal orientation } \\
\text { Motive- } \\
\text { matching/choice } \\
\text { Familiarity }\end{array}$ \\
\hline $\begin{array}{l}\text { Confidence- } \\
\text { generating } \\
\text { features }\end{array}$ & $\begin{array}{l}\text { Clear learning } \\
\text { requirements } \\
\text { Opportunities for } \\
\text { success } \\
\text { Personal control } \\
\text { options }\end{array}$ & $\begin{array}{l}\text { Clear learning } \\
\text { requirements } \\
\text { Opportunities for } \\
\text { success } \\
\text { Personal control } \\
\text { options }\end{array}$ & $\begin{array}{l}\text { Clear learning } \\
\text { requirements } \\
\text { Opportunities for } \\
\text { success } \\
\text { Personal control } \\
\text { options }\end{array}$ & $\begin{array}{l}\text { Clear learning } \\
\text { requirements } \\
\text { Opportunities for } \\
\text { success } \\
\text { Personal control } \\
\text { options }\end{array}$ \\
\hline $\begin{array}{l}\text { Satisfaction- } \\
\text { generating } \\
\text { features }\end{array}$ & $\begin{array}{c}\text { Natural } \\
\text { consequences } \\
\text { Positive } \\
\text { consequences } \\
\text { Equity }\end{array}$ & $\begin{array}{c}\text { Natural consequences } \\
\text { Positive consequences } \\
\text { Equity }\end{array}$ & $\begin{array}{c}\text { Natural } \\
\text { consequences } \\
\text { Positive } \\
\text { consequences } \\
\text { Equity }\end{array}$ & $\begin{array}{c}\text { Natural } \\
\text { consequences } \\
\text { Positive } \\
\text { consequences } \\
\text { Equity }\end{array}$ \\
\hline $\begin{array}{c}\text { General } \\
\text { comments }\end{array}$ & & & & \\
\hline
\end{tabular}

Table 5: Course Syllabi Comparison Chart

Courses labeled ID signify those non-QM-designed course, while those that have been designed to conform to QM rubric standards are denoted by QM. Comparison results will demonstrate the types of motivational tactics used in each course to discover if any significant differences exist between these QM-designed and ID-designed graduate courses.

The syllabus is the most important document to analyze in the formation of a case study of an online course. Instructors are responsible for presenting course materials so students are able to build their knowledge of the subject and successfully achieve course objectives. The syllabus they provide should be a comprehensive guide to all information students need to be successful in the class: course description and structure, learning objectives, required software, 
texts, and equipment, class procedures and policies, assessment procedure and point-value, assignment and due date information, instructor expectations and availability, technical support information, and university-required information (Eberly, Newton \& Wiggins, 2001).

\section{Instructor Interviews}

Instructors of each course were interviewed via email to discover their perspectives about the characteristics of their course. Questions drawn from Keller’s Motivational Design Worksheet explored instructor perspectives on course content and conditions, curriculum rationale, context, and experience:

1. What is the major goal of this course?

2. Have you taught this course before? Will you teach it again in the future?

3. What curriculum need or requirement is supposed to be met with this course?

4. What are the benefits to students?

5. How does this course relate to other courses taken before or after this one?

6. What delivery system and method(s) will be used (synchronous/asynchronous elements; instructor-led/self-paced, etc.)?

7. How much subject-matter expertise does instructor have?

8. How much instructional design experience does instructor have?

Keller's worksheet used to design these interview questions is part of his 10 -step process that provides a series of instructor activities joined in a systems approach to identify motivational problems and goals to develop learning environments to stimulate and sustain student motivation (Keller, 2010). This series of instructor activities begins with a comparison between motivational design steps and traditional instructional design steps (Table 6): 


\begin{tabular}{|c|c|c|}
\hline \multicolumn{3}{|c|}{$\begin{array}{l}\text { Table } 6 \\
\text { Summary of Motivational Design in Relation to Instructional Design }\end{array}$} \\
\hline Generic Design & Motivational Design Steps & Instructional Design Steps \\
\hline Analyze & $\begin{array}{l}\text { Obtain course information } \\
\text { Obtain audience information } \\
\text { Analyze audience } \\
\text { Analyze existing materials }\end{array}$ & $\begin{array}{l}\text { Identify problems where instruction is the } \\
\text { appropriate solution } \\
\text { Identify instructional goals } \\
\text { Identify entry behaviors \& characteristics } \\
\text { Conduct instructional analysis }\end{array}$ \\
\hline Design & $\begin{array}{l}\text { List objectives \& assessments } \\
\text { List potential tactics } \\
\text { Select \& design tactics } \\
\text { Integrate with instruction }\end{array}$ & $\begin{array}{l}\text { Write performance objectives } \\
\text { Develop criterion-referenced tests } \\
\text { Develop instructional strategy }\end{array}$ \\
\hline Develop & Select \& develop materials & Select \& develop instruction \\
\hline Pilot Test & Evaluate \& revise & $\begin{array}{l}\text { Design \& conduct formative evaluation } \\
\text { Design \& conduct summative evaluation } \\
\text { Revise instruction }\end{array}$ \\
\hline
\end{tabular}

Table 6: Summary of Motivational Design in Relation to Instructional Design

\section{Collection and Analysis Procedures}

Syllabi were evaluated using content analysis, specifically conceptual analysis (Colorado State University [CSU], 2015a), to determine which motivational design elements were present in each course. This qualitative data formed the Course Syllabus Comparison Chart (Table 5, p. 43) and were analyzed to determine differences in ARCS motivational design elements between courses, as well as to determine the presence of QM design elements in all courses.

A study matrix of all data sources, complete with collection and analysis procedures for each data source, is provided in Table 7: 
Table 7. Data Sources, Collection, and Analysis Procedures

RQ: Do Instructional design decisions influence student motivation in online courses?

RQ\#1a: What motivational elements are present in QM vs non-QM designed courses?

RQ\#1b: Do motivational elements differ in QM vs non-QM designed courses?

\begin{tabular}{|ll|}
\hline Data Source(s) & $\begin{array}{l}\text { Collection Procedures for each data } \\
\text { source (number each step) }\end{array}$ \\
\hline 1. Course syllabi & $\begin{array}{l}\text { 1.1. Design Course Syllabus Comparison } \\
\text { Chart of motivational design elements, } \\
\text { based on Keller's ARCS framework. } \\
\text { 1.2. Gather syllabi from instructors } \\
\text { 1.3 Obtain QM higher education rubric }\end{array}$ \\
& \\
& \\
2. Qualtrics surveys & 2.1 Create surveys in Qualtrics. \\
(Keller’s Course & 2.2. Email students invitation to \\
Interest [CIS] & anonymously participate in the surveys. \\
Survey \& & 2.3. Send Qualtrics URL links for \\
Instruction & instructors to email to course students. \\
Materials & 2.4. Gather qualitative results from \\
Motivation Survey & Qualtrics (ANOVA) \\
[IMMS]) &
\end{tabular}

Analysis Procedures for each Data Source (number each step)
1.1. Content analysis to record ARCS- related keywords and key-ideas on Course Syllabus Comparison Chart*.
1.2. Comparative analysis to determine differences in ARCS motivational design elements between the courses.
1.3. Comparative analysis to determine design elements of QM standards.

2.1. Analyze survey results to determine student motivation rating in each course.

2.2. Comparison analysis between Qualtrics scores and Course Syllabus Comparison Chart* to seek correlations or differences in overall motivation.

2.3. Comparison analysis between Qualtrics motivation subcategory scores and Course Syllabus Comparison Chart* to seek correlations or differences in each of the four elements of motivation.

3. Course Syllabi Comparison Chart
3.1. Completed chart from textual analysis discussed in 1.1 analysis above.
3.1. Comparative analysis with Qualtrics survey results to seek correlations or differences in overall student motivation between courses.

3.2. Comparison analysis with Qualtrics motivation subcategory scores to seek correlations or differences in each of the four elements of motivation. 


\begin{tabular}{|c|c|c|}
\hline $\begin{array}{l}\text { 4. Instructor } \\
\text { interviews }\end{array}$ & $\begin{array}{l}\text { 4.1. Create Interview survey questions } \\
\text { designed using Keller's theory in } \\
\text { Qualtrics. } \\
\text { 4.2. Interview survey link will be emailed } \\
\text { to each instructor near the beginning of } \\
\text { the semester. }\end{array}$ & $\begin{array}{l}\text { 4.1. Researcher will use textual analysis to } \\
\text { review instructor responses to gain insight into } \\
\text { their perspectives about their course and their } \\
\text { teaching and instructional design experience. } \\
\text { 4.2 Comparison of textual analysis results with } \\
\text { Course Syllabi ARCS data and student rating } \\
\text { of motivation in each course will be used to } \\
\text { develop case studies on each course. }\end{array}$ \\
\hline $\begin{array}{l}\text { 5. Observation } \\
\text { Research }\end{array}$ & $\begin{array}{l}\text { 5.1. Researcher will be added as class } \\
\text { auditor to each of the four online courses } \\
\text { by instructors via learning management } \\
\text { system (LMS). }\end{array}$ & $\begin{array}{l}\text { 5.1. Observation research will examine how } \\
\text { actual course experience reflects syllabus } \\
\text { description for motivation elements of } \\
\text { attention, relevance, confidence, and } \\
\text { satisfaction. } \\
\text { 5.2. Results will complete the study matrix. }\end{array}$ \\
\hline
\end{tabular}

Table 7: Data Sources, Collection, and Analysis Procedures

Qualitative data from the instructor interviews were evaluated using content analysis, specifically relational analysis (CSU, 2015b), to determine similarities or differences in instructor perceptions of their online courses, as well as teaching and instructional design experience.

Qualtrics online survey software was used to deliver an anonymous survey link to students in each course. Both the Course Interest Survey (CIS) and the Instructional Materials Motivational Survey (IMMS) were administered during Week 5 of the 6-week term. In keeping with IRB guidelines, students received an email request from this researcher to participate in this study. Instructors provided students with anonymous links to the study surveys, which remained active for seven days to allow an adequate completion time.

The CIS (Table 8) was scored using the Likert-type scale and measured motivation for each of the four ARCS subcategories or present a total score. Items marked "reverse" are stated in a negative manner, and responses were reversed before they were added into the response 
total. The minimum score on this 34-item survey was 34, with a maximum score of 170 and a median score of 102 (Keller, 2010).

\begin{tabular}{|llll|}
\hline \multicolumn{2}{|l|}{ Table 8} & & \\
Scoring Guide for & \multicolumn{2}{l|}{ the Course Interest Survey (CIS) } & \\
\hline Attention & Relevance & Confidence & Satisfaction \\
\hline 1 & 2 & 3 & 7 (reverse) \\
4 (reverse) & 5 & 6 (reverse) & 12 \\
10 & 8 (reverse) & 9 & 14 \\
15 & 13 & 11 (reverse) & 16 \\
21 & 20 & 17 (reverse) & 18 \\
24 & 22 & 27 & 19 \\
26 (reverse) & 23 & 30 & 31 (reverse) \\
29 & 25 (reverse) & 34 & 32 \\
& 28 & & 33 \\
\hline
\end{tabular}

Table 8: Scoring Guide for the Course Interest Survey (CIS)

As with the CIS, the IMMS was scored using the Likert-type scale and measured motivation for each of the four ARCS subcategories (Table 9) or present a total score:

\begin{tabular}{|c|c|c|c|}
\hline \multicolumn{4}{|c|}{$\begin{array}{l}\text { Table } 9 \\
\text { Scoring Guide for the Instructional Materials Motivational Scale (IMMS) }\end{array}$} \\
\hline Attention & Relevance & Confidence & Satisfaction \\
\hline 2 & 6 & 1 & 5 \\
\hline 8 & 9 & 3 (reverse) & 14 \\
\hline 11 & 10 & 4 & 21 \\
\hline 12 (reverse) & 16 & 7 (reverse) & 27 \\
\hline 15 (reverse) & 18 & 13 & 32 \\
\hline 17 & 23 & 19 (reverse) & 36 \\
\hline 20 & 26 (reverse) & 25 & \\
\hline 22 (reverse) & 30 & 34 (reverse) & \\
\hline 24 & 33 & 35 & \\
\hline \multicolumn{4}{|l|}{28} \\
\hline \multicolumn{4}{|l|}{29 (reverse) } \\
\hline 31 (reverse) & & & \\
\hline
\end{tabular}

Table 9: Scoring Guide for the Instructional Materials Motivational Survey (IMMS) 
Items marked "reverse” are stated in a negative manner, and responses were reversed before they were added into the response total. The minimum score on this 36-item survey was 36, with a maximum score of 180 and a median score of 108 (Keller, 2010). Due to the inequality of questions in each subscale, scores for each can be determined by dividing the total score in each category by the number of items in that scale (Keller, 2010).

Quantitative survey data was tabulated by the Qualtrics survey software using factor analysis (Qualtrics, 2015), then examined by the researcher to determine relationships in online student motivation within and between the four courses being evaluated. Analysis of the individual ARCS subcategory survey scores sought to determine correlations or differences between QM- and ID-designed courses in the areas of attention, relevance, confidence, and satisfaction.

Observation research examined how actual course experience reflected the syllabus description for motivation elements of attention, relevance, confidence, and satisfaction. Monitoring an active course allowed the researcher to clearly see how instructional design and motivation design choices affected student motivation within each course in real time as the term progressed. Observational research results completed the study matrix (Table 2) of all data used to develop the four comprehensive case studies that ultimately provided much-needed insight into the influence instructional design decisions have on student motivation in online courses.

\section{Chapter Summary}

The great demand for high-quality online learning experiences makes this study of utmost importance at this time. Educational institutes, while dedicated to providing the best education possible for learners, remain dependent on student retention. If the awareness and addition of motivational design factors can help decrease attrition while providing more valuable education 
opportunities, the course can then truly be classified as "high-quality” for all stakeholder groups. Administrators are happy because the courses bring in and retain students; instructional designers and faculty are happy because motivated learners are more productive and proactive; and students are happy because they feel good about learning new material that will be useful to them in some manner. Designing “quality” and “value” into a course is an ongoing process that takes vigilance and ongoing evaluation. A “quality” course is always evolving, continually improving and adapting to best meet the needs of the learners. 


\section{Chapter 4: Results}

Each of the courses that make up the four case studies was offered during the first half of the 2015 summer semester. All were graduate courses offered through the College of Education and Human Development at a mid-Atlantic public university. Each course was regularly taught by the same instructor, each of whom had over ten years teaching experience. Courses A and B were non-QM-designed (ID) courses, while Courses C and D were designed using Quality Matters rubric criteria (QM).

Course A (ID) and Course D (QM) are each required for completion of a graduate Education program of study, while Course B (ID) and Course C (QM) are elective courses relevant to multiple graduate Education programs of study.

Course C (QM) and Course D (QM) are designed primarily for beginning Education graduate students and assume the least amount of prerequisite knowledge, while Course A (ID) and Course B (ID) are designed for more experienced students.

Course $\mathrm{D}(\mathrm{QM})$ is primarily theoretical in nature, while the other three courses are more project-oriented and demonstrative.

Finally, each course is relevant for practicing teachers; however, technology-oriented students may have heightened attention and interest in Course A (ID), Course B (ID), and Course $\mathrm{C}(\mathrm{QM})$ as these explore practical, hands-on techniques that could be immediately adopted in the student's classroom to enhance learning experiences.

\section{Course A}

Instructor A Interview Results

Course A is a 6-week graduate Education course that focuses on interactively identifying and sampling instructional delivery systems such as Moodle and Blackboard. This course is 
designed to be the third of three required for the Distance Education portion of the graduate degree program. Students enrolled in this course will have already completed a distance education overview course, as well as an authoring systems course. The overview course provides students with a theoretical understanding of distance education concepts and issues, while the authoring systems course is specific to developing online modules using an authoring system. Course A, oriented toward delivery of courses and programs online, was designed as a culminating experience that provides students with "a complete set of skills and knowledge about delivering instruction at a distance” (Instructor interview notes, July, 2015). The final project for Course $\mathrm{A}$ is the design of a learning module that in some way features USDA nutrition labels, delivered using the Moodle online delivery platform.

The instructor (Professor A), with more than 35 years academic and instructional design experience, consults with state agencies on the design and deployment of instructional delivery systems. Professor A has designed instructional delivery systems and has published extensively on the concepts. This instructor was instrumental in the development of Course A, has taught the course before, and will teach it again in the future. Professor A describes the major goal of the course as being two-fold: it provides a theoretical background of instructional delivery systems as well as a practical experience designing and deploying an actual course module using the widely-available, no-cost instructional delivery system, Moodle. Professor A states that students benefit from the hands-on nature of the course and are provided with an opportunity to think about larger issues as they are given complete freedom to choose, arrange, and present education elements and resources for their final project.

Course A was delivered using a self-paced, flipped approach via the university LMS, Blackboard. Direct instruction was provided by a comprehensive series of YouTube videos 
created by Professor A to explain and demonstrate course concepts, resources, and activities within Moodle. Synchronous video or voice chats were scheduled and held weekly using course LMS features. While optional, these real-time chats enabled students to directly ask questions and seek feedback from the instructor or interact with peers. These instructional design decisions could influence student motivation by prompting and promoting attention to course details and resources, enhancing student confidence by providing the weekly sessions, reinforcing subject-matter relevance, and ultimately promoting student satisfaction with the overall learning experience.

\section{Syllabus A Analysis}

While the syllabus for this non-QM-designed course, at just two pages, was the shortest of the four examined in this study, it contained multiple motivational design elements and was appropriate when considered in the context of an advanced student audience, as well as course delivery options and features available via the university LMS. This course was designed for students nearing completion of their degree studies. The course audience was expected to be comprised of experienced students, most familiar with the instructor, the general instruction style and expectations, and standard "housekeeping" issues such as university policies or accessibility assistance. Advanced students are already motivated to complete their degree studies because of the time, money, and energy they have invested. Coming into a new class, advanced students primarily want to know what they have to do, and how and when they have to do it. The syllabus for Course A provides just that: an attention-getting course description showing relevance to student interests, the course objectives, required materials, activities, assignments and assessment overview. Advanced students will know that additional university and course information is available within the course delivered to them through the university LMS. While it is vital for 
students to have ready access to this additional university and course information, there is no need for it to be replicated on this particular course syllabus.

The Course A syllabus can be read at a glance, with large, bolded headings and points in bullet or number format. The course name, credit hours, and instructor name appears at the top of the document. The course Description reminds students of the relevance and importance of technology tools "from the classroom to the boardroom" (Syllabus A, 2015). To promote clarity of purpose, the primary topic -- instructional delivery systems -- is immediately defined in a bulleted overview. This design decision can help activate existing knowledge about online course delivery and encourage students to begin looking for and making connections with the new materials and activities they will encounter throughout the course.

The Units section immediately follows the course description. Students are provided with a bulleted overview of the course content structure and presentation order. This simplistic format provides concise statements that students can easily access to independently gauge their course progress. This design decision can enhance student confidence at the very beginning of the course by providing a clear theoretical and practical path toward the end-results: outcomes, the section immediately following.

The Outcomes section provides a five-point checklist highlighting knowledge and skills that will be gained upon course completion. This concise design decision emphasizes goalorientation and motive-matching, two relevance-generating features of motivational design. The presentation of clear learning goals and opportunities for success should generate confidence and promote self-efficacy in students by outlining what can be achieved as a results of their efforts. 
The Materials section states simply that all course materials are accessible via the course LMS. The design decision to use no-cost online resources will certainly enhance student satisfaction since saving money on textbooks is always a positive experience.

The Activities, Assignments and Assessments section includes several hyperlinks that provide additional details about assignments and technology tools. The instructional design choice to use functioning hyperlinks within the syllabus is ideal for a document that students access and interact with online. This decision causes the syllabus document itself to become shorter, which in itself can have a positive influence on student confidence and motivation. The hyperlinks can direct and enhance student attention by stimulating curiosity. They demonstrate relevance of theory to practical application, and may increase student confidence by offering swift access to course resources and providing clear assessment details that delineate course requirements and expectations.

The primary theoretical assessment for this online delivery course is the creation and delivery of a persuasive three-to-five-minute "talk," a presentation in the style of the popular

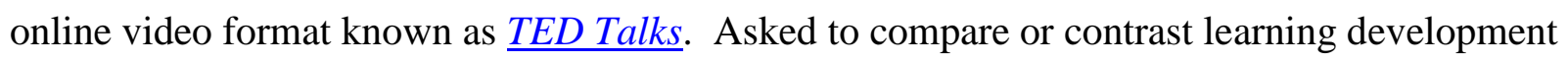
systems with virtual learning environments, students are given a choice of several applications that can be used to deliver the "talk." This instructional design decision to allow choice of delivery methods can increase student attention and provide an enhanced sense of relevance, confidence, and satisfaction. In providing students with choices, they are presented with the opportunity to either use a familiar application or learn to use a new one in the delivery of their findings. Due date and assignment details, including functioning hyperlinks to assigned topic and potential delivery tools, are clearly stated on the Course A syllabus. 
Students are given complete freedom to choose, arrange, and present education elements and resources for their final project, a unique learning module centered on a common theme of nutrition labels. In describing the assessment measure, Professor A chose to provide a link to previous student projects done using Moodle. The instructional design decision to make assessment examples available could positively enhance student confidence by providing visuals of acceptable work while attempting to establish a working community built on trust and support. This design decision would obviously not be available if course assessments had been designed as exam-based with specific "right or wrong" answers. The syllabus is typically the initial point of contact students have with any course; therefore, placement of a final-related hyperlink here is an experienced instructional design decision that may encourage students to begin thinking about their own final projects. Students enrolled in this summer session of Course A are already aware of the accelerated class format of six- versus the standard 15-weeks. By revealing and showcasing the importance and relevance of final projects at the beginning of the course, Professor A is stimulating student attention while helping them build confidence in their abilities and establish a thought process that shows a path to course completion beginning on Day One.

\section{Course A Observation Data}

While the Course A syllabus document is brief, the online course design is detailed and in-depth. The "Course Info" page provides the syllabus and course description, then includes unit objectives details, learning outcomes, required course materials, a summary of required projects, and optional Tuesday evening chats.

This was the only course to offer regularly-scheduled, but optional, real-time chats which were video-archived for later access. These three design decisions -- to offer the chats, to make 
them optional, and to record them for later access -- should greatly increase student confidence that they have ongoing access to the instructor, as well as all other resources needed to be successful in the course.

A PDF link to a comprehensive textbook on online learning design and delivery is included at the end of the online syllabus. The design decisions to use an open-source textbook, then to place the link at the end of the online syllabus, should draw student attention to the importance of the resource. Student attention and satisfaction should increase as a result of the instructor consideration of textbook costs in selecting course resources. These design decisions show the relevance and importance of the text to the course and provide early insight into the teaching style of the instructor. Student confidence and satisfaction should increase as they see they will be provided with the materials and resources needed to master the topic and succeed in the course.

Student attention and confidence should be heightened as they review the online course because instructor engagement continues to be evident in the design of the "Lessons" section: it is this student's observation that during accelerated summer courses, instructors often do not modify course design to reflect the shorter timeframe. Rather, students are generally assigned a combination of lessons that are very obviously from a standard full-length term. In Course A, the six (6) weekly lessons reflect the accelerated six-week summer term, each clearly labeled and containing a weekly learning synopsis and all the resources required to learn the material and complete the assignments. 
One of the most unique features of Course A is a series of instructor-made YouTube videos which discuss the weekly lesson and give helpful suggestions on understanding the materials in order to not only complete the assigned tasks, but to use the knowledge in future instructional design activities.

In summation, observational research indicates that the actual course experience greatly surpasses the brief syllabus description and includes numerous motivation elements that should promote student attention, relevance, confidence, and satisfaction.

\section{Course A Student Ratings of Motivation: CIS Survey}

Motivation can be defined as the direction and intensity of behavior, defining the goals people choose to pursue and how much effort is expended to achieve those goals (Keller, 2010). The two survey instruments used in this study to explore student motivation in an online course environment are intended to measure student motivation in a particular course. These surveys, the Course Interest Survey (CIS) and the Instructional Materials Motivation Scale (IMMS), were designed by Keller to provide a quantitative measure for the theory of motivational design.

The CIS (Appendix A) has 34 items, featuring eight (8) each for the Attention and Confidence subscales, and nine (9) each for the Relevance and Satisfaction subscales (Table 8). From the 12 students enrolled in Course A, seven students (58.3\%) completed the CIS. Results are seen in Table 10 below, including number of responses, mean score, and applicable ARCS element: 


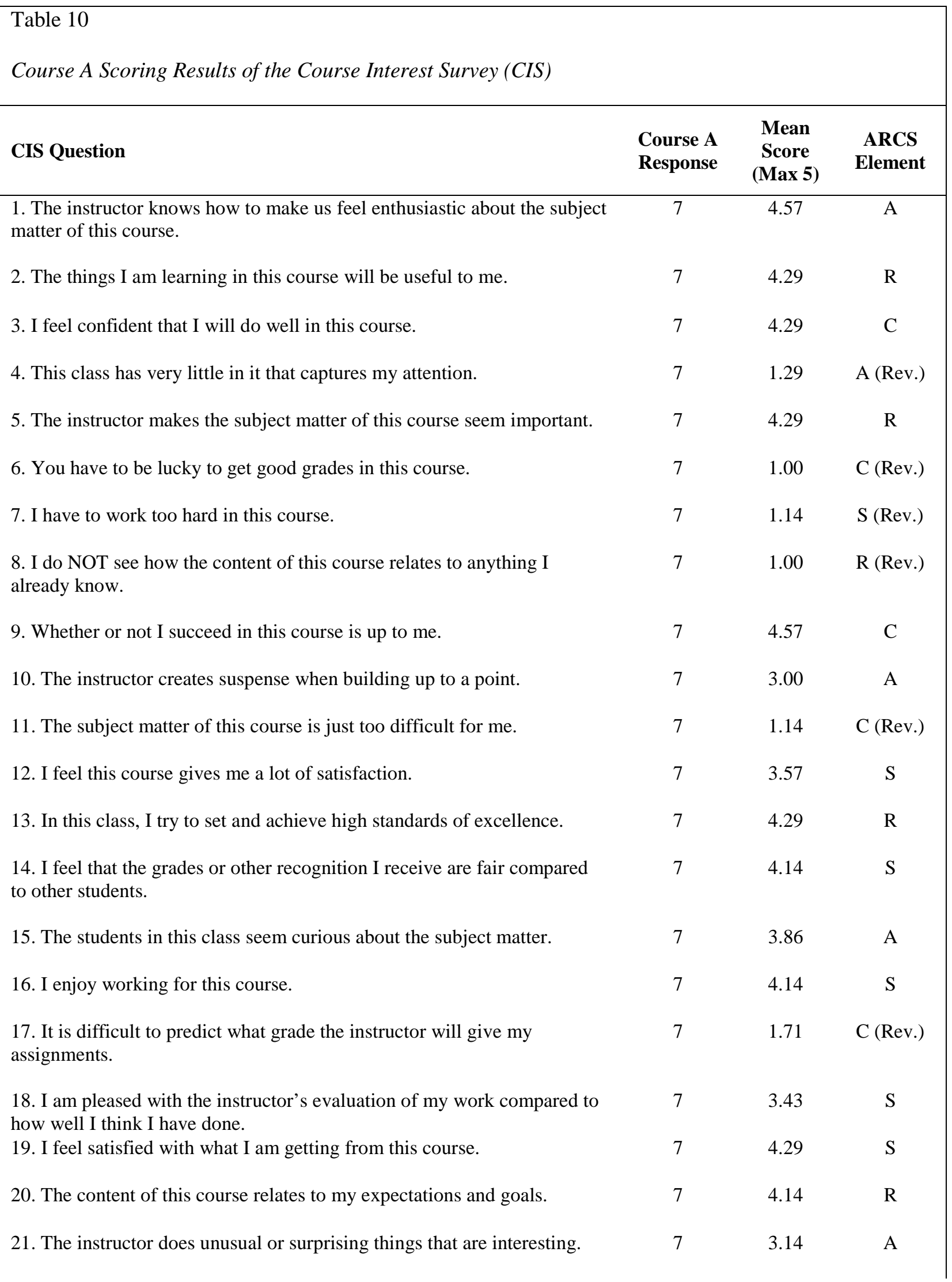




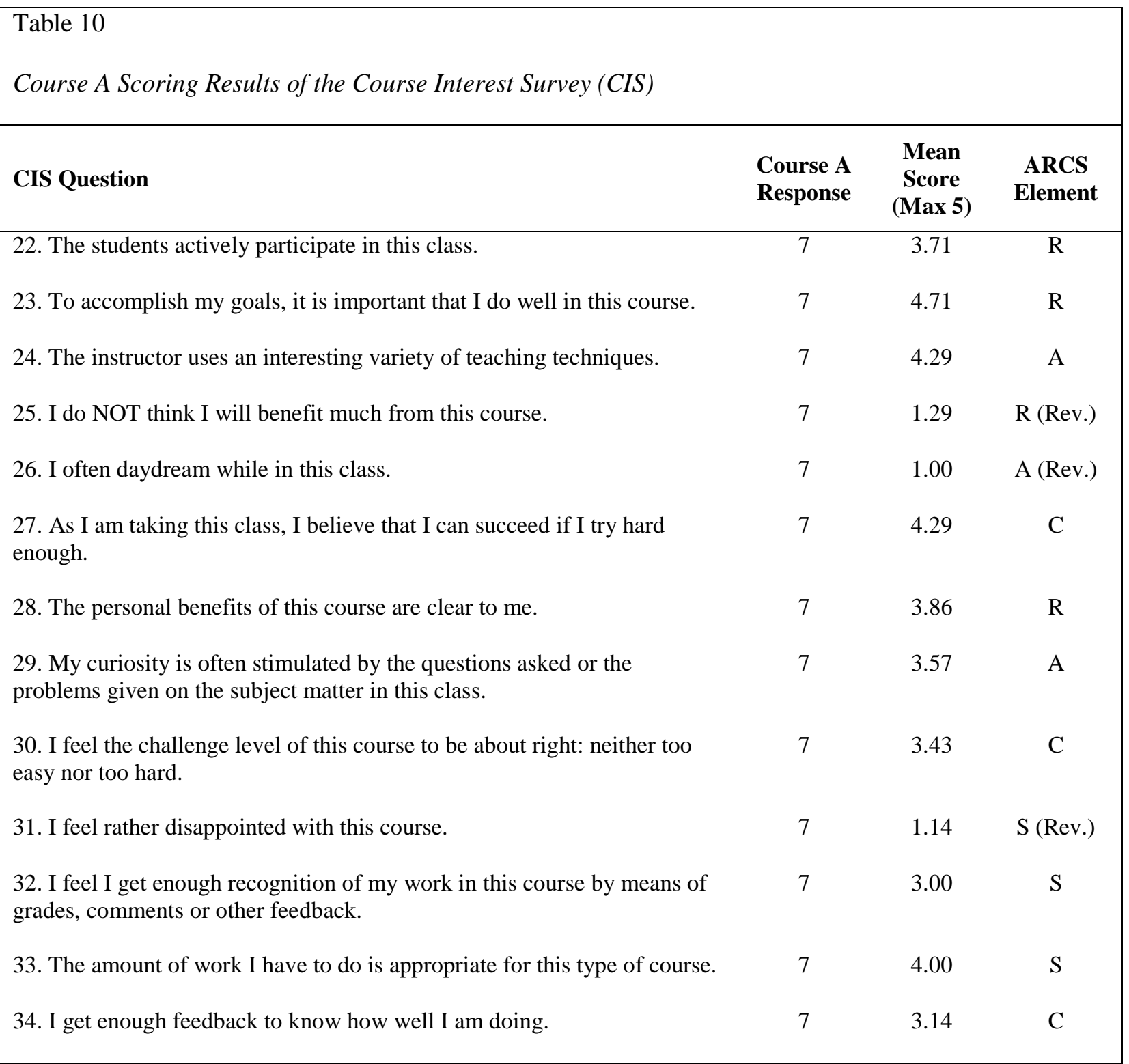

Table 10: Course A Scoring Results - Course Interest Survey (CIS)

Overall, students seemed motivated to both participate and excel in Course A. When reverse scores on the CIS are converted, on the scale of one to five, Course A received mean average scores of ARCS motivational elements as follows in Table 11 below: 


\begin{tabular}{|c|c|}
\hline $\begin{array}{l}\text { Table } 11 \\
\text { Course A CIS Motivational Averages }\end{array}$ \\
\hline ARCS Element & Course A CIS Avg. \\
\hline Attention & 3.77 \\
Relevance & 4.11 \\
Confidence & 3.89 \\
Satisfaction & 3.81 \\
\hline
\end{tabular}

CIS results appear to indicate that a small minority of respondents did not find as much value and worth in the course or its content as their classmates: every question in the Course A CIS had one or two responses lower in value than the majority.

Attention elements include design decisions that invoke feelings: enthusiasm, suspense, curiosity, surprise, interest, and stimulation. These elements are captured in CIS questions 1, 10, 15, 21, 24, and 29, with questions 4 and 26 providing reversed responses. Course A received an average Attention score of 3.77 of a possible 5.0 rating, certainly above average yet the lowest of the four motivational element scores measured by the CIS. Many Course A design decisions can contribute to high scores in the Attention element of motivation, including evidence of instructor engagement and availability; the availability of no-cost online texts and resources; availability and option of weekly chats, archived for convenience and accessibility; custom-designed videos that provided simplistic but comprehensive instructions for working through some of the more difficult technical aspects of the assignments, and the availability of peer discussion boards and contact information. Instructor enthusiasm for the subject matter (CIS question 1) received the highest Attention motivation score, ranking 4.57 of a possible 5 rating. Students acknowledged the variety of teaching techniques (CIS question 24), ranking this design decision with a 4.29 out of a possible 5 Attention rating. 
Course A received the highest overall rating for the Relevance motivational element, averaging 4.11 of a possible 5 rating. Students determine course relevance by how closely course goals and projects align with their own interests and ambitions. Relevance elements of Course A are captured in CIS questions 2, 5, 13, 20, 22, 23, and 28, with questions 8 and 25 providing reversed responses. Each of these questions received high student ratings, ranging from 3.71 to 4.71 of a possible 5 rating. These questions examine motivational factors such as future importance of course content, personal benefit of course completion, establishment of personal or professional standards of excellence, and achievement of goals and expectations. Course success to achieve personal goals (CIS question 23) received the highest Relevance motivation ranking from students, scoring 4.71 out of a possible 5 rating. Personal usefulness of content (CIS question 2) and the establishment and achievement of high standards of excellence (CIS question 13) also received high Relevance ratings, each scoring 4.29 of a possible 5 rating. Confidence elements are measured by seeking to determine the degree to which design decisions allow students to believe they can be successful in completing all assignments and tasks required for the course. These elements are captured in CIS questions 3, 9, 27, 30, and 34, with questions 6, 11, and 17 providing reversed responses. Course A received the second highest overall score in Confidence elements, averaging 3.89 of a possible 5.0 rating. Acknowledgement of personal accountability for learning (CIS question 9) received the highest motivational score, ranking 4.57 out of a possible 5 rating. The flexibility and custom design of course resources may have attributed to high Confidence motivation scores, including student confidence to succeed (CIS question 3) and success through effort (CIS question 27), each scoring 4.29 out of a possible 5 rating. 
Satisfaction ratings are determined by questions that focus on instructor fairness and attention, instructor and peer recognition, amount of required work, personal enjoyment of course content, as well as interaction with the online community, including instructor. These elements are captured in CIS questions 12, 14, 16, 18, 19, 32, and 33, with questions 7 and 31 providing reversed responses. Course A received the average Satisfaction score of 3.81 out of 5, with individual responses ranging from a low of 3 to a high of 4.29 out of a possible 5 rating. Overall satisfaction with the course scored highest, ranking 4.29 out of a possible 5 rating. Personal enjoyment of the course (CIS question 16) and fairness of grading and recognition (CIS question 14) closely followed, each scoring 4.14 out of a possible 5 rating.

\section{Course A Student Ratings of Motivation: IMMS Survey}

The Instructional Materials Motivation Scale (IMMS) is designed to measure student reaction to self-directed instructional materials. There are 36 items, with 12 for the Attention subscale, nine (9) items each for the Relevance and Confidence subscales, and six (6) items for the Satisfaction subscale. Keller (2010) attributes the higher number of items that examine Attention elements to a prevailing educational notion that text-based instructional materials contribute to boredom and lack of stimulation, while the lower number of Satisfaction items reflects that this motivational element has fewer connections to printed materials than the other subcategories do. Keller (2010) designed a Motivational Tactics Checklist that can be useful in developing and evaluating instructional materials for motivation (p. 286-292).

From the 12 students enrolled in Course A, seven students (58.3\%) completed the IMMS. Results are seen in Table 12 below, including number of responses, mean score, and applicable ARCS element: 


\begin{tabular}{|c|c|c|c|}
\hline IMMS Question & $\begin{array}{l}\text { Course A } \\
\text { Response }\end{array}$ & $\begin{array}{c}\text { Mean } \\
\text { Score } \\
\text { (Max. 5) }\end{array}$ & $\begin{array}{c}\text { ARCS } \\
\text { Element }\end{array}$ \\
\hline $\begin{array}{l}\text { 1. When I first looked at this course, I had the impression that it would } \\
\text { be easy for me. }\end{array}$ & 7 & 2.14 & $\mathrm{C}$ \\
\hline $\begin{array}{l}\text { 2. There is something interesting at the beginning of each lesson that } \\
\text { gets my attention. }\end{array}$ & 7 & 3.29 & A \\
\hline $\begin{array}{l}\text { 3. This course material was more difficult to understand than I would } \\
\text { like it to be. }\end{array}$ & 7 & 1.29 & C (Rev.) \\
\hline $\begin{array}{l}\text { 4. After reading the introductory information, I felt confident that I knew } \\
\text { what I was supposed to learn from each lesson in this course. }\end{array}$ & 7 & 3.71 & $\mathrm{C}$ \\
\hline $\begin{array}{l}\text { 5. Completing the exercises in each lesson gave me a satisfying feeling } \\
\text { of accomplishment. }\end{array}$ & 7 & 4.29 & $\mathrm{~S}$ \\
\hline $\begin{array}{l}\text { 6. It is clear to me how the content of this course is related to things I } \\
\text { already know. }\end{array}$ & 7 & 4.57 & $\mathrm{R}$ \\
\hline $\begin{array}{l}\text { 7. Many of the resources have so much information that it is hard to pick } \\
\text { out and remember the important points. }\end{array}$ & 7 & 1.43 & C (Rev.) \\
\hline 8. The materials are eye-catching. & 7 & 3.71 & A \\
\hline $\begin{array}{l}\text { 9. There were stories, pictures, or examples that showed me how this } \\
\text { material could be important to some people. }\end{array}$ & 7 & 4.14 & $\mathrm{R}$ \\
\hline 10. Completing this course successfully is important to me. & 7 & 4.86 & $\mathrm{R}$ \\
\hline 11. The quality of the writing helped to hold my attention. & 7 & 3.43 & A \\
\hline $\begin{array}{l}\text { 12. This course lessons were so abstract that it was hard to keep my } \\
\text { attention on them. }\end{array}$ & 7 & 1.14 & A (Rev.) \\
\hline $\begin{array}{l}\text { 13. As I worked on each lesson, I was confident I could learn the } \\
\text { content. }\end{array}$ & 7 & 4.14 & C \\
\hline $\begin{array}{l}\text { 14. I enjoyed this course so much that I would like to know more about } \\
\text { this topic. }\end{array}$ & 7 & 4.57 & S \\
\hline 15. The resources for this course look dry and unappealing. & 7 & 1.43 & A (Rev.) \\
\hline 16. The content of this course is relevant to my interests. & 7 & 4.43 & $\mathrm{R}$ \\
\hline 17. The way the information is arranged helped keep my attention. & 7 & 4.29 & A \\
\hline $\begin{array}{l}\text { 18. There are examples or explanations of how people can use the } \\
\text { knowledge from this course. }\end{array}$ & 7 & 4.29 & $\mathrm{R}$ \\
\hline
\end{tabular}




\begin{tabular}{|c|c|c|c|}
\hline IMMS Question & $\begin{array}{l}\text { Course A } \\
\text { Response }\end{array}$ & $\begin{array}{c}\text { Mean } \\
\text { Score } \\
\text { (Max. 5) }\end{array}$ & $\begin{array}{l}\text { ARCS } \\
\text { Element }\end{array}$ \\
\hline 19. The exercises in this course are too difficult. & 7 & 1.29 & C (Rev.) \\
\hline 20. This course has things that stimulate my curiosity. & 7 & 4.00 & A \\
\hline 21. I really enjoyed studying the lessons in this course. & 7 & 4.00 & $\mathrm{~S}$ \\
\hline $\begin{array}{l}\text { 22. The amount of repetition in course lessons caused me to get bored } \\
\text { sometimes. }\end{array}$ & 7 & 1.14 & A (Rev.) \\
\hline $\begin{array}{l}\text { 23. The content and style of writing in the lessons convey the impression } \\
\text { that its content is worth knowing. }\end{array}$ & 7 & 4.00 & $\mathrm{R}$ \\
\hline 24. I learned some things that were surprising or unexpected. & 7 & 3.71 & A \\
\hline $\begin{array}{l}\text { 25. After working on the lessons, I was confident that I would be able to } \\
\text { pass the course. }\end{array}$ & 7 & 4.29 & $\mathrm{C}$ \\
\hline $\begin{array}{l}\text { 26. This course is not relevant to my needs because I already knew most } \\
\text { of the material. }\end{array}$ & 7 & 1.29 & R (Rev.) \\
\hline $\begin{array}{l}\text { 27. The wording of feedback after the exercises, or other comments on } \\
\text { the lessons, helped me feel rewarded for my efforts. }\end{array}$ & 7 & 3.14 & $\mathrm{~S}$ \\
\hline $\begin{array}{l}\text { 28. The variety of readings, exercises, illustrations, etc., helped keep my } \\
\text { attention on the lessons. }\end{array}$ & 7 & 3.86 & A \\
\hline 29. The style of writing used in the course resources is boring. & 7 & 1.43 & A (Rev.) \\
\hline $\begin{array}{l}\text { 30. I could relate the content of this course to things I have seen, done, } \\
\text { or thought about in my own life. }\end{array}$ & 7 & 4.43 & $\mathrm{R}$ \\
\hline $\begin{array}{l}\text { 31. There were so many words on each page of reading that it was } \\
\text { irritating. }\end{array}$ & 7 & 1.14 & A (Rev.) \\
\hline 32. It felt good to successfully complete the lessons. & 7 & 4.57 & $\mathrm{~S}$ \\
\hline 33. The content of the lessons will be useful to me. & 7 & 4.57 & $\mathrm{R}$ \\
\hline 34. I could not really understand quite a bit of material in this course. & 7 & 1.14 & C (Rev.) \\
\hline $\begin{array}{l}\text { 35. The good organization of content helped me be confident that I } \\
\text { would learn the material. }\end{array}$ & 7 & 4.00 & $\mathrm{C}$ \\
\hline 36. It was a pleasure to work on such a well-designed course. & 7 & 4.29 & $\mathrm{~S}$ \\
\hline
\end{tabular}

Table 12: Course A Scoring Results - Instructional Materials Motivational Scale (IMMS) 
Overall, students seemed very motivated by the instructional materials used in Course A: On the scale of one to five, when reverse scores on the IMMS are converted, Course A received mean average ARCS motivational element ratings, as follows in Table 13 below:

\begin{tabular}{|c|c|}
\hline \multicolumn{2}{|c|}{$\begin{array}{l}\text { Table } 13 \\
\text { Course A IMMS Motivational Averages }\end{array}$} \\
\hline ARCS Element & Course A IMMS Avg. \\
\hline Attention & 3.77 \\
\hline Relevance & 4.11 \\
\hline Confidence & 3.89 \\
\hline Satisfaction & 3.81 \\
\hline
\end{tabular}

Table 13: Course A IMMS Motivational Averages

As in the CIS results, IMMS results also appear to indicate a small minority of respondents did not find as much value and worth in the course or its content as their classmates: every question in the Course A IMMS had one or two responses lower in value than the majority.

Attention elements as related to the design and selection of instructional materials for the course include decisions that will provoke feelings like enthusiasm, suspense, curiosity, surprise, interest, and stimulation. Visual stimulation of instructional materials is an especially important consideration in an online environment. Attention elements can include perceptual interest and concreteness, curiosity/inquiry arousal, and variability of format, style, and sequence (Keller, 2010). These elements are examined in IMMS questions 2, 8, 11, 17, 20, 24, and 28, with questions 12, 15, 22, 29, and 31 providing reversed responses. Course A received an average Attention score of 3.75 of a possible 5.0 rating, with individual question responses ranging from 3.29 to 4.29. Students found the variety (IMMS question 28), presentation/arrangement (IMMS 
question 17), and visual appearance (IMMS question 8) of materials to be highly motivating Attention elements, ranking them at 3.86, 4.29, and 3.71 respectively.

There are nine (9) Relevance items measured in the IMMS. Course A received the highest overall rating for the Relevance motivational elements, averaging 4.33 of a possible 5 rating. Relevance of instructional materials is determined by goal orientation; motive-matching, including present worth and future value, and familiarity, including connection to previous experience, and options for individualization (Keller, 2010). Relevance is assessed by IMMS questions $6,9,10,16,18,23,30$, and 33, with question 26 providing a reversed response. Each of these nine questions received high student ratings, ranging from 3.71 to 4.86 of a possible 5 rating. Student response indicated successful completion of the course as the highest relevance motivator at 4.86, followed by student experience with content (IMMS questions 6 and 30), rated at 4.57 each, and course content relevance to personal interests (IMMS 16) rated at 4.43.

Confidence elements are measured on the IMMS based on clear learning requirements, positive outcomes that will enhance student competence, and accountability for learning (Keller, 2010). These are assessed by IMMS questions $1,4,13,25$, and 35, with questions 3, 7, 19, and 34 providing reversed responses. Individual items scored responses ranging from 2.14 to 4.29 out of a possible 5 rating. The highest Confidence rating, 4.29, was received by IMMS question 25, which states confidence in passing the course increased as students worked through the lessons. The lowest Confidence rating, at just 2.14, was received by IMMS question 1, which states the course looked easy based on first impressions of the instructional materials. It was interesting to note that Course A provided the shortest syllabus, at just two pages.

Satisfaction elements are measured on the IMMS based on intrinsic reinforcement, including positive recognition and continuing motivation; potential extrinsic rewards, and equity 
or fair treatment (Keller, 2010). Satisfaction elements were measured by IMMS questions 5, 14, 21, 27, 32, and 36, and individual items were rated from 3.14 to 4.57. Personal satisfaction in completing assignments (IMMS question 32), as well as the desire to further explore the topic (IMMS question 14) each received the highest Satisfaction-based IMMS score of 4.57. Students indicated a high sense of personal accomplishment (IMMS question 5) and enjoyment (IMMS question 36) upon completion of assignments, rating each of these elements at 4.29.

\section{Course B}

\section{Instructor B Interview Results}

Course B is a 6-week graduate Education course that focuses on identifying and using various technology solutions for teachers. This elective course has no prerequisite and can be taken at any point throughout the degree program. Course B provides students with experiences to consider so they are able to make informed decisions about using emerging technologies for instructional purposes. The course audience consists primarily of Master's degree students, most teachers in the K-12 setting. For students new to instructional design studies, this course "provides a background on the technology component of the design process as it relates to instructional strategies (pedagogy) and subject-matter (content)” (Instructor interview notes, July, 2015). Course B was designed to provide students with the opportunity to explore and discuss various emerging technologies, and to design and reflect on learning activities incorporating such technologies. Students further along in their instructional design studies will find opportunities to apply their theoretical knowledge, to practice technology integration from a “perspective that emphasizes the importance of content, pedagogy, and technology for successful and meaningful use of educational technologies” (Instructor interview notes, July, 2015). The 
final project for the course is a Prezi presentation about one of the technology tools explored during the course.

Professor B has over a decade of instructional design and academic experience, participating in grant and contract projects, teaching, and research. With numerous academic presentations and awards, Professor B has published prolifically on educational technologies, instructional design, professional development for teachers, and teacher experience with educational technologies. This instructor was instrumental in the development of Course B, has taught the course before, and will teach it again in the future. Asked how the course fulfilled curriculum needs, Professor B provided an outstanding summation: "While many of the other courses focus on the design and development of instructional interventions as well as theories of instructional technology, this course fills the gap by providing an opportunity for students to learn about technology integration not only as a theory but also as a practice where they are exposed to various emerging tools in educational settings, and apply their pedagogical understanding and content knowledge to design technology-enhanced learning activities” (Instructor interview notes, July, 2015). Both curricular and student needs are met by the handson opportunities provided in this course.

Course B is delivered via the university LMS, Blackboard. Asynchronous online forums are provided for assignment submissions and reading discussions. Online office hours are scheduled upon student request. Direct instruction is provided from online resources, including journal articles, book chapters, conceptual manuscripts, and media sources. These instructional design decisions allow for complete asynchronous class attendance, the course format most accommodating for working adult learners. Students are required to research and experiment with several technology tools, then discuss their efforts, and reflect on the learning activities they 
design. Peer interaction is mandatory: students are required to comment on peer postings, an instructional design decision that can lead to deeper connections between theoretical concepts and actual classroom implementation, as well as to a stronger sense of an online learning community. Community-building efforts are further enhanced by encouraging students to share their own research findings and experience as part of the weekly discussions. With ongoing weekly interaction and instructor support available as needed, students should reasonably be able to complete their coursework without feelings of isolation sometimes associated with asynchronous online courses.

\section{Syllabus B Analysis}

The non-QM-designed Course B syllabus provides an Updated current date in the header. This is a positive design tactic that clearly shows instructor diligence to ensuring the course and all resources are as up-to-date, timely, and relevant as possible. Syllabus B is six pages in length, including a colorful two-page weekly schedule of assignments, activities, and due dates. This course is designed for students at any stage of their degree studies. Syllabus B contained multiple motivational design elements, and was appropriate for a mixed-experience student audience, as well as for the course delivery options and features available via the university LMS. As an elective course, enrollment alone signals students will have some degree of intrinsic motivation to successfully complete the course.

Syllabus B begins with a traditional “details” layout that includes course name, semester, credit hours, prerequisites, format, and instructor information. This design decision may enhance student confidence by allowing them to quickly skim general course details for relevance before moving that information from working memory. To accommodate the fully-online nature of the course, Professor B included phone number, email address, Skype contact information, and the 
option of video-chat via the course LMS to conduct virtual office hours as requested. The design decision to provide alternative access methods demonstrates instructor accommodation and accessibility, which may increase student confidence that assistance or feedback is available when needed.

The Course Objectives section establishes student interest, relevance, and confidence by linking objectives to practical applications of the technologies in real-life career-paths. The design decision to use empowering phrases such as, “experiences to consider," "make informed decisions," and “the opportunity to explore” impart a sense of curiosity, implying a satisfactory learning adventure.

The Expected Learning Outcomes section provides students with a three-point checklist highlighting knowledge and skills that will be gained upon course completion. This design decision emphasizes goal-orientation and motive-matching, two relevance-generating features of motivational design. The presentation of clear learning goals and opportunities for success should generate confidence and promote self-efficacy in students by outlining what will be achieved as a results of their efforts.

A Readings section provides a general summary that resources used in the course are accessible online, therefore, no text purchases are required. This design decision will enhance student satisfaction as saving money is always a positive experience. Professor B then provides the expectation that students also search, select, and share their own readings or resources as part of the weekly discussion. By stipulating the "expectation" of resource-sharing, this design strategy should stimulate student attention and show the desire to establish a community of learners within the online course environment. This strategy can also enhance student 
confidence by outlining the opportunities for success and personal control offered by the option to share resources with the group.

A color Assessment overview begins page 2 of Syllabus B, showing an assignment summary with approximate due dates and point values. While this section will attract student attention simply because it is vital to course completion, this design strategy could enhance student confidence and increase self-efficacy by providing a table format that can be quickly referenced as needed. Color sections provide eye-catching contrast within the text list that strategically highlights discussions and final project. The design decision to award points for peer comments reinforces the potential impact and importance of community-building and resource-sharing discussed in the previous Readings section.

Grading scale and policy sections logically follow the assessment section. The Grading Policy section clearly states work is due by specified deadlines and must be submitted through the course LMS. Professor B places a statement, in bold-face lettering, informing students the university LMS undergoes routine maintenance on Sundays that may restrict accessibility. These sections are attention-generating for their impact on successful course completion. Student confidence may be enhanced by a statement that late submissions can receive half-credit. The establishment of clear due-dates allows students to form a rudimentary working schedule they can follow to successfully complete the course, thus demonstrating personal control options and clear learning requirements, necessary in generating confidence. Natural and positive consequences, elements of satisfaction, will occur as assignments are submitted and performance is assessed. The stated point-value of each assignment provides equity, the way in which course outcomes genuinely reflect student efforts and task completion, another feature of satisfaction. 
A Software Requirements section informs students all technology tools to be used in the course are open-access and web-based. A bulleted list of specific software tools is provided, including functioning hyperlinks for each. In addition to the satisfaction generated by the costsavings of using free software, student interest and confidence should be enhanced by having swift access to required course technology tools through the syllabus document. The instructional design choice to use functioning hyperlinks within the syllabus is ideal for a document that students access and interact with online.

Each assessment measure is then detailed on Syllabus B, including specific resources to be used, instructions for technology tool exploration and reflection, and suggested length and writing style for written assignments and discussions. All assignment requirements are clearly outlined using personal and possessive pronouns (“you;” “your”) that encourage students to take ownership of the learning that is to occur by completing the assignment. An activity template and final-project rubric are available for student reference, a design decision that can enhance confidence by providing the tools required to self-evaluate these larger-point-value projects. Exploration of these additional grading tools may reveal opportunities for success and personal control (relevance) by providing greater detail on the projects and can contribute to heightened interest or curiosity about course content (attention).

Syllabus B includes two university policy statements pertinent to online learning: inclusivity and sexual harassment. Extensive information, outside resources, and functioning hyperlinks are clearly defined. This design decision brings attention to these important issues and may enhance student confidence in instructor sensitivity, perhaps fostering a sense of trust that could help build an effective online community of learners. 
The final two pages of Syllabus B consist of a color-coded Tentative Course Schedule. Each of the two-week blocks consist of four primary activity objectives: explore, discuss, design, and reflect. The schedule, presented in an easy-to-read, bulleted format with specific due-dates highlighted in red, should enhance student confidence by providing an easily-accessible, comprehensive overview of the course. Opportunities for success and personal control are presented by assignment structure of discussion, reflection, and design.

\section{Course B Observation Data}

Using a standard LMS appearance with navigation tabs on the left, the online design of Course B promotes the development of an online community of learners by assigning regular peer interaction in the discussions. This design decision may increase student attention and confidence that they may find, or be able to provide, peer support as needed.

In consideration of the topic of the course, the design decision to offer students the use of an app that provided a personalized feel to the online environment should increase student attention, relevance, and satisfaction. Student attention should be heightened by the use of current and practical technology tools that show the relevance and importance of course content for teachers. A comprehensive assessment rubric is provided, as well as detailed directions to course success. These design decisions should increase student attention and confidence by showing a clear path to achieving course objectives.

Observation research confirms the syllabus acknowledgement that, despite the accelerated summer timeframe, this is a demanding yet interesting and relevant course. Online course content is well-organized, has clear instructions for completion, and reflects a depth of instructional planning. This course expects active participation, as reflected in the assignment structures and assessment activities, which should increase student attention. 


\section{Course B Student Ratings of Motivation: CIS Survey}

Motivation can be defined as the direction and intensity of behavior, defining the goals people choose to pursue and how much effort is expended to achieve those goals (Keller, 2010). Two survey instruments were used in this study to explore student motivation in an online course environment. These surveys, the Course Interest Survey (CIS) and the Instructional Materials Motivation Scale (IMMS), were designed by Keller to provide a quantitative measure for the theory of motivational design. From the 10 students enrolled in Course B, four students (40\%) completed the Course Interest Survey. Results are seen in Table 14 below, including number of responses, mean score and ARCS element:

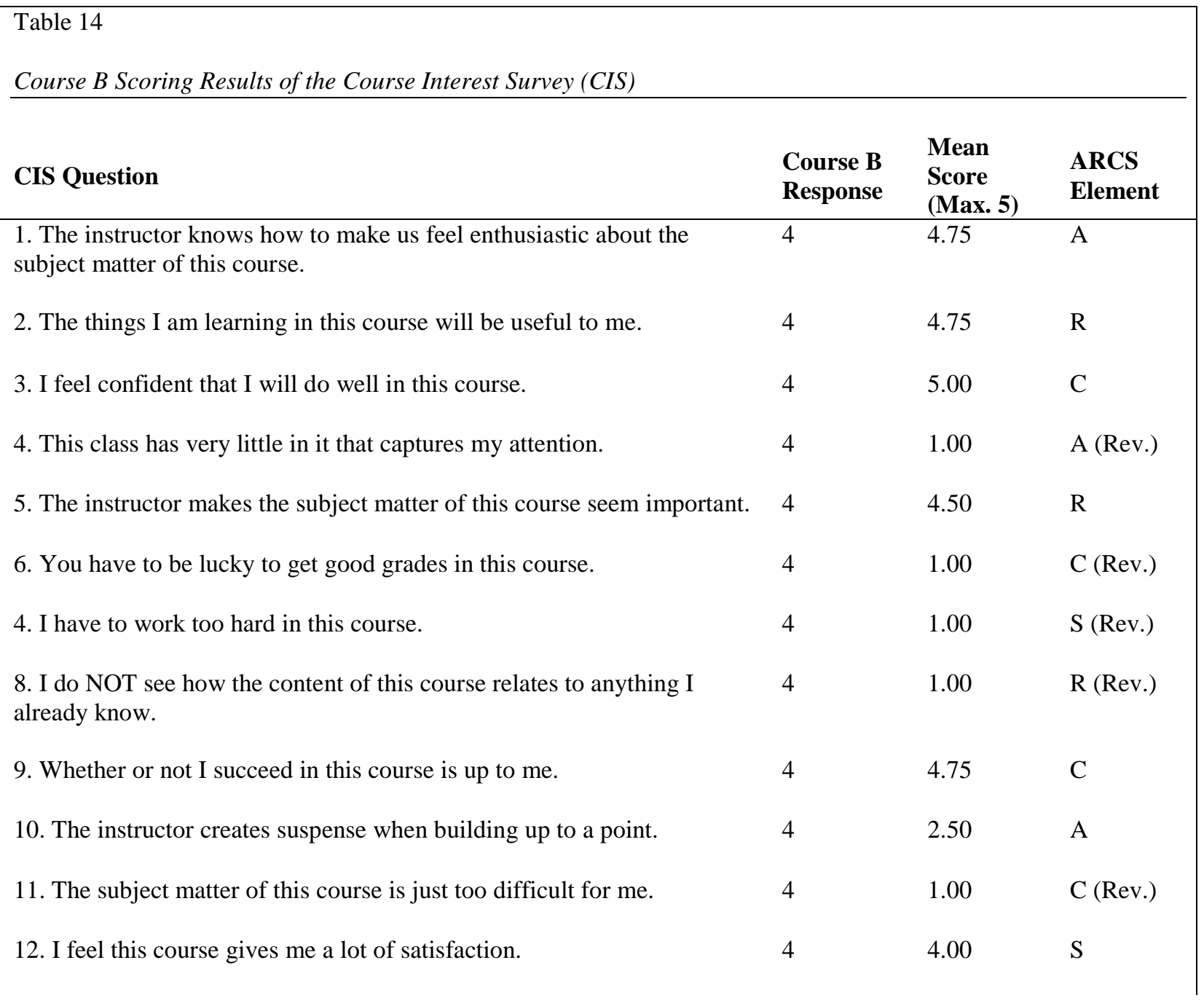




\begin{tabular}{|c|c|c|c|}
\hline CIS Question & $\begin{array}{l}\text { Course B } \\
\text { Response }\end{array}$ & $\begin{array}{l}\text { Mean } \\
\text { Score } \\
\text { (Max. 5) }\end{array}$ & $\begin{array}{l}\text { ARCS } \\
\text { Element }\end{array}$ \\
\hline 13. In this class, I try to set and achieve high standards of excellence. & 4 & 4.75 & $\mathrm{R}$ \\
\hline $\begin{array}{l}\text { 14. I feel that the grades or other recognition I receive are fair compared } \\
\text { to other students. }\end{array}$ & 4 & 5.00 & $\mathrm{~S}$ \\
\hline 15. The students in this class seem curios about the subject matter. & 4 & 4.50 & A \\
\hline 16. I enjoy working for this course. & 4 & 4.50 & S \\
\hline $\begin{array}{l}\text { 17. It is difficult to predict what grade the instructor will give my } \\
\text { assignments. }\end{array}$ & 4 & 1.00 & C (Rev.) \\
\hline $\begin{array}{l}\text { 18. I am pleased with the instructor's evaluation of my work compared } \\
\text { to how well I think I have done. }\end{array}$ & 4 & 5.00 & $\mathrm{~S}$ \\
\hline 19. I feel satisfied with what I am getting from this course. & 4 & 4.75 & S \\
\hline 20. The content of this course relates to my expectations and goals. & 4 & 4.75 & $\mathrm{R}$ \\
\hline 21. The instructor does unusual or surprising things that are interesting. & 4 & 2.50 & A \\
\hline 22. The students actively participate in this class. & 4 & 4.25 & $\mathrm{R}$ \\
\hline 23. To accomplish my goals, it is important that I do well in this course. & 4 & 5.00 & $\mathrm{R}$ \\
\hline 24. The instructor uses an interesting variety of teaching techniques. & 4 & 3.50 & A \\
\hline 25. I do NOT think I will benefit much from this course. & 4 & 1.00 & R (Rev.) \\
\hline 26. I often daydream while in this class. & 4 & 1.50 & A (Rev.) \\
\hline $\begin{array}{l}\text { 27. As I am taking this class, I believe that I can succeed if I try hard } \\
\text { enough. }\end{array}$ & 4 & 5.00 & $\mathrm{C}$ \\
\hline 28. The personal benefits of this course are clear to me. & 4 & 4.75 & $\mathrm{R}$ \\
\hline $\begin{array}{l}\text { 29. My curiosity is often stimulated by the questions asked or the } \\
\text { problems given on the subject matter in this class. }\end{array}$ & 4 & 4.25 & A \\
\hline $\begin{array}{l}\text { 30. I feel the challenge level of this course to be about right: neither too } \\
\text { easy nor too hard. }\end{array}$ & 4 & 4.75 & $\mathrm{C}$ \\
\hline 31. I feel rather disappointed with this course. & 4 & 1.25 & S (Rev.) \\
\hline $\begin{array}{l}\text { 32. I feel I get enough recognition of my work in this course by means } \\
\text { of grades, comments or other feedback. }\end{array}$ & 4 & 4.50 & S \\
\hline
\end{tabular}




\begin{tabular}{|llll|}
\hline Table 14 & & & \\
Course B Scoring Results of the Course Interest Survey (CIS) & & \multicolumn{1}{c|}{$\begin{array}{l}\text { Mean } \\
\text { CIS Question } \\
\text { (Max. 5) }\end{array}$} & $\begin{array}{l}\text { ARCS } \\
\text { Element }\end{array}$ \\
\hline $\begin{array}{l}\text { 33. The amount of work I have to do is appropriate for this type of } \\
\text { course. }\end{array}$ & 4 & 4.25 & $\mathrm{~S}$ \\
$\begin{array}{l}\text { 34. I get enough feedback to know how well I am doing. } \\
\text { Response }\end{array}$ & 4 & 5.00 & $\mathrm{C}$ \\
\hline
\end{tabular}

Table 14: Course B Scoring Results - Course Interest Survey (CIS)

Overall, students seemed motivated to both participate and excel in Course B. When reverse scores on the CIS are converted, on the scale of one to five, Course B received mean average scores of ARCS motivational elements as follows in Table 15 below:

\begin{tabular}{|c|c|}
\hline \multicolumn{2}{|c|}{$\begin{array}{l}\text { Table } 15 \\
\text { Course B CIS Motivational Averages }\end{array}$} \\
\hline ARCS Element & Course B CIS Avg. \\
\hline Attention & 3.69 \\
\hline Relevance & 4.53 \\
\hline Confidence & 4.56 \\
\hline Satisfaction & 4.42 \\
\hline
\end{tabular}

Table 15: Course B CIS Motivational Averages

Attention elements include design decisions that invoke feelings such as enthusiasm, suspense, curiosity, surprise, interest, and stimulation. These elements are captured in CIS questions 1, 10, 15, 21, 24, 29, with questions 4 and 26 providing reversed responses. Course B received an average Attention score of 3.69 of a possible 5 rating, certainly above average yet the lowest of the four motivational element scores measured by the CIS. Many Course B design decisions can contribute to high scores in the Attention element of motivation, particularly the topic itself: this optional graduate course provides opportunities and resources for students to 
explore open-source technology tools that can be implemented in their own classrooms. Other attention-generating design elements include evidence of instructor availability and engagement; the availability of no-cost online resources; online community-building requirement, and detailed information on completing assignments, and thus, the course.

Course B received a 4.53 of a possible 5 rating for the Relevance motivational element. Students determine course relevance by how closely course goals and projects align with their own interests and ambitions. Relevance elements of Course B are captured in CIS questions 2, 5, 13, 20, 22, 23, and 28, with questions 8 and 25 providing reversed responses. Each of these questions received high student ranking, ranging from 4.0 to 4.75 out of a possible 5 rating. These questions examine student responses to motivational factors such as future importance of course content, personal benefit of course completion, establishment of personal or professional standards of excellence, and achievement of goals and expectations. The design decisions to include flexibility in assignments and technology experimentation appear to have greatly impacted relevance -- four of the nine CIS Relevance questions (2, 13, 20 and 28) received a 4.75 out of 5 rating. These questions examined useful of course content, setting and achieving high standards of excellence, content matching expectations and goals, and personal benefits of the course. Achievement of personal goals through successful course completion (CIS question 23) received the maximum 5 of 5 rating.

Confidence elements are measured by seeking to determine the degree to which design decisions allow students to believe they can be successful in completing all assignments and tasks required for the course. These elements are captured in CIS questions 3, 9, 27, 30, and 34, with questions 6,11 , and 17 providing reversed responses. Course B received the second highest overall score in Confidence elements, averaging 4.56 of a possible 5.0 rating. Three of the CIS 
Confidence questions earned maximum score ratings of 5 of 5 , including those examining overall confidence to succeed (CIS question 3), level of student success based on level of effort (CIS question 27), and appropriate feedback to accurately gauge progress (CIS question 34).

Satisfaction ratings are determined by questions that focus on instructor fairness and attention, instructor and peer recognition, amount of required work, personal enjoyment of course content, as well as interaction with the online community, including instructor. These elements are captured in CIS questions 12, 14, 16, 18, 19, 32, and 33, with questions 7 and 31 providing reversed responses. Course B received the average Satisfaction score of 4.42 out of 5, with individual responses ranging from 3.75 to 5 of a possible 5 rating. Questions pertaining to instructor evaluation of work (CIS question 18) and fairness of grading and recognition (CIS question 14) each received the maximum 5 of 5 ratings. Overall course satisfaction scored 4.75 out of a possible 5 rating, followed by personal enjoyment of the course (CIS question 16) and adequate recognition via grades, comments and feedback (CIS question 32), with each receiving 4.5 out of a possible 5 Satisfaction rating.

\section{Course B Student Ratings of Motivation: IMMS Survey}

The Instructional Materials Motivation Scale (IMMS) is designed to measure student reaction to self-directed instructional materials. There are 36 items, with 12 for the Attention subscale, nine (9) items each for the Relevance and Confidence subscales, and six (6) items for the Satisfaction subscale. Keller (2010) attributes the higher number of items that examine Attention elements to a prevailing educational notion that text-based instructional materials contribute to boredom and lack of stimulation, while the lower number of Satisfaction items reflects that this motivational element has fewer connections to printed materials than the other 
subcategories do. Keller (2010) designed a Motivational Tactics Checklist that can be useful in developing and evaluating instructional materials for motivation (p. 286-292).

From the 10 students enrolled in Course B, two students (20\%) completed the IMMS survey. Results are seen in Table 16 below, including number of responses, mean score and ARCS element:

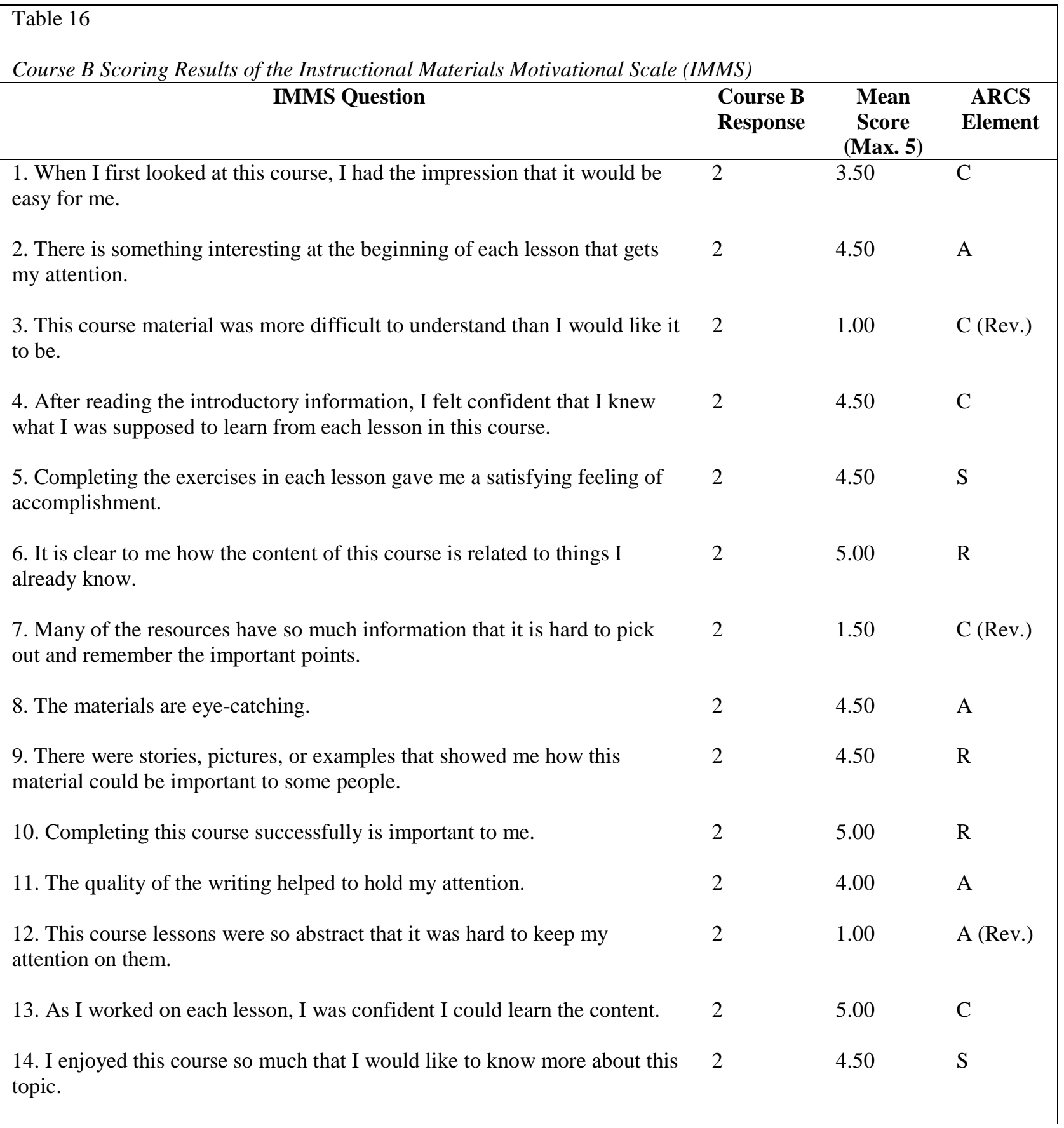




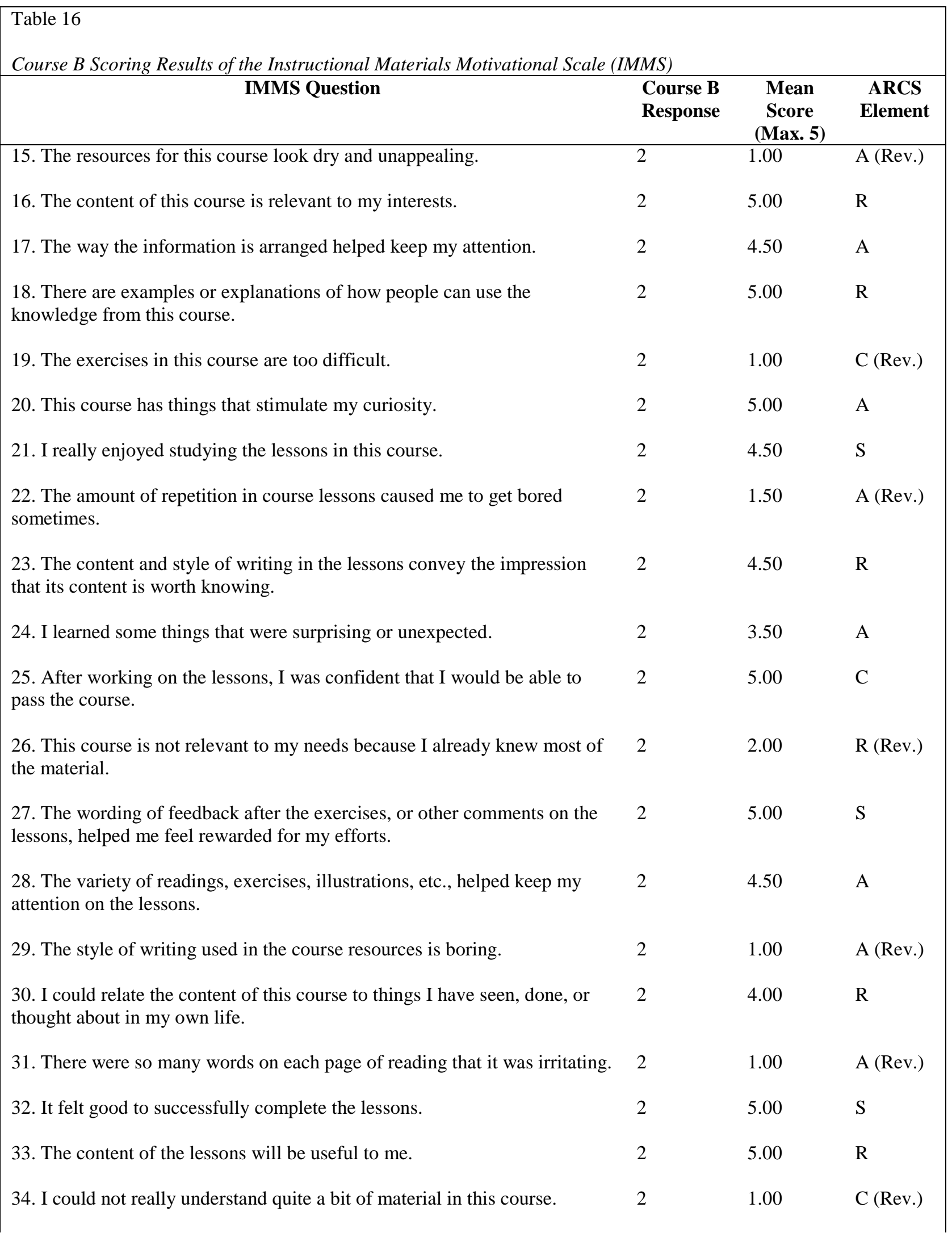




\begin{tabular}{|lccc|}
\hline \multicolumn{1}{|l|}{ Table 16} & & \\
Course B Scoring Results of the Instructional Materials Motivational Scale (IMMS) & Course B \\
\hline \multicolumn{1}{|c|}{ IMMS Question } & $\begin{array}{c}\text { Mean } \\
\text { Score } \\
\text { (Max. 5) }\end{array}$ & $\begin{array}{c}\text { ARCS } \\
\text { Element }\end{array}$ \\
\hline $\begin{array}{l}\text { 35. The good organization of content helped me be confident that I would } \\
\text { learn the material. }\end{array}$ & 2 & 5.00 & $\mathrm{C}$ \\
36. It was a pleasure to work on such a well-designed course. & 2 & 5.00 & $\mathrm{~S}$ \\
\hline
\end{tabular}

Table 16: Course B Scoring Results - Instructional Materials Motivational Scale (IMMS)

Overall, students seemed very motivated by the instructional materials used in Course B.

On the scale of one to five, when reverse scores on the IMMS are converted, Course B received mean average scores of ARCS motivational elements as follows in Table 17 below:

\begin{tabular}{|c|c|}
\hline \multicolumn{2}{|c|}{$\begin{array}{l}\text { Table } 17 \\
\text { Course B IMMS Motivational Averages }\end{array}$} \\
\hline ARCS Element & Course B IMMS Avg. \\
\hline Attention & 4.17 \\
\hline Relevance & 4.56 \\
\hline Confidence & 4.28 \\
\hline Satisfaction & 4.70 \\
\hline
\end{tabular}

Table 17: Course B IMMS Motivational Averages

Attention elements as related to the design and selection of instructional materials for the course include decisions that will provoke feelings like enthusiasm, suspense, curiosity, surprise, interest, and stimulation. Visual stimulation of instructional materials is an especially important consideration in an online environment. Attention elements can include perceptual interest and concreteness, curiosity/inquiry arousal, and variability of format, style, and sequence (Keller, 2010). These elements are examined in IMMS questions 2, 8, 11, 17, 20, 24, and 28, with questions 12, 15, 22, 29, and 31 providing reversed responses. Course B received an average Attention score of 4.17 of a possible 5.0 rating, with individual question responses ranging from 
3.5 to 5 . Students ranked the ability of instructional materials to arouse curiosity (IMMS question 20) at the maximum rating of 5. Variety (IMMS question 28), interest factor (IMMS question 2), presentation or arrangement (IMMS question 17), and visual appearance (IMMS question 8) of materials were also found to be highly motivating Attention elements, each ranked at 4.5.

There are nine (9) Relevance items measured in the IMMS. Course B received the highest overall rating for the Relevance motivational elements, averaging 4.56 of a possible 5 rating. Relevance of instructional materials is determined by goal orientation; motive-matching, including present worth and future value, and familiarity, including connection to previous experience, and options for individualization (Keller, 2010). Relevance is assessed by IMMS questions $6,9,10,16,18,23,30$, and 33, with question 26 providing a reversed response. Each of these nine questions received high student ratings, ranging from 3 to 5 of a possible 5 rating. Five of the nine questions were ranked at the maximum rate of 5: content related to existing knowledge, interest, and experience (IMMS questions 6, 16, and 30); importance of course completion (IMMS question 10), and usefulness of content (IMMS question 33).

Confidence elements are measured on the IMMS based on clear learning requirements, positive outcomes that will enhance student competence, and accountability for learning (Keller, 2010). These are assessed by IMMS questions $1,4,13,25$, and 35, with questions 3, 7, 19, and 34 providing reversed responses. Individual items scored responses ranging from 3.5 to 5 out of a possible 5 rating. Three of the nine questions were rated at the maximum rate of 5: organization of content (IMMS question 35) led to increased student confidence to learn the content (IMMS question 13) and pass the course (IMMS question 25).

Satisfaction elements are measured on the IMMS based on intrinsic reinforcement, including positive recognition and continuing motivation; potential extrinsic rewards, and equity 
or fair treatment (Keller, 2010). Satisfaction elements were measured by IMMS questions 5, 14, 21, 27, 32, and 36, and individual items were rated from 4.5 to 5 of a possible 5 rating. Students expressed the most satisfaction with rewarding feedback (IMMS question 27), personal satisfaction (IMMS question 32) and enjoyment (IMMS question 36) upon completion of assignments and ranked each at the maximum value of 5. A sense of accomplishment and enjoyment upon completion of assignments, as well as the desire to learn more about the topic, were each ranked at 4.5.

\section{Course C}

\section{Instructor C Interview Results}

Course $\mathrm{C}$ is a 6-week graduate Education course that examines $21^{\text {st }}$ century teaching and learning by exploring emerging technology tools and developing an understanding of classroom integration and pedagogy. This elective course is designed to meet technology course requirements for several Education-related graduate degree programs. Course C, similar to Course B, was designed to provide students with a strong foundation of knowledge and skills in technology integration which they can apply to other courses. This is accomplished by exploring and discussing various emerging technologies, designing learning activities incorporating such technologies, and reflecting on the experience. While Course $\mathrm{C}$ does not require any prerequisite courses, the syllabus states previous classroom experience is beneficial as most activities require students to reflect on teaching experiences and identify how course concepts could be applied in a classroom environment. Course objectives and activities closely parallel both university professional education goals and state professional teaching standards. The final project for this course is a five-day lesson plan that demonstrates technology integration as a teaching and 
learning enhancement tool. A detailed grading rubric is included in the syllabus following the detailed description of the project expectations.

Professor $\mathrm{C}$ has over a decade of teaching experience and nearly a decade of instructional design experience. This instructor was instrumental in the design and development of Course C, has taught the course before, and will teach it again in the future. Professor $\mathrm{C}$ states the course is beneficial to students in learning about the Framework for $21^{\text {st }}$ Century Skills, established by the Partnership for $21^{\text {st }}$ Century Learning (P21), a national nonprofit dedicated to "serve as a catalyst and build collaborative partnerships among education, business, community and government leaders to that all learners acquire the knowledge and skills they need to thrive in a world where change is constant and learning never stops” (P21 FAQ). There are currently 19 P21Leadership states: Arizona, California, Illinois, Iowa, Kansas, Kentucky, Louisiana, Maine, Massachusetts, Nevada, New Jersey, North Carolina, Ohio, Oklahoma, South Carolina, South Dakota, Vermont, West Virginia, and Wisconsin (P21.org). Students also have the opportunity "to learn about current technology tools, methods of integrating these tools into their teaching, factors related to this integration process, and considerations such as the safe, ethical, and responsible utilization of technology” (Instructor interview notes, 2015).

Course C is delivered via the university LMS, Blackboard. Asynchronous online forums are provided for assignment submissions and reading discussions. During the first week, students are given the option to participate in a synchronous online chat; however, in the summer course section being studied, only one student participated before deciding to switch to asynchronous discussion like their peers. Online office hours are scheduled upon student request and conducted either by telephone or LMS chat. Direct instruction is provided from online resources, including journal articles, book chapters, conceptual manuscripts, and media sources. These instructional 
design decisions allow for complete asynchronous class attendance, the course format most accommodating for working adult learners.

\section{Syllabus C Analysis}

Designed to meet QM standards, Syllabus C is a detailed, 12-page document that provides students with the information necessary to successfully access and complete each activity and assessment measure used throughout the course. This course is designed for students at any stage of their degree studies and has no prerequisites, although a subsection in the Overview states that many activities require students to reflect on their experiences and to identify how they might apply course concepts to actual classroom practice. Syllabus C contained multiple motivational design elements, and was appropriate for a mixed-experience student audience, as well as for the course delivery options and features available via the university LMS. As an elective course, enrollment alone signals students will have some degree of intrinsic motivation to successfully complete the course. Course information is presented in a clear outline format with bold-faced headings to distinguish the various sections. Several tables and rubrics are used to provide specific details about course objectives and activities.

Following the course title, Syllabus C begins with an Instructor section that includes instructor name, office location, telephone number, and email address. Office hours can be arranged and conducted by telephone or LMS chat. A brief paragraph provides students with details about the teaching style and philosophy of Professor C, as well as general expectations for course success that include community-building and timeliness of work. This design decision to place instructor information directly under the course title and before the course overview creates an anchor for future student reference that may enhance confidence by providing details about and alternative contact methods for the instructor. 
The Overview section provides subsections with additional details on course format, credit hours, narrative description, and course structure. The narrative description is designed to attract attention and reflect course content relevance to real-world career goals in education. The course structure subsection attracts attention and may promote curiosity by referencing the Activities section presented later in the syllabus. Modes of communication, prerequisite and technology requirements, acceptable online behavior (netiquette), and course objectives subsections complete the three-page Overview. The subsection on modes of communication reinforces instructor interest, availability, and actions in assisting students in the online environment, providing an established time-frame and method for instructor response and feedback that could increase student confidence by reaffirming assistance is available as needed. The Prerequisites and Technology Requirements subsection reinforces that no prerequisite courses are needed and provides functioning hyperlinks to help students ensure computer compatibility with LMS software. Information, including telephone number and email address, is provided for students to obtain technical support. This design decision to include functioning hyperlinks along with the text should attract attention and bolster student confidence by providing options to obtain technical assistance if necessary. The design decision to include a brief section on acceptable online interaction demonstrates commitment to a fair and friendly learning environment, which may capture attention, enhance confidence, and ultimately improve student satisfaction with the course. Course C objectives are presented in a table format that provides a detailed analysis of how the course objectives, units, and activities align with State professional teaching standards and university professional education conceptual framework and goals. This strategy reinforces the course design intent to target practicing or potential K-12 teachers. While providing an excellent relevance- and confidence-enhancing resource for this 
audience, however, this design strategy may elicit feelings of exclusion or course irrelevance in students from other Education programs who enroll in the course as an elective, specifically those who live or work out of the state or those who specialize in adult education and learning.

The Required Text \& Materials section follows the Overview, specifically emphasizing there is no required textbook for the course since all content and web-based materials used are included within the course LMS. A substantial paragraph follows, explaining that students who are enrolled in the “advanced online master’s program” are required to purchase an online subscription for an electronic portfolio application. This passage outlines details, cost, and functioning hyperlink needed to complete the purchase. It is noted these students will not receive proper credit for a final project that is not submitted through this online portfolio application. A university email contact is provided for students unsure of whether they are enrolled in this advanced program. This latter choice may indicate the knowledge that the design decision to include this optional program information might be construed as confusing to some students.

The Syllabus C Evaluation/Assessment section begins with a clear delineation of all assignments and the point values of each. This is an effective instructional design decision that allows students to see at a glance how much weight each assignment carries and may contribute to enhanced student motivation by capturing attention, revealing relevance through goalorientation, and generating confidence through establishment of clear learning requirements, opportunities for success and personal control over outcomes. Satisfaction may be directly impacted by natural consequences that result from assignment effort and submission. The design decision to award points for peer comments reinforces the potential impact and importance of community-building. Professor C sets forth overall submission guidelines and instructs students where to find a detailed schedule including due-dates within the course LMS. Although late 
work is penalized, Professor C encourages students to improve their graded work or projects by providing an opportunity to resubmit work within three days of receiving feedback. These instructional design decisions demonstrate the importance of meeting both overall and specific deadlines, as well as the importance and benefits of program evaluation and modification, factors which may enhance student attention and confidence, thereby increasing motivation to excel in the course. A detailed grading scale closes this section, using the standard ten-point delineation between letter grades. The design decision to include an A+ category, which includes scores in the 98-100 percentile, may increase motivation to excel in students intrinsically driven toward perfection.

The Activities section, at six pages in length, provides intricate detail into each assignment that students are responsible for completing throughout Course C, including the scoring rubrics for each assessment measure.

Syllabus C concludes with a Support Services section that includes links to university services, including accessibility, student affairs, the library system, and the writing center. This section is followed by several university and course statements, including Social Justice, Academic Integrity, and Inclusion Statements, guidelines for Military Service absences, a statement on course absences, and a statement prohibiting the sale of course materials.

\section{Course C Observation Data}

The online course design of Course C reflects the highly-detailed syllabus document, with the exception of the Course Home Page, simply titled “Course Home.”

The “Course Information” link first provides the instructor profile, including educational and work experience, primary research interests, student mentoring experience, and contact 
information. This is important information for students who may be seeking mentors or advisors during their program of study and should, therefore, increase student attention and confidence.

The Instructor Profile is followed by a clearly-labeled “Read Me First” document which, upon opening, congratulates the student for finding the course resources and directs them on how to proceed with the course by first reading the Syllabus and Course Schedule document links. The design strategy to incorporate the hyperlinks to these resources, then demonstrating them in an introductory task, should increase student attention and confidence that they will have access to all required resources and assignment details.

Course structure is discussed following the initial activity. Assignments for the first week are then presented, followed by the instructor email. The design decision to repeat the instructor email should capture student attention and increase confidence that they know how to contact the instructor should they have questions or need assistance with any assignments.

Following the Syllabus and Course Schedule links, there is a link for the Week 1 Student Biographies assignment, six Technical links, and an extensive Campus Resources section, which includes department, library, and university services and support systems.

Each of the six units containing substantial details, resources, and information. The Unit Overview is followed by a table containing the weekly tasks, resources, and objectives for both unit and course. The unit content is presented in text format using hyperlinks to direct students to the online resources needed. This design decision to incorporate so much detail could potentially decrease student attention and confidence by making the course appear extremely overlycomplex and time-consuming. Assignment instructions and due-dates close out each unit and should increase student confidence that they can complete each assignment by following the written instructions. The design decision to form an online community of learning, presented via 
assignments that require students to post substantive peer responses, should increase student attention to the need to thoroughly complete all readings and create relevant discussion postings worthy of peer responses. This could also increase student attention and confidence that they may find, or be able to provide, peer support as needed.

In summation, observational research indicates that actual course experience did reflect the experience promised in the detailed syllabus, while also incorporating numerous motivation elements that should promote student attention, relevance, confidence, and satisfaction.

\section{Course C Student Ratings of Motivation: CIS Survey}

Motivation can be defined as the direction and intensity of behavior, defining the goals people choose to pursue and how much effort is expended to achieve those goals (Keller, 2010). Two survey instruments were used in this study to explore student motivation in an online course environment. These surveys, the Course Interest Survey (CIS) and the Instructional Materials Motivation Scale (IMMS), were designed by Keller to provide a quantitative measure for the theory of motivational design.

From the 14 students enrolled in Course C, seven students (50\%) completed the CIS survey. Results are seen in Table 18 below, including number of responses, mean score, and applicable ARCS element:

\begin{tabular}{|llll|}
\hline Table 18 & & & \\
Course C Scoring Results of the Course Interest Survey (CIS) & & \\
\hline CIS Question & $\begin{array}{l}\text { Course C } \\
\text { Response }\end{array}$ & $\begin{array}{l}\text { Mean } \\
\text { Score } \\
\text { (Max 5) }\end{array}$ & $\begin{array}{l}\text { ARCS } \\
\text { Element }\end{array}$ \\
\hline $\begin{array}{l}\text { 1. The instructor knows how to make us feel enthusiastic about the subject } \\
\text { matter of this course. }\end{array}$ & 7 & 4.29 & A \\
2. The things I am learning in this course will be useful to me. & 7 & 4.86 & R
\end{tabular}




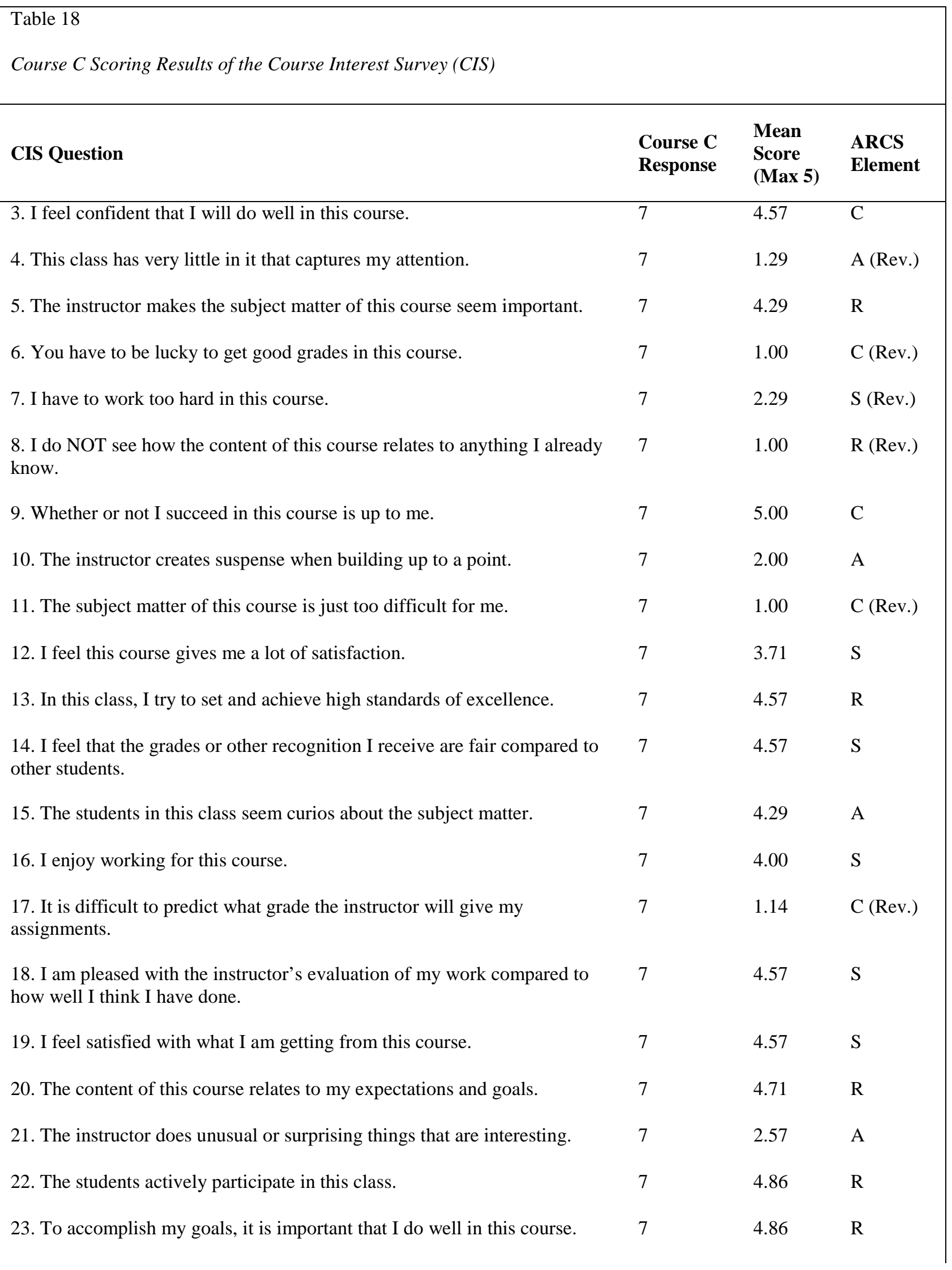




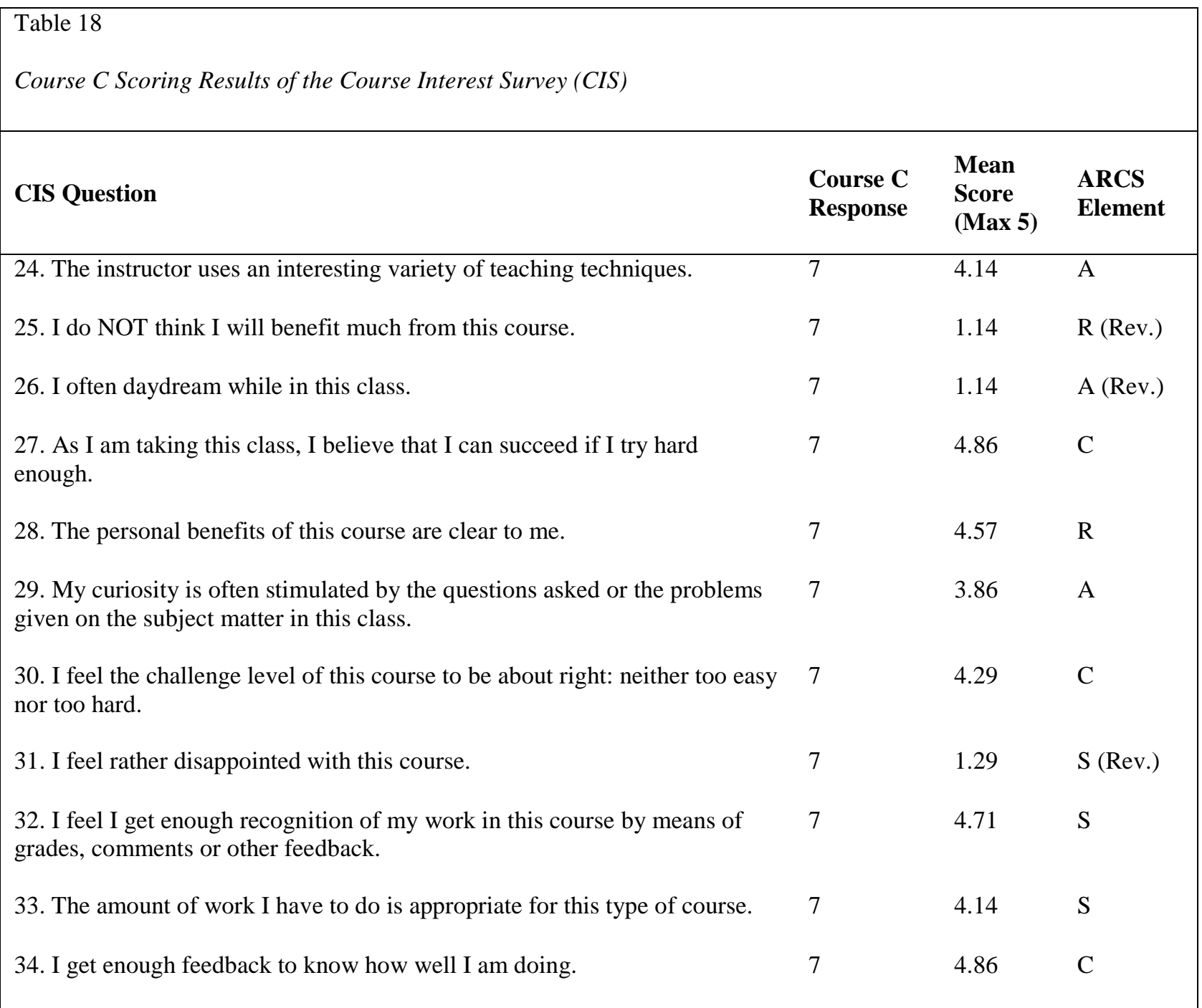

Table 18: Course C Scoring Results - Course Interest Survey (CIS)

Overall, students seemed motivated to both participate and excel in Course C. When reverse scores on the CIS are converted, on the scale of one to five, Course C received mean average scores of ARCS motivational elements as follows: 


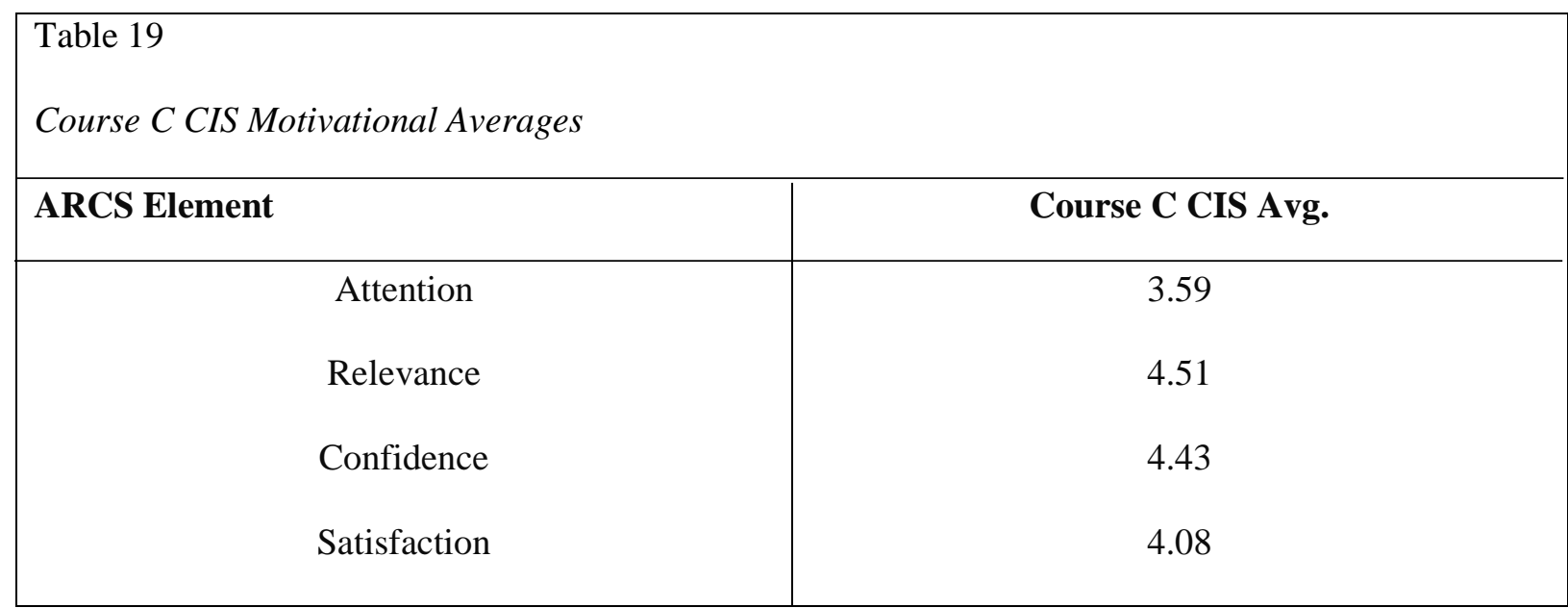

Table 19: Course C CIS Motivational Averages

Attention elements include design decisions that invoke feelings: enthusiasm, suspense, curiosity, surprise, interest, and stimulation. These elements are captured in CIS Questions 1, 10, 15, 21, 24, 29, with Questions 4 and 26 providing reversed responses. Course C received an average Attention score of 3.59 of a possible 5.0 rating, certainly above average yet the lowest of the four motivational element scores measured by the CIS. Instructor enthusiasm for the subject matter (CIS question 1) and peer curiosity about the subject matter (CIS question 15) each received the highest Attention motivational score, ranking 4.29 of a possible 5 rating.

Course $\mathrm{C}$ received the highest overall rating for the Relevance motivational element, averaging 4.51 of a possible 5.0. Students determine course relevance by how closely the course goals and projects align with their own interests and ambitions. Relevance elements of Course C are captured in CIS questions 2, 5, 13, 20, 22, 23, and 28, with questions 8 and 25 providing reversed responses. Each of these questions received high student ratings, ranging from 3.86 to 4.86 of a possible 5 rating. These questions examine student motivation factors such as future importance of course content; personal benefit of course completion; establishment of personal or professional standards of excellence, and achievement of goals and expectations. Active peer participation (CIS question 22) received a 4.86 score in Relevance to student motivation. This 
was the same rating students assigned to personal usefulness of information (CIS question 2), and the importance of doing well to accomplish personal goals (CIS question 23).

Confidence elements are measured by seeking to determine the degree to which design decisions allow students to believe they can be successful in completing all assignments and tasks required for the course. These elements are captured in CIS questions 3, 9, 27, 30, and 34, with questions 6,11 , and 17 providing reversed responses. Course $C$ received the second highest overall score in Confidence elements, averaging 4.43 of a possible 5.0 rating. Course C design decisions that may impact student confidence include instructor engagement, feedback, and availability; no-cost online texts and resources; thoroughly detailed assignment instructions, and availability of peer interaction via discussion boards and contact information. Student ratings indicate two design decisions greatly increase student confidence: providing thoroughly detailed assignment instructions (CIS question 27), and consistent instructor feedback (CIS question 34). Each of these elements received a 4.86 from a possible 5 rating.

Satisfaction ratings are determined by questions that focus on instructor fairness and attention, instructor and peer recognition, amount of required work, personal enjoyment of course content, as well as interaction with the online community, including instructor. These elements are captured in CIS questions 12, 14, 16, 18, 19, 32, and 33, with questions 7 and 31 providing reversed responses. Course C received the average Satisfaction score of 4.08 out of 5, with individual responses ranging from a low of 2.71 to a high of 4.71 out of a possible 5 rating. The highest Satisfaction element rating of 4.71 was recognition of work via grades, comments, or other feedback (CIS question 32). Satisfaction pertaining to instructor evaluation of student performance (CIS question18), grading fairness (CIS question 14), and personal satisfaction (CIS 
question 19) each received 4.57 of possible 5 ratings. The lowest Satisfaction rating pertained to the amount of effort required for the course (CIS question 7).

Course C Student Ratings of Motivation: IMMS Survey

The Instructional Materials Motivation Scale (IMMS) is designed to measure student reaction to self-directed instructional materials. There are 36 items, with 12 for the Attention subscale, nine (9) items each for the Relevance and Confidence subscales, and six (6) items for the Satisfaction subscale. Keller attributes the higher number of items that examine Attention elements to a prevailing educational notion that text-based instructional materials contribute to boredom and lack of stimulation, while the lower number of Satisfaction items reflects that this motivational element has fewer connections to printed materials than the other subcategories do (Keller, 2010). Keller designed a Motivational Tactics Checklist that can be useful in developing and evaluating instructional materials for motivation (2010, p. 286-292).

From the 14 students enrolled in Course C, five students (35.7\%) completed the IMMS survey. Results are seen in Table 20 below, including number of responses, mean score, and applicable ARCS element:

\begin{tabular}{|c|c|c|c|}
\hline $\begin{array}{l}\text { Table } 20 \\
\text { Course C Scoring Results of the Instructional Materials Motivational S }\end{array}$ & (IMMS) & & \\
\hline IMMS Question & $\begin{array}{l}\text { Course C } \\
\text { Response }\end{array}$ & $\begin{array}{l}\text { Mean } \\
\text { Score } \\
(\text { Max. 5) }\end{array}$ & $\begin{array}{l}\text { ARCS } \\
\text { Element }\end{array}$ \\
\hline $\begin{array}{l}\text { 1. When I first looked at this course, I had the impression that it would } \\
\text { be easy for me. }\end{array}$ & 5 & 2.80 & $\mathrm{C}$ \\
\hline $\begin{array}{l}\text { 2. There is something interesting at the beginning of each lesson that } \\
\text { gets my attention. }\end{array}$ & 5 & 3.60 & A \\
\hline $\begin{array}{l}\text { 3. This course material was more difficult to understand than I would } \\
\text { like it to be. }\end{array}$ & 5 & 1.00 & C (Rev.) \\
\hline
\end{tabular}




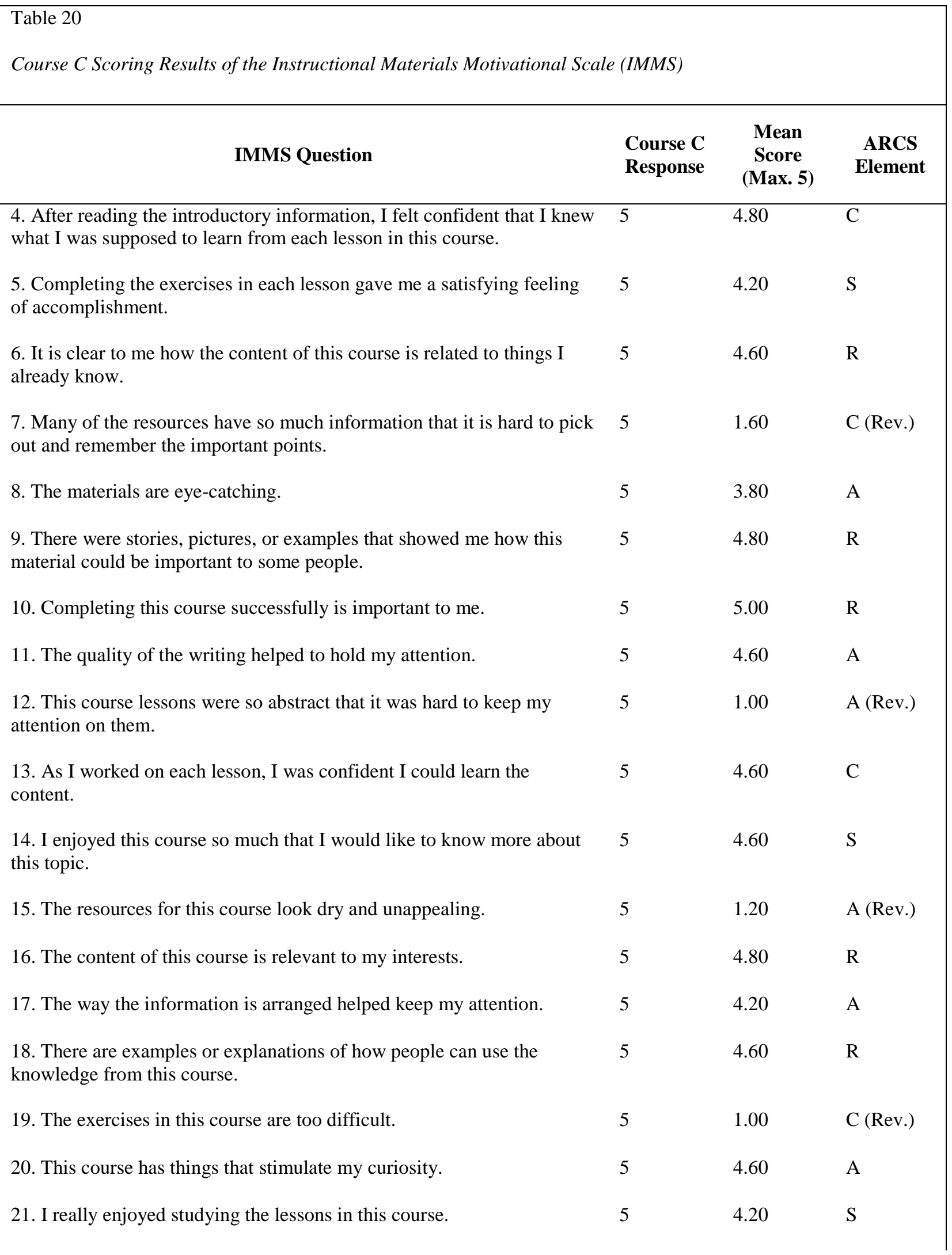




\begin{tabular}{|c|c|c|c|}
\hline \multicolumn{4}{|c|}{$\begin{array}{l}\text { Table } 20 \\
\text { Course C Scoring Results of the Instructional Materials Motivational Scale (IMMS) }\end{array}$} \\
\hline IMMS Question & $\begin{array}{l}\text { Course C } \\
\text { Response }\end{array}$ & $\begin{array}{l}\text { Mean } \\
\text { Score } \\
\text { (Max. 5) }\end{array}$ & $\begin{array}{l}\text { ARCS } \\
\text { Element }\end{array}$ \\
\hline $\begin{array}{l}\text { 22. The amount of repetition in course lessons caused me to get bored } \\
\text { sometimes. }\end{array}$ & 5 & 1.40 & A (Rev.) \\
\hline $\begin{array}{l}\text { 23. The content and style of writing in the lessons convey the impression } \\
\text { that its content is worth knowing. }\end{array}$ & 5 & 4.80 & $\mathrm{R}$ \\
\hline 24. I learned some things that were surprising or unexpected. & 5 & 4.40 & A \\
\hline $\begin{array}{l}\text { 25. After working on the lessons, I was confident that I would be able to } \\
\text { pass the course. }\end{array}$ & 5 & 4.80 & $\mathrm{C}$ \\
\hline $\begin{array}{l}\text { 26. This course is not relevant to my needs because I already knew most } \\
\text { of the material. }\end{array}$ & 5 & 1.00 & R (Rev.) \\
\hline $\begin{array}{l}\text { 27. The wording of feedback after the exercises, or other comments on } \\
\text { the lessons, helped me feel rewarded for my efforts. }\end{array}$ & 5 & 4.80 & $\mathrm{~S}$ \\
\hline $\begin{array}{l}\text { 28. The variety of readings, exercises, illustrations, etc., helped keep my } \\
\text { attention on the lessons. }\end{array}$ & 5 & 4.20 & A \\
\hline 29. The style of writing used in the course resources is boring. & 5 & 1.00 & A (Rev.) \\
\hline $\begin{array}{l}\text { 30. I could relate the content of this course to things I have seen, done, } \\
\text { or thought about in my own life. }\end{array}$ & 5 & 4.40 & $\mathrm{R}$ \\
\hline $\begin{array}{l}\text { 31. There were so many words on each page of reading that it was } \\
\text { irritating. }\end{array}$ & 5 & 1.20 & A (Rev.) \\
\hline 32. It felt good to successfully complete the lessons. & 5 & 4.40 & S \\
\hline 33. The content of the lessons will be useful to me. & 5 & 5.00 & $\mathrm{R}$ \\
\hline 34. I could not really understand quite a bit of material in this course. & 5 & 1.20 & C (Rev.) \\
\hline $\begin{array}{l}\text { 35. The good organization of content helped me be confident that I } \\
\text { would learn the material. }\end{array}$ & 5 & 4.60 & $\mathrm{C}$ \\
\hline 36. It was a pleasure to work on such a well-designed course. & 5 & 4.40 & $\mathrm{~S}$ \\
\hline
\end{tabular}

Table 20: Course C Scoring Results - Instructional Materials Motivational Scale (IMMS)

Overall, students seemed very motivated by the instructional materials used in Course C. On the scale of one to five, when reverse scores on the IMMS are converted, Course C received mean average scores of ARCS motivational elements as follows in Table 21 below: 


\begin{tabular}{|c|c|}
\hline \multicolumn{2}{|c|}{\begin{tabular}{|l|} 
Table 21 \\
Course C IMMS Motivational Averages
\end{tabular}} \\
\hline ARCS Element & Course C IMMS Avg. \\
\hline Attention & 4.05 \\
\hline Relevance & 4.67 \\
\hline Confidence & 4.09 \\
\hline Satisfaction & 4.43 \\
\hline
\end{tabular}

Table 21: Course C IMMS Motivational Averages

Attention elements as related to the design and selection of instructional materials for the course include decisions that will provoke feelings like enthusiasm, suspense, curiosity, surprise, interest, and stimulation. Visual stimulation of instructional materials is an especially important consideration in an online environment. Attention elements can include perceptual interest and concreteness, curiosity/inquiry arousal, and variability of format, style, and sequence (Keller, 2010). These elements are examined in IMMS questions 2, 8, 11, 17, 20, 24, and 28, with questions 12, 15, 22, 29, and 31 providing reversed responses. Course $C$ received an average Attention score of 4.05 of a possible 5.0 rating, with individual question responses ranging from 3.6 to 4.6. Students ranked the writing quality of instructional materials, as well as the ability to arouse curiosity, at a 4.6 rating.

There are nine (9) Relevance items measured in the IMMS. Course C received the highest overall rating for the Relevance motivational elements, averaging 4.67 of a possible 5 rating. Relevance of instructional materials is determined by goal orientation; motive-matching, including present worth and future value, and familiarity, including connection to previous experience, and options for individualization (Keller, 2010). Relevance is assessed by IMMS questions $6,9,10,16,18,23,30$, and 33, with question 26 providing a reversed response. Each of these nine questions received high student ratings, ranging from 4 to 5 of a possible 5 rating. 
Two of the nine questions were ranked at the maximum rate of 5: the importance of course completion (IMMS question 10), and the future usefulness of content (IMMS question 33).

Confidence elements are measured on the IMMS based on clear learning requirements, positive outcomes that will enhance student competence, and accountability for learning (Keller, 2010). These are assessed by IMMS questions $1,4,13,25$, and 35, with questions 3, 7, 19, and 34 providing reversed responses. Individual items scored responses ranging from 2.8 to 4.8 out of a possible 5 rating. Two questions received the highest Confidence rating at 4.8: materials provided increased student confidence necessary to learn the content (IMMS question 4) and pass the course (IMMS question 25).

Satisfaction elements are measured on the IMMS based on intrinsic reinforcement, including positive recognition and continuing motivation; potential extrinsic rewards, and equity or fair treatment (Keller, 2010). Satisfaction elements were measured by IMMS questions 5, 14, 21, 27, 32, and 36, and individual items were rated from 4.2 to 4.8 . Students expressed the most satisfaction with rewarding feedback and comments (IMMS question 27), ranking this item at 4.8. The desire to learn more about the topic was ranked at 4.6. Achieving a sense of personal accomplishment (IMMS question 5) and enjoyment (IMMS question 21) were each rated at 4.2

\section{Course D}

\section{Instructor D Interview Results}

Course D is a 6-week graduate Education course designed to explore the psychological principles of learning and development as related to the process of instruction. This course was designed to provide an overview of educational theories and practice, and is required for nearly all Education-related graduate degree programs. This is the only course of the four examined for 
this study that did not have a final project. Rather, course score was a culmination of points earned on written assignments and quizzes completed during the semester.

Professor D is well-published, with over 35 years of instructional design and adult teaching experience. This instructor has taught this introductory course for more than a decade and will teach it again in the future. Professor D states that for some students, the course provides a solid review of content covered in an undergraduate course. For others, however, it is an introduction to educational psychology that should become "a foundation on which they build as they prepare to teach” (Instructor interview notes, 2015).

Course D is delivered via the university LMS, Blackboard. Asynchronous online forums are provided for assignment submissions and reading discussions. Online office hours can be scheduled upon student request. While an option for synchronous chat is extended in the first week of the course, students seldom choose this option, preferring the asynchronous online discussions for assignments (Instructor interview notes, 2015). Direct instruction is provided from online resources, including journal articles, book chapters, conceptual manuscripts, and media sources. These instructional design decisions allow for complete asynchronous class attendance, the course format most accommodating for working adult learners.

\section{Syllabus D Analysis}

Designed using QM principles, the syllabus for this entry-level course is a very detailed 13-page document which provides students with an in-depth look at course objectives and requirements, course information, technology requirements, university policies, and complete assignment details, including a "Week-at-a-Glance" schedule. The syllabus is well-designed, adheres to QM guidelines, contains an abundance of each of the four motivation design elements, and is appropriate for entry-level students in an online LMS. 
Syllabus D beings with the course name, section numbers and term in large blue type. A bordered text-block follows, featuring a photo of Instructor D with a welcoming, friendly smile. Complete contact information is placed within the text-block to the right of the photo, including office location, phone and fax numbers, and both home and work email. There are several motivational design elements present in the layout of Syllabus D. The font size and color and the use of an instructor information text-block draw attention to the syllabus content, encouraging a curiosity to read further. By establishing an initial online presence, combining complete contact information with a photo that presents a positive image, Instructor D has laid the foundation for the establishment of an online community, a design decision that should enhance confidence levels in the target audience of new online graduate students in a required course. Attempts to grow the online learning community continue in one of the first assignments where students are asked to create and post an introduction with photo. It is interesting to note the design choice to award points for the student introduction assignment, as well as for the completion of a syllabus quiz. In scoring the two introductory assignments, this design strategy underlines the importance of establishing an online "presence" and the need to fully understand course navigation. These strategies both enhance student confidence by allowing them to earn "easy" points and create a positive first impression for beginning online students.

The Course Description for Syllabus D provides confidence- and relevance enhancing elements, stating the course, intended for beginning graduate students, includes discussion of psychological principles of learning as related to the instruction process. Students are reassured they need no prerequisite knowledge for the course.

Syllabus D features six numbered Objectives designed to address both the course subject and $21^{\text {st }}$ Century Skills, the national framework also embraced by Course C. A functioning 
hyperlink for more information on the framework is included. This design decision should increase the relevance aspect of motivation by providing real-world examples of how course knowledge can be used, not only to complete the course, but also in future graduate courses or education-based careers.

The Required Text section clearly provides the complete title and ISBN number of the text to be used, as well as purchasing information for new or used texts. The course textbook has a companion website that includes chapter themes, teaching suggestions, class applications and more. The design decision to make the companion web site a separate syllabus section from the textbook, including a functioning web link and instructions, as well as an instructor note that former students have found the website "very helpful," may increase student attention and enhance confidence by providing detailed yet simplistic instructions for accessing and utilizing this supplemental material.

The Class Format section follows, defining the course as web-based with no face-to-face sessions. Details are then provided on student expectations and recommendations for successful completion of the accelerated format.

The instructor next provides a detailed section on Online Office Hours and Questions, informing students of a discussion devoted specifically to course-related questions. The LMS settings for this discussion were set by the instructor to automatically notify students when a question has been posted and when the instructor posts a response. This strategy should increase student confidence that any questions or concerns encountered will be quickly addressed. The instructor notes that, based on past experience, if one student has a question then others probably have the same question. This statement could increase student attention to this discussion section 
as a source for obtaining information needed to aid in course success. The instructor provides a detailed explanation of course email communication, providing expectations and response times.

Instructor D created a Class Chat Room within the LMS which allows and encourages the creation of an online learning community for the course. This feature could increase student confidence that they may find or provide peer support as needed.

The next section outlines Minimum Technology Requirements and includes hyperlinks students may use to install, configure, or troubleshoot the technology components of the course. The section concludes with a five-item checklist of Minimum Technical Skills required. The technology sections should pique student attention, demonstrate relevance to the course, and enhance student confidence that technology resources are available to them as needed.

Assessment measures, well-defined and described in detail in Syllabus D, include chapter quizzes, case studies, reflection and resource assignments, and wiki assignments. There are 10 chapter quiz assessments required, and students are provided with choices within each Assignment category: reflection (8/15), resource (5/15), case studies (2/7), and wiki (2/3). Sample responses may increase student confidence by providing direction for acceptable submissions. The experience of Instructor D in teaching the more accelerated summer section of the course is evidenced by the provision of a very detailed Week-At-A-Glance Course Schedule, as well as by offering students a choice of assignments. These design strategies should increase student confidence by providing a blueprint for student success and a method of establishing relevance to individual student interests.

A two-page section of University Policies follows, demonstrating instructor commitment to academic and social policies. Descriptions and functioning hyperlinks are provided. This design strategy of providing additional policy resources should increase student confidence. 
Syllabus D concludes with a Grade Calculation Form, defined as a self-regulation strategy students may use to ensure compliance with all course requirements. This detailed tool should attract student attention, demonstrate relevance of course activities, and increase student satisfaction by ensuring all assignments and their values are listed in one, easily accessible location.

\section{Course D Observation Data}

At 17 enrolled students, this was the largest of the four courses observed and the only one specifically targeted toward new graduate students. A “Welcome” PDF was emailed to students and was also posted in the online course. This is an excellent attention-getting and confidenceenhancing design decision for all courses but works especially well in one aimed at new students.

Course D had the most LMS customization of the four courses observed. The course home page featured a "Start Here" link, another highly-effective design strategy for students new to online learning. Links were customized within the LMS to reflect the different sections of the course and were grouped as follows: Course information and content; Course assignments; Course-related LMS features, and University-related LMS features. This design decision should increase student attention, visually demonstrate relevance to the course or overall program of study, and enhance confidence that they have ready access to all the information needed to succeed in both the course and as a new student.

The "Start Here" section includes links for the LMS tutorial, a design decision that could greatly increase confidence in new or inexperienced graduate students. Other links in this section included: Syllabus; Instructor bio; Self-evaluation for online students to determine "fitness" for online learning; online etiquette, and State teaching requirements. The Course Assignments link 
contained detailed information about assessments, assignments details, case studies, discussions, and wikis. Optional features and links under the Course-related LMS features section included Announcements, Chat, Messages, and My Grades. Information in the University-related LMS features section included campus resources, rubrics, tools, and web links. Each of the wiki assignments had its own grading rubric that students could access to ensure they submit the best possible product.

This was the only course of the four observed that required quizzes. Quiz assessments had a time limit of 1 hour but allowed multiple attempts, a design decision that could alleviate test-anxiety and increase student confidence. The quiz is set up to "save” and automatically submit when time expires, a design decision that can allow the instructor to determine if a particular student is having problems using the LMS quiz technology. For example, while the quiz can be saved and resumed at any point until the allotted time expires, the timer continues to run if a student exits the test without saving.

Online community-building techniques included required peer discussion responses, as well as the availability of optional discussion areas for different Education-related interests or majors, for example: Elementary; Secondary; CLM; IDT; Child Development.

There were a total of 10 chapter quizzes and 17 written assignments due within the accelerated 6-week summer semester. Of the four courses observed, Course D had the most assessments, and students were required to make the most use of the LMS technology tools. However, despite the intense demands of this introductory course during such a brief time-frame, it is interesting to note a parting comment posted by a student:

“... I felt that this class was well designed and challenging with enough variety and quick pace to keep my interest level high. I definitely feel great about my choice to enroll in 
[the] Instructional Design MA program after this class and am genuinely looking forward to my next class. Thank you Dr. [D] for leading the way, and I hope to take another class from you again in the future!”

In summation, observational research indicates that actual course experience did reflect the experience promised in the detailed syllabus, while also incorporating multiple motivation elements that should promote student attention, relevance, confidence, and satisfaction.

\section{Course D Student Ratings of Motivation: CIS Survey}

Motivation can be defined as the direction and intensity of behavior, defining the goals people choose to pursue and how much effort is expended to achieve those goals (Keller, 2010).

Two survey instruments were used in this study to explore student motivation in an online course environment. These surveys, the Course Interest Survey (CIS) and the Instructional Materials Motivation Scale (IMMS), were designed by Keller to provide a quantitative measure for the theory of motivational design.

From the 17 students enrolled in Course D, seven students (41.2\%) completed the CIS. Results are seen in Table 22 below, including number of responses, mean score, and applicable ARCS element:

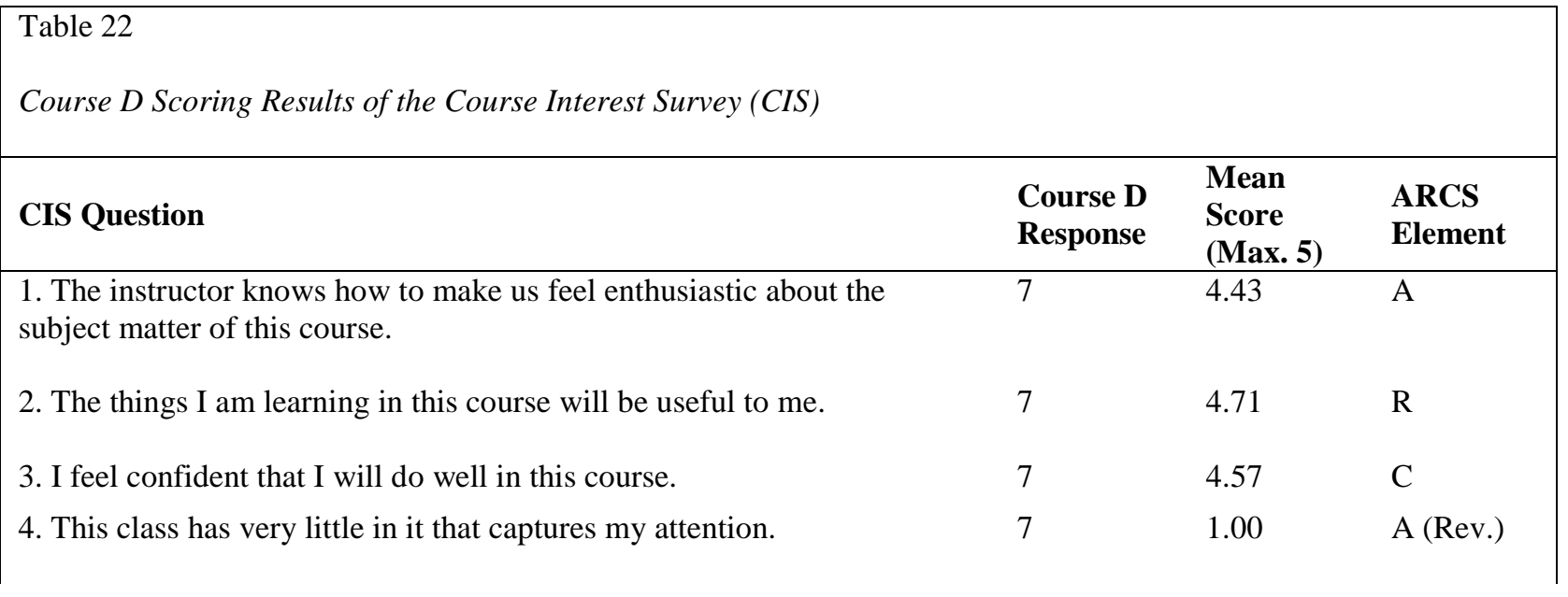




\begin{tabular}{|c|c|c|c|}
\hline $\begin{array}{l}\text { Table } 22 \\
\text { Course D Scoring Results of the Course Interest Survey (CIS) }\end{array}$ & & & \\
\hline CIS Question & $\begin{array}{l}\text { Course D } \\
\text { Response }\end{array}$ & $\begin{array}{l}\text { Mean } \\
\text { Score } \\
\text { (Max. 5) }\end{array}$ & $\begin{array}{l}\text { ARCS } \\
\text { Element }\end{array}$ \\
\hline 5. The instructor makes the subject matter of this course seem important. & 7 & 4.57 & $\mathrm{R}$ \\
\hline 6. You have to be lucky to get good grades in this course. & 7 & 1.43 & C (Rev.) \\
\hline 7. I have to work too hard in this course. & 7 & 2.86 & S (Rev.) \\
\hline $\begin{array}{l}\text { 8. I do NOT see how the content of this course relates to anything I } \\
\text { already know. }\end{array}$ & 7 & 1.00 & R (Rev.) \\
\hline 9. Whether or not I succeed in this course is up to me. & 7 & 4.86 & $\mathrm{C}$ \\
\hline 10. The instructor creates suspense when building up to a point. & 7 & 2.43 & A \\
\hline 11. The subject matter of this course is just too difficult for me. & 7 & 1.00 & C (Rev.) \\
\hline 12. I feel this course gives me a lot of satisfaction. & 7 & 3.43 & $\mathrm{~S}$ \\
\hline 13. In this class, I try to set and achieve high standards of excellence. & 7 & 4.71 & $\mathrm{R}$ \\
\hline $\begin{array}{l}\text { 14. I feel that the grades or other recognition I receive are fair compared } \\
\text { to other students. }\end{array}$ & 7 & 4.86 & $\mathrm{~S}$ \\
\hline 15. The students in this class seem curios about the subject matter. & 7 & 3.57 & A \\
\hline 16. I enjoy working for this course. & 7 & 3.57 & $\mathrm{~S}$ \\
\hline $\begin{array}{l}\text { 17. It is difficult to predict what grade the instructor will give my } \\
\text { assignments. }\end{array}$ & 7 & 1.14 & C (Rev.) \\
\hline $\begin{array}{l}\text { 18. I am pleased with the instructor's evaluation of my work compared to } \\
\text { how well I think I have done. }\end{array}$ & 7 & 4.86 & $\mathrm{~S}$ \\
\hline 19. I feel satisfied with what I am getting from this course. & 7 & 4.43 & $\mathrm{~S}$ \\
\hline 20. The content of this course relates to my expectations and goals. & 7 & 4.57 & $\mathrm{R}$ \\
\hline 21. The instructor does unusual or surprising things that are interesting. & 7 & 2.71 & A \\
\hline 22. The students actively participate in this class. & 7 & 3.57 & $\mathrm{R}$ \\
\hline 23. To accomplish my goals, it is important that I do well in this course. & 7 & 4.71 & $\mathrm{R}$ \\
\hline 24. The instructor uses an interesting variety of teaching techniques. & 7 & 4.29 & A \\
\hline 25. I do NOT think I will benefit much from this course. & 7 & 1.00 & R (Rev.) \\
\hline 26. I often daydream while in this class. & 7 & 1.29 & A (Rev.) \\
\hline
\end{tabular}




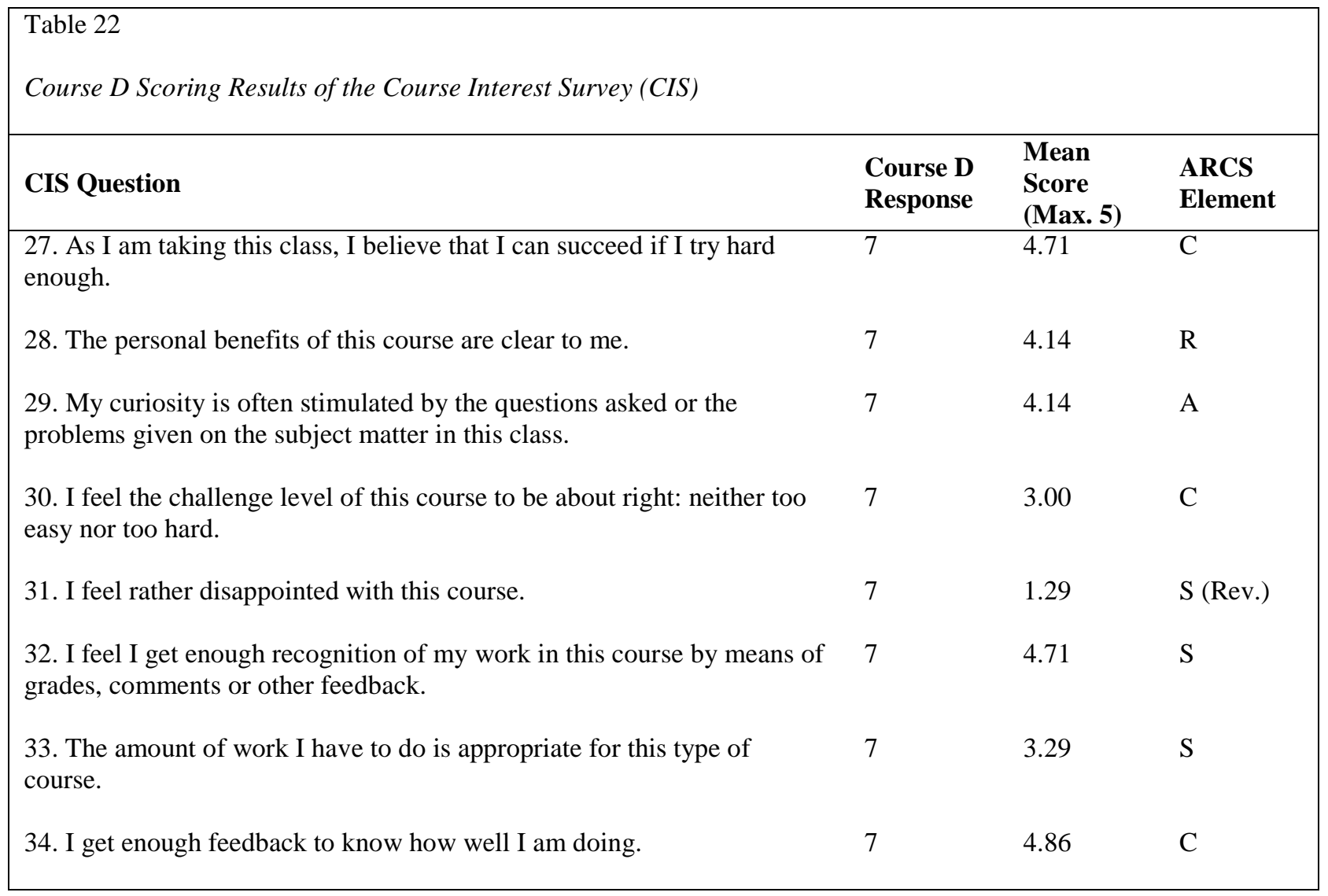

Table 22: Course D Scoring Results - Course Interest Survey (CIS)

Overall, students seemed motivated to both participate and excel in Course D. When reverse scores on the CIS are converted, on the scale of one to five, Course D received mean average scores of ARCS motivational elements as follows in Table 23 below:

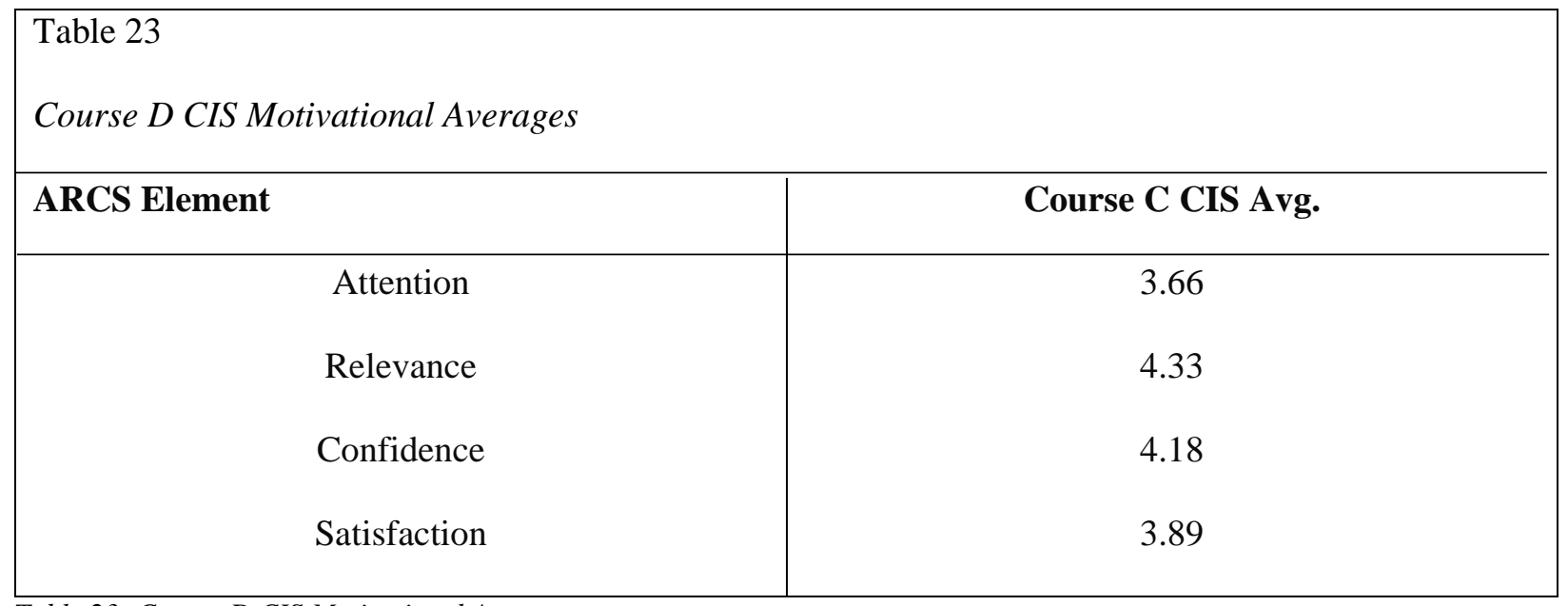


Attention elements include design decisions that invoke feelings: enthusiasm, suspense, curiosity, surprise, interest, and stimulation. These elements are captured in CIS questions 1, 10, 15, 21, 24, 29, with questions 4 and 26 providing reversed responses. Course D received an overall average Attention score of 3.66 of a possible 5.0 rating, certainly above average yet the lowest of the four motivational element scores measured by the CIS. Instructor enthusiasm for the subject matter (CIS question 1) received the highest student motivation rating, scoring a 4.43 of a possible 5 Attention rating. The second highest-ranking motivational factor was the design decision to provide an interesting variety of teaching techniques (CIS question 24), which scored a 4.29 from a possible 5 rating.

Course D received the highest overall rating for the Relevance motivational element, averaging 4.33 of a possible 5.0. Students determine course relevance by how closely course goals and projects align with their own interests and ambitions. Relevance elements of Course D are captured in CIS questions 2, 5, 13, 20, 22, 23, and 28, with questions 8 and 25 providing reversed responses. Each of these questions received high student ratings, ranging from 3.57 to 4.71 out of 5. These questions examine motivation factors such as future importance of content, personal benefit of course completion, establishment of personal or professional standards of excellence, and achievement of goals and expectations. Factors that received highest Relevance scores examined the personal usefulness of content (CIS question 2), setting and achieving high standards of personal excellence (CIS question 13), and excelling in course to achieve personal goals (CIS question 23). Each of these questions ranked 4.71 from a possible 5 rating.

Confidence elements are measured by seeking to determine the degree to which design decisions allow students to believe they can be successful in completing all assignments and tasks required for the course. These elements are captured in CIS questions 3, 9, 27, 30, and 34, 
with questions 6,11 , and 17 providing reversed responses. Course D received the second highest overall score in Confidence, averaging 4.18 of a possible 5.0 rating. Individual question ratings ranged from 3 to 4.86 from a possible 5 rating. Ownership of learning is acknowledged in CIS question 9 on student accountability for success. Appropriate instructor feedback (CIS question 34) is also an indicator of increased student confidence. These two questions received the highest Confidence motivational ranking, scoring 4.86 of a possible 5 rating. The lowest rating, with a score of 3 out of a possible 5 rating, was indicated in CIS question 30 regarding the challenge level of the course as being neither too easy nor too hard.

Satisfaction ratings are determined by questions that focus on instructor fairness and attention, instructor and peer recognition, amount of required work, personal enjoyment of course content, as well as interaction with the online community, including instructor. These elements are captured in CIS questions 12, 14, 16, 18, 19, 32, and 33, with questions 7 and 31 providing reversed responses. Course D received the average Satisfaction score of 3.89 out of 5, with individual responses ranging from 2.14 to 4.86 out of a possible 5 rating. Instructor evaluation of student performance (CIS question18), as well as grading fairness and recognition (CIS question 14), received the highest Satisfaction element rating of 4.86 out of a possible 5 rating. Recognition of work via grades, comments, or other feedback (CIS question 32), closely followed, receiving a 4.71 of a possible 5 rating. The lowest Satisfaction rating of 2.14 pertained to the amount of effort required for the course (CIS question 7).

\section{Course D Student Ratings of Motivation: IMMS Survey}

The Instructional Materials Motivation Scale (IMMS) is designed to measure student reaction to self-directed instructional materials. There are 36 items, with 12 for the Attention subscale, nine (9) items each for the Relevance and Confidence subscales, and six (6) items for 
the Satisfaction subscale. Keller attributes the higher number of items that examine Attention elements to a prevailing educational notion that text-based instructional materials contribute to boredom and lack of stimulation, while the lower number of Satisfaction items reflects that this motivational element has fewer connections to printed materials than the other subcategories do (Keller, 2010). Keller designed a Motivational Tactics Checklist that can be useful in developing and evaluating instructional materials for motivation (2010, p. 286-292).

From the 17 students enrolled in Course D, seven students (41.2\%) completed the IMMS. Results are seen in Table 24 below, including number of responses, mean score, and applicable ARCS element:

\begin{tabular}{|c|c|c|c|}
\hline IMMS Question & $\begin{array}{l}\text { Course D } \\
\text { Response }\end{array}$ & $\begin{array}{c}\text { Mean } \\
\text { Score } \\
\text { (Max. 5) }\end{array}$ & $\begin{array}{l}\text { ARCS } \\
\text { Element }\end{array}$ \\
\hline $\begin{array}{l}\text { 1. When I first looked at this course, I had the impression that it would be easy } \\
\text { for me. }\end{array}$ & 7 & 3.29 & $\mathrm{C}$ \\
\hline $\begin{array}{l}\text { 2. There is something interesting at the beginning of each lesson that gets my } \\
\text { attention. }\end{array}$ & 7 & 3.14 & A \\
\hline $\begin{array}{l}\text { 3. This course material was more difficult to understand than I would like it to } \\
\text { be. }\end{array}$ & 7 & 1.29 & C (Rev.) \\
\hline $\begin{array}{l}\text { 4. After reading the introductory information, I felt confident that I knew what I } \\
\text { was supposed to learn from each lesson in this course. }\end{array}$ & 7 & 3.86 & $\mathrm{C}$ \\
\hline $\begin{array}{l}\text { 5. Completing the exercises in each lesson gave me a satisfying feeling of } \\
\text { accomplishment. }\end{array}$ & 7 & 3.57 & S \\
\hline $\begin{array}{l}\text { 6. It is clear to me how the content of this course is related to things I already } \\
\text { know. }\end{array}$ & 7 & 4.57 & $\mathrm{R}$ \\
\hline $\begin{array}{l}\text { 7. Many of the resources have so much information that it is hard to pick out and } \\
\text { remember the important points. }\end{array}$ & 7 & 2.43 & C (Rev.) \\
\hline 8. The materials are eye-catching. & 7 & 3.43 & A \\
\hline $\begin{array}{l}\text { 9. There were stories, pictures, or examples that showed me how this material } \\
\text { could be important to some people. }\end{array}$ & 7 & 4.57 & $\mathrm{R}$ \\
\hline 10. Completing this course successfully is important to me. & 7 & 5.00 & $\mathrm{R}$ \\
\hline
\end{tabular}




\begin{tabular}{|c|c|c|c|}
\hline \multicolumn{4}{|l|}{\begin{tabular}{|l} 
Table 24 \\
Course D Scoring Results of the Instructional Materials Motivational Scale (IMMS)
\end{tabular}} \\
\hline ( & $\begin{array}{l}\text { Course D } \\
\text { Response }\end{array}$ & $\begin{array}{l}\text { Mean } \\
\text { Score } \\
\text { (Max. 5) }\end{array}$ & $\begin{array}{l}\text { ARCS } \\
\text { Element }\end{array}$ \\
\hline 11. The quality of the writing helped to hold my attention. & 7 & 3.43 & A \\
\hline $\begin{array}{l}\text { 12. This course lessons were so abstract that it was hard to keep my attention on } \\
\text { them. }\end{array}$ & 7 & 1.43 & A (Rev.) \\
\hline 13. As I worked on each lesson, I was confident I could learn the content. & 7 & 4.43 & $\mathrm{C}$ \\
\hline $\begin{array}{l}\text { 14. I enjoyed this course so much that I would like to know more about this } \\
\text { topic. }\end{array}$ & 7 & 3.57 & $\mathrm{~S}$ \\
\hline 15. The resources for this course look dry and unappealing. & 7 & 1.43 & A (Rev.) \\
\hline 16. The content of this course is relevant to my interests. & 7 & 4.57 & $\mathrm{R}$ \\
\hline 17. The way the information is arranged helped keep my attention. & 7 & 3.86 & A \\
\hline $\begin{array}{l}\text { 18. There are examples or explanations of how people can use the knowledge } \\
\text { from this course. }\end{array}$ & 7 & 4.71 & $\mathrm{R}$ \\
\hline 19. The exercises in this course are too difficult. & 7 & 1.29 & C (Rev.) \\
\hline 20. This course has things that stimulate my curiosity. & 7 & 4.00 & A \\
\hline 21. I really enjoyed studying the lessons in this course. & 7 & 3.57 & $\mathrm{~S}$ \\
\hline $\begin{array}{l}\text { 22. The amount of repetition in course lessons caused me to get bored } \\
\text { sometimes. }\end{array}$ & 7 & 2.00 & A (Rev.) \\
\hline $\begin{array}{l}\text { 23. The content and style of writing in the lessons convey the impression that its } \\
\text { content is worth knowing. }\end{array}$ & 7 & 4.29 & $\mathrm{R}$ \\
\hline 24. I learned some things that were surprising or unexpected. & 7 & 4.14 & A \\
\hline $\begin{array}{l}\text { 25. After working on the lessons, I was confident that I would be able to pass the } \\
\text { course. }\end{array}$ & 7 & 4.86 & $\mathrm{C}$ \\
\hline $\begin{array}{l}\text { 26. This course is not relevant to my needs because I already knew most of the } \\
\text { material. }\end{array}$ & 7 & 2.00 & R (Rev.) \\
\hline $\begin{array}{l}\text { 27. The wording of feedback after the exercises, or other comments on the } \\
\text { lessons, helped me feel rewarded for my efforts. }\end{array}$ & 7 & 4.71 & $\mathrm{~S}$ \\
\hline $\begin{array}{l}\text { 28. The variety of readings, exercises, illustrations, etc., helped keep my } \\
\text { attention on the lessons. }\end{array}$ & 7 & 3.71 & A \\
\hline 29. The style of writing used in the course resources is boring. & 7 & 1.71 & A (Rev.) \\
\hline
\end{tabular}




\begin{tabular}{|c|c|c|c|}
\hline \multicolumn{4}{|l|}{$\begin{array}{l}\text { Table } 24 \\
\text { Course D Scoring Results of the Instructional Materials Motivational Scale (IMMS) }\end{array}$} \\
\hline IMMS Question & $\begin{array}{l}\text { Course D } \\
\text { Response }\end{array}$ & $\begin{array}{l}\text { Mean } \\
\text { Score } \\
\text { (Max. 5) }\end{array}$ & $\begin{array}{l}\text { ARCS } \\
\text { Element }\end{array}$ \\
\hline $\begin{array}{l}\text { 30. I could relate the content of this course to things I have seen, done, or } \\
\text { thought about in my own life. }\end{array}$ & 7 & 4.57 & $\mathrm{R}$ \\
\hline 31. There were so many words on each page of reading that it was irritating. & 7 & 2.00 & A (Rev.) \\
\hline 32. It felt good to successfully complete the lessons. & 7 & 4.29 & $\mathrm{~S}$ \\
\hline 33. The content of the lessons will be useful to me. & 7 & 4.29 & $\mathrm{R}$ \\
\hline 34. I could not really understand quite a bit of material in this course. & 7 & 1.00 & C (Rev.) \\
\hline $\begin{array}{l}\text { 35. The good organization of content helped me be confident that I would learn } \\
\text { the material. }\end{array}$ & 7 & 4.57 & $\mathrm{C}$ \\
\hline 36. It was a pleasure to work on such a well-designed course. & 7 & 4.29 & $\mathrm{~S}$ \\
\hline
\end{tabular}

Table 24: Course D Scoring Results - Instructional Materials Motivational Scale (IMMS)

Overall, students seemed very motivated by the instructional materials used in Course D.

On the scale of one to five, when reverse scores on the IMMS are converted, Course D received mean average scores of ARCS motivational elements as follows in Table 25:

\begin{tabular}{|c|c|}
\hline \multicolumn{2}{|c|}{$\begin{array}{l}\text { Table } 25 \\
\text { Course D IMMS Motivational Averages }\end{array}$} \\
\hline ARCS Element & Course D IMMS Avg. \\
\hline Attention & 3.51 \\
\hline Relevance & 4.40 \\
\hline Confidence & 3.89 \\
\hline Satisfaction & 4.00 \\
\hline
\end{tabular}

Table 25: Course D IMMS Motivational Averages

Attention elements as related to the design and selection of instructional materials for the course include decisions that will provoke feelings like enthusiasm, suspense, curiosity, surprise, interest, and stimulation. Visual stimulation of instructional materials is an especially important 
consideration in an online environment. Attention elements can include perceptual interest and concreteness, curiosity/inquiry arousal, and variability of format, style, and sequence (Keller, 2010). These elements are examined in IMMS questions 2, 8, 11, 17, 20, 24, and 28, with questions 12, 15, 22, 29, and 31 providing reversed responses. Course D received an average Attention score of 3.51 of a possible 5.0 rating, with individual question responses ranging from 3 to 4.14. The low ratings of 3.0 reflect repetition in lessons (IMMS question 22) and excessive text (IMMS question 31). The highest Attention ranking represented surprising or unexpected examples (IMMS question 24), which was rated at 4.14.

There are nine (9) Relevance items measured in the IMMS. Course D received the highest overall rating for the Relevance motivational elements, averaging 4.4 of a possible 5 rating. Relevance of instructional materials is determined by goal orientation; motive-matching, including present worth and future value, and familiarity, including connection to previous experience, and options for individualization (Keller, 2010). Relevance is assessed by IMMS questions $6,9,10,16,18,23,30$, and 33, with question 26 providing a reversed response. Each of these nine questions received high student ratings, ranging from 3 to 5 . Because Course D is a required course in the program of study, it was not surprising that course completion (IMMS question 10) was ranked at the maximum rate of 5. Four of the nine questions were ranked at the rate of 4.57: content related to existing knowledge (IMMS question 6); relevant and interesting examples (IMMS question 9); student interest in content (IMMS questions 16), and content relationship to life experience (IMMS question 30).

Confidence elements are measured on the IMMS based on clear learning requirements, positive outcomes that will enhance student competence, and accountability for learning (Keller, 2010). These are assessed by IMMS questions $1,4,13,25$, and 35, with questions 3, 7, 19, and 
34 providing reversed responses. Students gave an average Confidence rate of 3.89, with individual responses ranging from 2.57 to 4.86 out of a possible 5 rating. Students indicated good content organization (IMMS question 35) helped provide the confidence necessary to learn the content (IMMS question 13) and pass the course (IMMS question 25).

Satisfaction elements are measured on the IMMS based on intrinsic reinforcement, including positive recognition and continuing motivation; potential extrinsic rewards, and equity or fair treatment (Keller, 2010). These elements were measured by IMMS questions 5, 14, 21, 27, 32, and 36. Course D received an average Satisfaction rating of 4.0 of a possible 5, while individual items were rated from 3.57 to 4.71 . Students expressed the most satisfaction with rewarding feedback and comments (IMMS question 27), ranking this item at 4.71. Personal satisfaction (IMMS question 32) and enjoyment (IMMS question 36) were each rated at 4.29.

\section{Chapter Summary}

Goodwin (2014) defines a case study as an in-depth examination, often undertaken over time, of something like a policy or a program, while comparative case studies seek to determine factors that produce more generalized results about why and how things work or do not (1). Four case studies were developed for this research study that sought to determine if instructional design decisions influence student motivation in online courses. The primary instructional design distinction between the courses was the decision to use the Quality Matters (QM) rubric. Two of the courses used the QM rubrics in the course design, while two did not. Motivational elements were identified and analyzed for differences between the QM- and non-QM-designed courses. Instructor interviews affirm that each of the four online graduate courses examined was an Education-based course which was designed by the experienced instructor who had taught the 
course previously and planned to teach it again. Other data from instructor interview questions

are found at the beginning of each case study.

Content analysis was conducted on each course syllabus to identify ARCS-related

keywords, ideas, and phrases. Data were used to create summative statements for each

motivational design element within each course. It was determined each course syllabus, whether

QM- or non-QM-designed (ID), contained significant motivational design elements that should

contribute to overall student motivation within each course. While specific motivational design

elements and potential outcomes were discussed within each case-study, summative statements

are presented in the competed Course Syllabus Comparison Chart (Table 26) below:

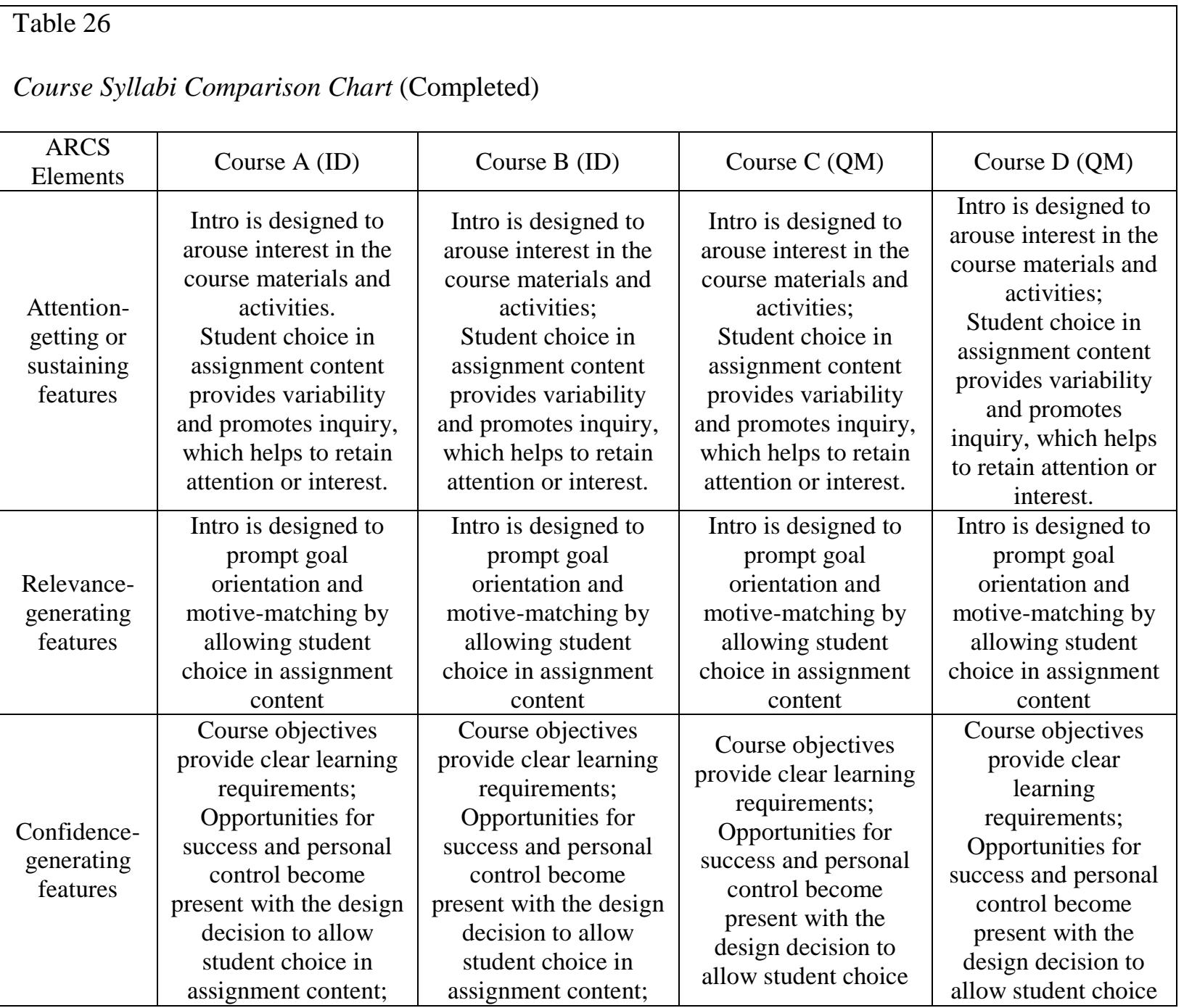




\begin{tabular}{|c|c|c|c|c|}
\hline \multicolumn{5}{|c|}{$\begin{array}{l}\text { Table } 26 \\
\text { Course Syllabi Comparison Chart (Completed) }\end{array}$} \\
\hline \multirow[t]{2}{*}{$\begin{array}{c}\text { ARCS } \\
\text { Elements }\end{array}$} & Course A (ID) & Course B (ID) & Course C (QM) & Course D (QM) \\
\hline & $\begin{array}{l}\text { Open access to } \\
\text { professor }\end{array}$ & $\begin{array}{l}\text { Open access to } \\
\text { professor }\end{array}$ & $\begin{array}{l}\text { in assignment } \\
\text { content; } \\
\text { Open access to } \\
\text { professor }\end{array}$ & $\begin{array}{l}\text { in assignment } \\
\text { content; } \\
\text { Open access to } \\
\text { professor }\end{array}$ \\
\hline $\begin{array}{l}\text { Satisfaction- } \\
\text { generating } \\
\text { features }\end{array}$ & $\begin{array}{l}\text { Natural consequences } \\
\text { are reflected by each } \\
\text { student’s efforts in } \\
\text { using course- } \\
\text { recommended } \\
\text { technology tools to } \\
\text { create an online } \\
\text { education module. } \\
\text { Positive consequences } \\
\text { occur when the } \\
\text { module works as } \\
\text { planned or when } \\
\text { student learn hard } \\
\text { skills or techniques } \\
\text { useful in their } \\
\text { profession or further } \\
\text { studies. } \\
\text { Equity exists because } \\
\text { all students are } \\
\text { required to use the } \\
\text { same technology tools } \\
\text { to create an education } \\
\text { module that properly } \\
\text { functions online }\end{array}$ & $\begin{array}{l}\text { Natural consequences } \\
\text { are reflected by each } \\
\text { student’s efforts in } \\
\text { using course- } \\
\text { recommended } \\
\text { technology tools to } \\
\text { create an online } \\
\text { presentation. } \\
\text { Positive consequences } \\
\text { occur when the } \\
\text { presentation works as } \\
\text { planned or when } \\
\text { student learn hard } \\
\text { skills or techniques } \\
\text { useful in their } \\
\text { profession or further } \\
\text { studies. } \\
\text { Equity exists because } \\
\text { all students are } \\
\text { required to use the } \\
\text { same technology tools } \\
\text { to create an online } \\
\text { presentation that } \\
\text { properly functions }\end{array}$ & $\begin{array}{l}\text { Natural consequences } \\
\text { are reflected by each } \\
\text { student's efforts in } \\
\text { using course- } \\
\text { recommended } \\
\text { technology tools to } \\
\text { create an online } \\
\text { assignments. } \\
\text { Positive } \\
\text { consequences occur } \\
\text { as assignment points } \\
\text { are earned while } \\
\text { knowledge is } \\
\text { demonstrated \& } \\
\text { evaluated. } \\
\text { Equity exists because } \\
\text { all students are } \\
\text { required to use the } \\
\text { same technology tools } \\
\& \text { assessment } \\
\text { measures. }\end{array}$ & $\begin{array}{c}\text { Natural } \\
\text { consequences are } \\
\text { reflected by each } \\
\text { student's efforts in } \\
\text { using course- } \\
\text { recommended } \\
\text { technology tools to } \\
\text { demonstrate } \\
\text { proficiency \& } \\
\text { complete } 5 \text { types of } \\
\text { assessments. } \\
\text { Positive } \\
\text { consequences occur } \\
\text { as assignment points } \\
\text { are earned while } \\
\text { knowledge is } \\
\text { demonstrated \& } \\
\text { evaluated. } \\
\text { Equity exists because } \\
\text { all students are } \\
\text { required to use the } \\
\text { same technology } \\
\text { tools \& assessment } \\
\text { measures. }\end{array}$ \\
\hline $\begin{array}{c}\text { General } \\
\text { comments }\end{array}$ & $\begin{array}{l}2 \text { pp, discussing only } \\
\text { course objectives and } \\
\text { overview. Other } \\
\text { assignment details, } \\
\text { university policies, } \\
\text { etc. are included on } \\
\text { the course in LMS }\end{array}$ & $\begin{array}{l}4 \text { pp, includes } 2 \\
\text { university policy } \\
\text { statements and an } \\
\text { attached 3-pp detailed } \\
\text { weekly schedule. }\end{array}$ & $\begin{array}{c}12 \mathrm{pp} \text {; includes } \\
\text { University policies } \\
\text { replicated on LMS; } \\
\text { detailed explanation } \\
\text { of all assignments; } \\
\text { numerous } \\
\text { introductory elements } \\
\text { useful to beginning } \\
\text { graduate students }\end{array}$ & $\begin{array}{c}13 \text { pp; includes } \\
\text { University policies } \\
\text { replicated on LMS; } \\
\text { detailed explanation } \\
\text { of all assignments; } \\
\text { numerous } \\
\text { introductory } \\
\text { elements useful to } \\
\text { beginning graduate } \\
\text { students }\end{array}$ \\
\hline
\end{tabular}

Table 26: Course Syllabi Comparison Chart (Completed)

The most notable difference between the two design methods was the length of the syllabus. This may be attributed to QM rubric guidelines which state that etiquette expectations, university policies, technology requirements, and other supplemental information should be 
included in the Course Overview Introduction. The non-QM-designed (ID) courses include the same supplemental information as that found on the QM-designed course syllabi; however, this information is presented only within the course LMS and is not replicated on the course syllabi, as occurs in the QM-designed courses.

Comparative analysis was performed using the Course Syllabi Comparison Chart to determine if ARCS motivational design elements varied between courses. This analysis revealed a substantial number of motivational elements in each of the courses. Attention-, relevance-, and confidence-generating design tactics were fairly equal between all courses; however, the satisfaction-generating features differed based on course purpose and final project. For example, each syllabus contained highly-visible instructor contact information and several methods of contact. This information will capture attention, prove relevant, and provide a means of asking questions that can increase chances for student success, which will certainly result in the satisfaction of having a positive learning experience. This one design decision alone can address all four motivational elements of attention, relevance, confidence, and satisfaction.

Despite the design decision to use the Quality Matters rubric, response to the student motivation surveys was found to be comparatively equal across all four courses. The CIS seeks to determine the motivational value of instruction and presentation methods used to deliver the education. Table 27 below shows a comparison of CIS student motivation survey responses. Questions were sorted, in alphabetical order, via ARCS elements to better illustrate the results of each question across the four courses: 


\begin{tabular}{|c|c|c|c|c|c|}
\hline \multicolumn{6}{|l|}{$\begin{array}{l}\text { Table } 27 \\
\text { Comparison of Course CIS Results }\end{array}$} \\
\hline CIS Question \# & $\begin{array}{c}\text { ARCS } \\
\text { Element }\end{array}$ & $\begin{array}{c}\text { Course } \\
\text { A }\end{array}$ & \begin{tabular}{|c|} 
Course \\
B
\end{tabular} & $\begin{array}{c}\text { Course } \\
\text { C }\end{array}$ & $\begin{array}{c}\text { Course } \\
\text { D } \\
\end{array}$ \\
\hline $\begin{array}{l}\text { 1. The instructor knows how to make us feel } \\
\text { enthusiastic about the subject matter of this course. }\end{array}$ & A & 4.57 & 4.75 & 4.29 & 4.43 \\
\hline $\begin{array}{l}\text { 10. The instructor creates suspense when building up to } \\
\text { a point. }\end{array}$ & A & 3 & 2.5 & 2 & 2.43 \\
\hline $\begin{array}{l}\text { 15. The students in this class seem curious about the } \\
\text { subject matter. }\end{array}$ & A & 3.86 & 4.5 & 4.29 & 3.57 \\
\hline $\begin{array}{l}\text { 21. The instructor does unusual or surprising things that } \\
\text { are interesting. }\end{array}$ & A & 3.14 & 2.5 & 2.57 & 2.71 \\
\hline $\begin{array}{l}\text { 24. The instructor uses an interesting variety of teaching } \\
\text { techniques. }\end{array}$ & A & 4.29 & 3.5 & 4.14 & 4.29 \\
\hline $\begin{array}{l}\text { 29. My curiosity is often stimulated by the questions } \\
\text { asked or the problems given on the subject matter in this } \\
\text { class. }\end{array}$ & A & 3.57 & 4.25 & 3.86 & 4.14 \\
\hline $\begin{array}{l}\text { 4. This class has very little in it that captures my } \\
\text { attention. }\end{array}$ & A (Rev.) & 1.29 & 1 & 1.29 & 1 \\
\hline 26. I often daydream while in this class. & A (Rev.) & 1 & 1.5 & 1.14 & 1.29 \\
\hline 3. I feel confident that I will do well in this course. & $\mathrm{C}$ & 4.29 & 5 & 4.57 & 4.57 \\
\hline 9. Whether or not I succeed in this course is up to me. & $\mathrm{C}$ & 4.57 & 4.75 & 5 & 4.86 \\
\hline $\begin{array}{l}\text { 27. As I am taking this class, I believe that I can succeed } \\
\text { if I try hard enough. }\end{array}$ & $\mathrm{C}$ & 4.29 & 5 & 4.86 & 4.71 \\
\hline $\begin{array}{l}\text { 30. I feel the challenge level of this course to be about } \\
\text { right: neither too easy nor too hard. }\end{array}$ & $\mathrm{C}$ & 3.43 & 4.75 & 4.29 & 3 \\
\hline 34. I get enough feedback to know how well I am doing. & $\mathrm{C}$ & 3.14 & 5 & 4.86 & 4.86 \\
\hline $\begin{array}{l}\text { 6. You have to be lucky to get good grades in this } \\
\text { course. }\end{array}$ & C (Rev.) & 1 & 1 & 1 & 1.43 \\
\hline $\begin{array}{l}\text { 11. The subject matter of this course is just too difficult } \\
\text { for me. }\end{array}$ & C (Rev.) & 1.14 & 1 & 1 & 1 \\
\hline $\begin{array}{l}\text { 17. It is difficult to predict what grade the instructor will } \\
\text { give my assignments. }\end{array}$ & C (Rev.) & 1.71 & 1 & 1.14 & 1.14 \\
\hline $\begin{array}{l}\text { 2. The things I am learning in this course will be useful } \\
\text { to me. }\end{array}$ & $\mathrm{R}$ & 4.29 & 4.75 & 4.86 & 4.71 \\
\hline $\begin{array}{l}\text { 5. The instructor makes the subject matter of this course } \\
\text { seem important. }\end{array}$ & $\mathrm{R}$ & 4.25 & 4.5 & 4.29 & 4.57 \\
\hline $\begin{array}{l}\text { 13. In this class, I try to set and achieve high standards } \\
\text { of excellence. }\end{array}$ & $\mathrm{R}$ & 4.29 & 4.75 & 4.57 & 4.71 \\
\hline $\begin{array}{l}\text { 20. The content of this course relates to my expectations } \\
\text { and goals. }\end{array}$ & $\mathrm{R}$ & 4.14 & 4.75 & 4.71 & 4.57 \\
\hline 22. The students actively participate in this class. & $\mathrm{R}$ & 3.71 & 4.25 & 4.86 & 3.57 \\
\hline $\begin{array}{l}\text { 23. To accomplish my goals, it is important that I do } \\
\text { well in this course. }\end{array}$ & $\mathrm{R}$ & 4.71 & 5 & 4.86 & 4.71 \\
\hline 28. The personal benefits of this course are clear to me. & $\mathrm{R}$ & 3.86 & 4.75 & 4.57 & 4.14 \\
\hline $\begin{array}{l}\text { 8. I do NOT see how the content of this course relates to } \\
\text { anything I already know. }\end{array}$ & R (Rev.) & 1 & 1 & 1 & 1 \\
\hline 25. I do NOT think I will benefit much from this course. & R (Rev.) & 1.29 & 1 & 1.14 & 1 \\
\hline 12. I feel this course gives me a lot of satisfaction. & $\mathrm{S}$ & 3.57 & 4 & 3.71 & 3.43 \\
\hline $\begin{array}{l}\text { 14. I feel that the grades or other recognition I receive } \\
\text { are fair compared to other students. }\end{array}$ & $\mathrm{S}$ & 4.14 & 5 & 4.57 & 4.86 \\
\hline 16. I enjoy working for this course. & $\mathrm{S}$ & 4.14 & 4.5 & 4 & 3.57 \\
\hline
\end{tabular}




\begin{tabular}{|l|r|r|r|r|r|}
\hline Table 27 \\
Comparison of Course CIS Results \\
\hline \multicolumn{7}{|c|}{ CIS Question \# } & $\begin{array}{c}\text { ARCS } \\
\text { Element }\end{array}$ & $\begin{array}{c}\text { Course } \\
\text { A }\end{array}$ & $\begin{array}{c}\text { Course } \\
\text { B }\end{array}$ & $\begin{array}{c}\text { Course } \\
\text { C }\end{array}$ & $\begin{array}{c}\text { Course } \\
\text { D }\end{array}$ \\
\hline $\begin{array}{l}\text { 18. I am pleased with the instructor's evaluation of my } \\
\text { work compared to how well I think I have done. }\end{array}$ & S & 3.43 & 5 & 4.57 & 4.86 \\
\hline $\begin{array}{l}\text { 19. I feel satisfied with what I am getting from this } \\
\text { course. }\end{array}$ & S & 4.29 & 4.75 & 4.57 & 4.43 \\
\hline $\begin{array}{l}\text { 32. I feel I get enough recognition of my work in this } \\
\text { course by means of grades, comments or other } \\
\text { feedback. }\end{array}$ & S & 3 & 4.5 & 4.71 & 4.71 \\
\hline $\begin{array}{l}\text { 33. The amount of work I have to do is appropriate for } \\
\text { this type of course. }\end{array}$ & S & 4 & 4.25 & 4.14 & 3.29 \\
\hline 7. I have to work too hard in this course. & S (Rev.) & 1.14 & 1 & 2.29 & 2.86 \\
\hline 31. I feel rather disappointed with this course. & S (Rev.) & 1.14 & 1.25 & 1.29 & 1.29 \\
\hline \multicolumn{1}{|c|}{ Survey Responses } & & 7 & $\mathbf{4}$ & $\mathbf{7}$ & $\mathbf{7}$ \\
\hline
\end{tabular}

Table 27: Comparison of Course CIS Results

Instructor support is vital to student satisfaction, the final step in the ARCS motivational design process, and was evidenced in each of the four courses. Satisfaction can result from the intrinsic fulfillment gained by the successful completion of a challenging task (Beesley, Clark, Barker, Germeroth \& Apthorp, 2010; Hodges, 2004; Keller, 2010; Knowles, 2005; Liao, 2006) that was not previously possible, through student preference for challenge, and from student perception of equity in grading and evaluation of efforts or task completion compared to others in the course (Keller, 2010). These perceptions were evidenced by Satisfaction ratings on the Course Interest Survey (CIS), which ranged from 3.81 (Course A) to 4.42 (Course B). Students expressed greater satisfaction with the motivational quality of instructional materials, assigning high IMMS Satisfaction ratings from 4.00 (Course D) to 4.70 (Course B). Survey items for IMMS determination of Satisfaction included feelings of accomplishment, achievement, and enjoyment; a desire to learn more about the subject; useful, rewarding feedback, and acknowledgement of a well-designed course.

CIS results indicate all instructors provided ongoing, substantive feedback throughout the course, critical to establishing and maintaining high levels of student confidence and satisfaction. 
While still highly above average, Course A received the lowest Confidence score at 3.89. One course variable that may account for this lower score is the complexity of the primary assessment measure: this course is the last of three required for the Distance Education portion of the graduate degree program and was designed as a culminating experience in which students are required to produce a complete instructional module that is due at the end of the course.

Semester-long projects provide a comprehensive, often-individualized assessment measure but do not typically allow many opportunities for instructor or peer feedback, which could result in some degree of student anxiety or uncertainty. Ongoing feedback and positive reinforcement are essential to instilling confidence in students, and when corrective feedback is necessary, it can be presented in positive language that points out accomplishments or effort as well as errors.

The IMMS survey seeks to determine student impression of the motivational value of course materials, delivery method, and other written materials for the course. Table 28 below shows a comparison of the IMMS student motivation survey responses. Again, questions were sorted, in alphabetical order, via ARCS elements to better illustrate the results of each question across the four courses:

\section{Table 28}

Comparison of Course IMMS Results

\begin{tabular}{|c|c|c|c|c|c|}
\hline IMMS Question \# & $\begin{array}{c}\text { ARCS } \\
\text { Element }\end{array}$ & Course A & $\begin{array}{c}\text { Course } \\
\text { B }\end{array}$ & $\begin{array}{c}\text { Course } \\
\text { C }\end{array}$ & $\begin{array}{c}\text { Course } \\
\text { D }\end{array}$ \\
\hline $\begin{array}{l}\text { 2. There is something interesting at the beginning of } \\
\text { each lesson that gets my attention. }\end{array}$ & A & 3.29 & 4.5 & 3.6 & 3.14 \\
\hline 8. The materials are eye-catching. & A & 3.71 & 4.5 & 3.8 & 3.43 \\
\hline $\begin{array}{l}\text { 11. The quality of the writing helped to hold my } \\
\text { attention. }\end{array}$ & A & 3.43 & 4 & 4.6 & 3.43 \\
\hline $\begin{array}{l}\text { 17. The way the information is arranged helped keep my } \\
\text { attention. }\end{array}$ & A & 4.29 & 4.5 & 4.2 & 3.86 \\
\hline 20. This course has things that stimulate my curiosity. & A & 4 & 5 & 4.6 & 4 \\
\hline $\begin{array}{l}\text { 24. I learned some things that were surprising or } \\
\text { unexpected. }\end{array}$ & A & 3.71 & 3.5 & 4.4 & 4.14 \\
\hline $\begin{array}{l}\text { 28. The variety of readings, exercises, illustrations, etc., } \\
\text { helped keep my attention on the lessons. }\end{array}$ & A & 3.86 & 4.5 & 4.2 & 3.71 \\
\hline
\end{tabular}




\begin{tabular}{|c|c|c|c|c|c|}
\hline IMMS Question \# & $\begin{array}{c}\text { ARCS } \\
\text { Element }\end{array}$ & Course A & $\begin{array}{c}\text { Course } \\
\text { B }\end{array}$ & $\begin{array}{c}\text { Course } \\
\mathrm{C}\end{array}$ & $\begin{array}{c}\text { Course } \\
\text { D }\end{array}$ \\
\hline $\begin{array}{l}\text { 12. This course lessons were so abstract that it was hard } \\
\text { to keep my attention on them. }\end{array}$ & A (Rev.) & 1.14 & 1 & 1 & 1.43 \\
\hline $\begin{array}{l}\text { 15. The resources for this course look dry and } \\
\text { unappealing. }\end{array}$ & A (Rev.) & 1.43 & 1 & 1.2 & 1.43 \\
\hline $\begin{array}{l}\text { 22. The amount of repetition in course lessons caused } \\
\text { me to get bored sometimes. }\end{array}$ & A (Rev.) & 1.14 & 1.5 & 1.4 & 2 \\
\hline $\begin{array}{l}\text { 29. The style of writing used in the course resources is } \\
\text { boring. }\end{array}$ & A (Rev.) & 1.43 & 1 & 1 & 1.71 \\
\hline $\begin{array}{l}\text { 31. There were so many words on each page of reading } \\
\text { that it was irritating. }\end{array}$ & A (Rev.) & 1.14 & 1 & 1.2 & 2 \\
\hline $\begin{array}{l}\text { 1. When I first looked at this course, I had the } \\
\text { impression that it would be easy for me. }\end{array}$ & $\mathrm{C}$ & 2.14 & 3.5 & 2.8 & 3.29 \\
\hline $\begin{array}{l}\text { 4. After reading the introductory information, I felt } \\
\text { confident that I knew what I was supposed to learn from } \\
\text { each lesson in this course. }\end{array}$ & $\mathrm{C}$ & 3.71 & 4.5 & 4.8 & 3.86 \\
\hline $\begin{array}{l}\text { 13. As I worked on each lesson, I was confident I could } \\
\text { learn the content. }\end{array}$ & $\mathrm{C}$ & 4.14 & 5 & 4.6 & 4.43 \\
\hline $\begin{array}{l}\text { 25. After working on the lessons, I was confident that I } \\
\text { would be able to pass the course. }\end{array}$ & $\mathrm{C}$ & 4.29 & 5 & 4.8 & 4.86 \\
\hline $\begin{array}{l}\text { 35. The good organization of content helped me be } \\
\text { confident that I would learn the material. }\end{array}$ & $\mathrm{C}$ & 4 & 5 & 4.6 & 4.57 \\
\hline $\begin{array}{l}\text { 3. This course material was more difficult to understand } \\
\text { than I would like it to be. }\end{array}$ & C (Rev.) & 1.29 & 1 & 1 & 1.29 \\
\hline $\begin{array}{l}\text { 7. Many of the resources have so much information that } \\
\text { it is hard to pick out and remember the important points. }\end{array}$ & C (Rev.) & 1.43 & 1.5 & 1.6 & 2.43 \\
\hline 19. The exercises in this course are too difficult. & C (Rev.) & 1.29 & 1 & 1 & 1.29 \\
\hline $\begin{array}{l}\text { 34. I could not really understand quite a bit of material } \\
\text { in this course. }\end{array}$ & C (Rev.) & 1.14 & 1 & 1.2 & 1 \\
\hline $\begin{array}{l}\text { 6. It is clear to me how the content of this course is } \\
\text { related to things I already know. }\end{array}$ & $\mathrm{R}$ & 4.57 & 5 & 4.6 & 4.57 \\
\hline $\begin{array}{l}\text { 9. There were stories, pictures, or examples that showed } \\
\text { me how this material could be important to some } \\
\text { people. }\end{array}$ & $\mathrm{R}$ & 4.14 & 4.5 & 4.8 & 4.57 \\
\hline $\begin{array}{l}\text { 10. Completing this course successfully is important to } \\
\text { me. }\end{array}$ & $\mathrm{R}$ & 4.86 & 5 & 5 & 5 \\
\hline 16. The content of this course is relevant to my interests. & $\mathrm{R}$ & 4.43 & 5 & 4.8 & 4.57 \\
\hline $\begin{array}{l}\text { 18. There are examples or explanations of how people } \\
\text { can use the knowledge from this course. }\end{array}$ & $\mathrm{R}$ & 4.29 & 5 & 4.6 & 4.71 \\
\hline $\begin{array}{l}\text { 23. The content and style of writing in the lessons } \\
\text { convey the impression that its content is worth knowing. }\end{array}$ & $\mathrm{R}$ & 4 & 4.5 & 4.8 & 4.29 \\
\hline $\begin{array}{l}\text { 30. I could relate the content of this course to things I } \\
\text { have seen, done, or thought about in my own life. }\end{array}$ & $\mathrm{R}$ & 4.43 & 4 & 4.4 & 4.57 \\
\hline 33. The content of the lessons will be useful to me. & $\mathrm{R}$ & 4.57 & 5 & 5 & 4.29 \\
\hline $\begin{array}{l}\text { 26. This course is not relevant to my needs because I } \\
\text { already knew most of the material. }\end{array}$ & R (Rev.) & 1.29 & 2 & 1 & 2 \\
\hline $\begin{array}{l}\text { 5. Completing the exercises in each lesson gave me a } \\
\text { satisfying feeling of accomplishment }\end{array}$ & $\mathrm{S}$ & 4.29 & 4.5 & 4.2 & 3.57 \\
\hline
\end{tabular}




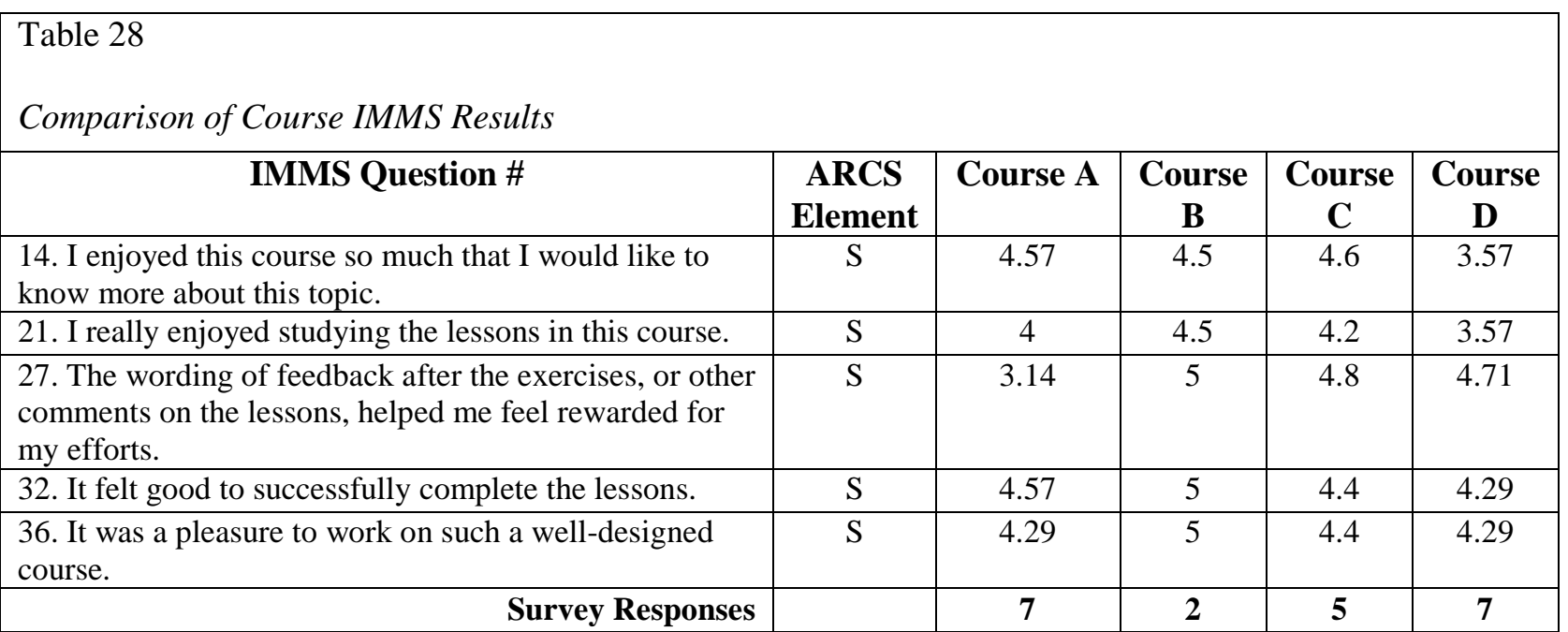

Table 28: Comparison of Course IMMS Results

IMMS results show Course B, a non-QM-designed course, and Course C, a QM-designed course, received scores above 4 of a possible 5 in all motivational elements, with Courses A and D receiving very high overall average ratings as well. One variable that may contribute to the high overall motivational averages of Courses B and C is that both are electives, while Courses A and D are required for the program of study. Student motivation is inherently higher in elective courses, as enrollment alone signals at least an intrinsic interest in the subject matter or content. Designers of required courses may have to work harder to establish relevance of subject matter for students, but may find success through incorporation of proven motivational strategies, such as flexible due-dates, customizable assignments, or variety in presentation and assessment methods, when possible.

Overall, student motivation ratings appear unaffected by the use of the QM rubric in the instructional design method, as shown in Tables 29 and 30 below: 


\begin{tabular}{|c|c|c|c|c|}
\hline $\begin{array}{l}\text { Table } 29 \\
\text { Analysis of } C\end{array}$ & Interest & ey (CIS) & & \\
\hline & $\begin{array}{c}\text { Course A } \\
\text { ID }\end{array}$ & $\begin{array}{c}\text { Course B } \\
\text { ID }\end{array}$ & $\begin{array}{c}\text { Course C } \\
\text { QM }\end{array}$ & $\begin{array}{c}\text { Course D } \\
\text { QM }\end{array}$ \\
\hline Attention & 3.77 & 3.69 & 3.59 & 3.66 \\
\hline Relevance & 4.11 & 4.53 & 4.51 & 4.33 \\
\hline Confidence & 3.89 & 4.56 & 4.43 & 4.18 \\
\hline Satisfaction & 3.81 & 4.42 & 4.08 & 3.89 \\
\hline $\begin{array}{c}\text { Motivational } \\
\text { Average }\end{array}$ & 3.89 & 4.30 & 4.15 & 4.01 \\
\hline
\end{tabular}

Table 29: Analysis of Course Interest Survey (CIS) Results

\begin{tabular}{|c|c|c|c|c|}
\hline \multicolumn{5}{|c|}{$\begin{array}{l}\text { Table } 30 \\
\text { Analysis of Instructional Materials Motivational Scale (IMMS) Results }\end{array}$} \\
\hline $\begin{array}{l}\text { Attention } \\
\text { Relevance } \\
\text { Confidence } \\
\text { Satisfaction }\end{array}$ & $\begin{array}{c}\text { Course A } \\
\text { ID } \\
3.75 \\
4.33 \\
3.68 \\
4.14\end{array}$ & $\begin{array}{c}\text { Course B } \\
\text { ID } \\
4.17 \\
4.56 \\
4.28 \\
4.70\end{array}$ & $\begin{array}{c}\text { Course C } \\
\text { QM } \\
4.05 \\
4.67 \\
4.09 \\
4.43\end{array}$ & $\begin{array}{c}\text { Course D } \\
\text { QM } \\
3.51 \\
4.40 \\
3.89 \\
4.00\end{array}$ \\
\hline $\begin{array}{c}\text { Motivational } \\
\text { Average }\end{array}$ & 3.98 & 4.44 & 4.31 & 3.95 \\
\hline
\end{tabular}

Table 30: Analysis of Instructional Materials Motivational Scale (IMMS) Results

While the non-QM-designed courses had a slightly higher combined CIS motivational

average at 4.10, compared to the QM-designed courses, with a combined average rating of 4.09.

The non-QM-designed courses also had a higher IMMS combined motivational average, at 4.21, than the QM-designed IMMS combined motivational average of 4.13; again, the distinction is negligible.

The greatest limitation in analyzing these results is the differing number of responses received from each courses. The CIS results reflect that Course B had the least number of respondents at 4, while the other three courses each had 7 respondents. On the IMMS survey, the number of responses decreased by two students for both Courses B and C. It was interesting that 
the higher number of responses were received from the two required courses (A and D), which maintained consistent response results in both surveys. 


\section{Chapter 5: Discussion}

This research study has sought to determine if instructional design decisions influence student motivation in online courses. Motivational elements were identified and compared in all four of the QM- and non-QM designed courses. However, despite the design decision to use the QM rubrics, there was no significant difference found in student motivation ratings among these four courses. In each course studied, instructor experience with the online course appeared to result in the selection and implementation of design tools and tactics needed to increase student attention, relevance, confidence and satisfaction.

The Course Interest Survey (CIS) indicated each course in the study used a variety of techniques to achieve high student motivation ratings. These motivational examples include:

- Clear description of course relevance to program of study and future application;

- Student choice in assignment specifics;

- Early opportunities for success;

- Instructor access options.

The Instructional Materials Motivational Scale (IMMS) indicted each course in the study used a variety of techniques and methods to achieve a high motivation rating, including:

- Syllabus appropriate to student audience;

- Comprehensive assignment details;

- Calendar of due dates;

- $\quad$ Scoring rubrics

These instructional design techniques were successfully used in all four courses studied and can provide a general guide for recognizing and accommodating varied student needs while providing a high-quality, meaningful educational experience that motivates. 
This study supports previous work (Beesley, Clark, Barker, Germeroth \& Apthorp, 2010; Hodges, 2004; Keller, 2010; Knowles, 2005; Liao, 2006; Westbrook, Kester \& Braver, 2013) that adult learners want to know how new knowledge will enhance their own lives, particularly the relevance to work or personal goals. Establishing relevance of course content to existing knowledge or experience allows the development of new or expanded schemas, memory structures that contain huge amounts of information but which are treated as a single entity by working memory (Koohang, 2004; Sweller, 1994; Sweller, et al., 1998). Learning activities designed to show relevance through the incorporation of experience and knowledge were found in all four courses studied. Motivational design tactics may foster the desire to learn more about a topic, which could result in lifelong learning activities. Each course provided comprehensive and diverse resources more than adequate for high-quality student learning for both course and future study. One design decision successfully used to establish relevance in all four case studies was the individualization of assignments. In Course B, for example, one assessment measure was discussion-based: students are asked to explore then post about their experience with a variety of open-source technologies that may be useful in an educational setting. Students were assigned to try a technology then create a posting “focusing on a few issues that you think are important” (Syllabus B, 2015). In Course C, choice was given in the majority of assessment measures. In one discussion-based assessment, students are asked to describe how they could apply an idea from the unit materials into a real-world teaching experience (Syllabus C, 2015). Granting choice provides a level of personal control over the learning experience, which allows students to become more vested in and take ownership of their own learning (Keller, 2010; Youger, R.E. Personal communications, 2014). The design decision to offer choice in topic or presentation method can greatly increase both relevance and confidence for students by allowing the 
recognition of their past experiences, which can lead to greater engagement and higher levels of learning (Means, et al., 1997).

Instructor engagement and experience, as reflected primarily in CIS results, can increase the quality and motivational value of any course. Instructor interviews, another data source used in this study, indicate that each of the instructors has taught their course more than ten times. Yet despite their experience, each instructor acknowledged and recognized in their interview answers that each group of students was viewing the course for the first time. Each instructor used course design tactics and techniques to demonstrate the importance of being "present" in that particular course. For example, Instructor A held a weekly live video-chat through the LMS. Students had a choice to attend weekly or only if they had questions or concerns. This is a very effective method of demonstrating consistent instructor presence. Regular instructor contact may increase student confidence by demonstrating the support needed to successfully complete the course is available. Each of the instructors in the case studies exhibited a level of engagement with both students and course content that was evident from introduction through final grade submission process. This instructional task was achieved by providing clear and current contact information, methods and opportunities, thus encouraging the development of an online learning community.

Student confidence will be greatly increased if grading is clear and fair: just as learners want to know why they should learn something, they want to know how they will be evaluated. Again the experience of each instructor in the case studies was evident. All provided students with comprehensive assignment and assessment details, as well as relevant, easily-accessible resources. As an example, each course used an assessment rubric which allowed assignment flexibility and individualization. This allowed students to create assignments that more closely aligned with individual interests or career goals. Such a design decision may increase student 
motivation to complete the course while simultaneously providing a consistent, comprehensive evaluation tool for the instructor.

Based on this study, instructor engagement and experience appear to result in design decisions that work effectively for both teacher and student. In Course A, for example, students are given complete freedom to choose, arrange, and present education elements and resources for their final project, a unique learning module centered on a common theme of nutrition labels. In describing the assessment measure, Professor A chose to provide a link to previous student projects done using Moodle. The instructional design decision to make assessment examples available could positively enhance student confidence by providing visuals of acceptable work while attempting to establish a working community built on trust and support.

One case study in particular presented an unexpected finding in relation to assessment measures: Students in Course D were required to complete 10 chapter quizzes and 17 written assignments within the accelerated 6-week summer semester. Yet despite the intense demands of this introductory course in such a brief time-frame, it is interesting to note a parting comment posted by a student:

“... I felt that this class was well designed and challenging with enough variety and quick pace to keep my interest level high. I definitely feel great about my choice to enroll in [the] Instructional Design MA program after this class and am genuinely looking forward to my next class. Thank you Dr. [D] for leading the way, and I hope to take another class from you again in the future!"

Such a positive comment was surprising considering that, of the four courses observed, Course D had the most assessments, and students were required to make the most use of many of the LMS technology tools. Yet this student publically posted appreciation of the course, the course design, 
and the instructor. This student statement, confirmed by high student motivation ratings across all four motivation elements on the Course D CIS and IMMS surveys, reinforce previous research on the value of a functioning online community of learners (Garrison, D. R., Anderson, T., \& Archer, W., 2010; Shattuck, 2013).Instructor experience resulted in the design selection of presentation and instruction methods and techniques that emphasized support and content relevance in this introductory level course.

Communication is critical in online courses and requires an ongoing review and update of all assignments, resources, dates, and links. The creation of assignment calendars and rubrics were two motivational design choices used in all four case studies that appeared successful in establishing student confidence. These instructional tools capture student attention and establish relevance, while also increasing student confidence by providing clear learning requirements, opportunities for success, and options for personal control over success. This should, therefore, increase both value and worth of the course for the student. These design decisions are also useful for the instructor, forcing a reexamination of due dates, procedures, and resources before each semester. This provides an opportunity to ensure all links and supplemental materials are updated, properly placed, and easily accessible by students. As indicated by this study, instructor engagement can lead to motivational design decisions that increase student confidence, and one technique includes a critical examination of course content and instructional materials, conducted prior to each course offering.

Providing opportunities for success early in the course was another motivational technique vital to establishing student confidence, especially for those new to online courses or the higher education setting, which was successfully used in all four case studies. Early success opportunities may include introduction postings or other activities that help students develop 
positive expectations and demonstrate they have some degree of personal control over their own learning outcomes. As is the case with having choice in assignment specifics, a sense of personal control can instill a sense of accountability, thereby making students more vested in their efforts to do well and pass the course (Keller, 2010). Based on the high overall motivational ratings students assigned to the courses in this study, the value and worth of online courses for students can increase if courses are relevant and satisfying. This can be achieved by adding motivational design processes and techniques to enhance existing instructional design skills. Several examples within each of the case studies illustrate that student motivation may be increased through the incorporation of variety and choice in assignments, assessments, resources, and methods of presentation, whenever possible.

Just as previous experience is useful in completing learning tasks, it is also critical to acknowledge the experience of being new to online learning and to address it in the design of courses aimed at incoming or beginning students. In Case Study D, for example, early on the first day of the term, Instructor D emailed a "Welcome” PDF to all students, as well as posted it within the online course. This is an excellent motivational design decision that can be used for any group of students, but seems an especially effective attention-getting, confidence-enhancing technique for new students. The instructor's welcoming introductory email provides a greeting, the course syllabus, and a how-to guide all in one. Within the LMS, Instructor D provided a visually-appealing course home-page that prominently featured a "Start Here” button. This section had links for a variety of important information, including a LMS tutorial, which can greatly increase confidence in new or inexperienced students; Course syllabus; Instructor information; Self-evaluation for online students to determine "fitness” for online learning; and Online etiquette. Links were customized in the LMS to reflect different sections of the course, 
grouped as follows: Course information and content; Course assignments; Course-related LMS features; and University-related LMS features. Finally, the instructor provided several ways to make contact if students have questions or concerns. The design decisions to provide clear and distinct information, placed in separate, clearly-labeled sections will capture student attention immediately. Content is relevant to each student and there were several methods of contacting the instructor, which can increase confidence by demonstrating resources required to succeed in the course are provided within the course and by the instructor. Survey results have indicated the overall design decisions did result in high student satisfaction with the learning experience

Satisfaction, the final element in Keller's motivational design theory, can be increased by providing students with the resources to make them confident they will successfully complete the course. Some methods demonstrated in the case studies include providing detailed instructor contact methods, clear assessment instructions, and functioning hyperlinks to resources. These tactics can be used to increase both student confidence and satisfaction, creating an overall pleasurable experience. Pharmacological studies (Frank \& Fossella, 2011) and advances in cognitive sciences have proven the brain releases the chemical dopamine when something is pleasurable. If learning activities are designed to have relevance and are presented in a logical, intuitive manner that is enjoyable for students, this design decision can promote intrinsic fulfillment for students, thus stimulating dopamine activity and increased cognitive effort (Frank \& Fossella, 2011). Providing students with the resources and support needed to successfully complete the course will create the self-confidence required for a more satisfying experience.

\section{Limitations}

The primary limitation of this study was small-scale implementation. It began with the small sample size of only four courses, further limited by the accelerated summer schedule. 
Department- or institution-wide sample size studies could reveal interesting results about the overall instructional design and potential motivational impact of online course offerings.

A second limitation is that these results reflect a single "snapshot in time.” A longevitybased study could provide better insight into the influence that instructional design decisions may have on student motivation. Online courses could be followed over multiple terms, with instructors being given the opportunity to enhance or improve course design following each offering, as discussed in Recommendations for Future Research below.

Additionally, there was a low number of motivational survey response rate in some of the courses, as well as inconsistent response rates within courses in completing both surveys. If a follow-up instructor interview was conducted at the end of the term, it may have revealed instructor perception of student motivation in that particular class section. This could also have confirmed the number of students enrolled in each course at the time of survey implementation during Week 5 to more effective determine response rates on the two motivational surveys.

Finally, this was primarily a qualitative study; therefore, limited quantitative analyses were conducted, which may have revealed additional results.

\section{Recommendations for Future Research}

Findings provided here may serve as a springboard to future research into instructional design choices and how decisions may impact, hopefully increase, student motivation to succeed. Future studies on student motivation, including studies into each of the Keller motivational elements of Attention, Relevance, Confidence, and Satisfaction, would certainly enhance existing literature on motivational instructional design.

No course, particularly an online course dependent on ever-changing technology, should ever be considered a "finished product." The motivational design tools created by Keller can be 
used periodically by instructors to monitor the perceived motivational value of both course and course materials to students. The surveys may help identify course components that could benefit from motivational design. As corrections and adjustments are made, it is important to be alert for any changes in student behavior or quality of work. Follow-up survey administration may reveal statistical changes that occurred as a result of the motivational design decisions.

While this study has shown that instructional design strategies in online courses can increase student motivation, more research is needed to better understand the correlation between student motivation and retention. In an effort to determine the quality, value, and worth of online courses for all stakeholder groups, researchers may wish to more broadly apply Keller’s Course Interest Survey (CIS) and Instructional Materials Motivation Scale (IMMS) tools, to evaluate online courses within a program of study, then compare motivational course scores with overall program retention.

\section{Conclusion}

Regardless of instructional design method used, based on the rigorous research and the findings in this study, experienced instructors make effective instructional design decisions and can have the greatest impact on student motivation because of their ability to capture student attention, reveal the relevance of the subject matter, provide resources and tools that allow the growth of confidence to successfully complete the course, and provide students with satisfaction of achievement by successfully completing both project and course. Student motivation to successfully complete each course in their program of study is a necessary for student retention and is, therefore, a critical concern to all stakeholder groups. 


\section{References}

Allen, I. E., \& Seaman, J. (2013). Changing Course: Ten years of tracking online education in the United States. Sloan Consortium. PO Box 1238, Newburyport, MA 01950, USA

Atkinson, J. W. (1981). Studying personality in the context of an advanced motivational psychology. American Psychologist, 36(2), 117-128.

Beesley, A., Clark, T., Barker, J., Germeroth, C., \& Apthorp, H. (2010). Expeditionary Learning Schools: Theory of action and literature review of motivation, character, and engagement. Mid-continent Research for Education and Learning (McREL).

Belland, B. R., Kim, C., \& Hannafin, M. J. (2013). A framework for designing scaffolds that improve motivation and cognition. Educational psychologist, 48(4), 243-270.

Bourne, J. R., \& Moore, J. C. (Eds.). (2004). Elements of quality online education: into the mainstream (No. 5). Olin College-Sloan-C.

Boston, W. E., Ice, P., \& Gibson, A. M. (2011). Comprehensive assessment of student retention in online learning environments. Online Journal of Distance Learning Administration, 14(4). Retrieved from http://www.westga.edu/ distance/ojdla/spring141/boston_ice_gibson141.html

Chen, K. C., \& Jang, S. J. (2010). Motivation in online learning: Testing a model of selfdetermination theory. Computers in Human Behavior, 26(4), 741-752.

Churches, A. (2008). Bloom's taxonomy blooms digitally. Tech \& Learning, 1. Retrieved from http://edorigami.wikispaces.com/Bloom\%27s+Digital+Taxonomy

Cognitive Atlas (2013). Cognitive effort. Retrieved from http://www.cognitiveatlas.org/concept/cognitive_effort 
Colorado State University. (2015a). Conceptual analysis. Retrieved from http://writing.colostate.edu/guides/page.cfm?pageid=1309\&guideid=61

Colorado State University. (2015b). Relational analysis. Retrieved from http://writing.colostate.edu/guides/page.cfm?pageid=1311\&guideid=61

Eberly, M. B., Newton, S. E., \& Wiggins, R. A. (2001). The syllabus as a tool for studentcentered learning. The Journal of General Education, 50(1), 56-74.

Eccles, J. S., \& Wigfield, A. (2002). Motivational beliefs, values, and goals. Annual Review of Psychology, 53, 109-132.

Frank, M. J., \& Fossella, J. A. (2011). Neurogenetics and pharmacology of learning, motivation, and cognition. Neuropsychopharmacology, 36(1), 133-152.

Garrison, D. R., Anderson, T., \& Archer, W. (2010). The first decade of the community of inquiry framework: A retrospective. The Internet and Higher Education, 13(1), 5-9.

Gorges, J., \& Kandler, C. (2012). Adults' learning motivation: Expectancy of success, value, and the role of affective memories. Learning and Individual Differences, 22(5), 610-617.

Goodrick, D. (2014). Comparative case studies. Methodological briefs: Impact evaluation, 9.Harvey, L. \& Green, D. (1993). Defining Quality. Assessment and Evaluation in Higher Education. V18, 1.

Hiltz, S. R., \& Goldman, R. (Eds.). (2005). Learning together online: Research on asynchronous learning networks. Routledge.

Hiltz, S. R., \& Shea, P. (2005). The student in the online classroom. Learning together online: Research on asynchronous learning networks, 145-168.

Horton, W. (2006). E-learning by design. John Wiley \& Sons.

Hunt Jr, J. B. (1998). Organizing for Learning: The View from the Governor's Office. 
Instructor A. (2015, July 23). Email interview, Youger dissertation research.

Instructor B. (2015, July 25). Email interview, Youger dissertation research.

Instructor C. (2015, August 4). Email interview, Youger dissertation research.

Instructor D. (2015, August 4). Email interview, Youger dissertation research.

Keller, J. M. (1987a). The systematic process of motivational design. Performance+ Instruction, 26(9-10), 1-8.

Keller, J. M. (1987b). Development and use of the ARCS model of instructional design. Journal of Instructional Development, 10(3), 2-10.

Keller, J. M. (2006). What is motivational design? [PDF file] Retrieved from http://www.arcsmodel.com/\#!motivational-design/c2275

Keller, J. M. (2010). Motivational design for learning and performance: The ARCS model approach. Springer-Verlag.

Knowles, M. S. (1970). The modern practice of adult education (41). New York: New York Association Press.

Knowles, M. S., Holton III, E. F., \& Swanson, R. A. (2005). The adult learner. Elsevier.

Kock, N. (2004). The psychobiological model: Towards a new theory of computer-mediated communication based on Darwinian evolution. Organization Science, 15(3), 327-348.

Koohang, A. (2004). Expanding the concept of usability. Informing Science, 7, 129-141.

Liao, L. F. (2006). A flow theory perspective on learner motivation and behavior in distance education. Distance Education, 27(1), 45-62.

Lin, Y., Lin, G., \& Laffey, J. M. (2008). Building a social and motivational framework for understanding satisfaction in online learning. Journal of Educational Computing Research, 38(1), 1-27. 
Lund, T., \& Haugen, R. (2000). Achievement motives, incentive values and attribution. Scandinavian Journal of Educational Research, 44(4), 423-432.

Malik, S. U. (2012). Customer satisfaction, perceived service quality and mediating role of perceived value. International Journal of Marketing Studies, 4(1).

Marmon, M., Vanscoder, J., \& Gordesky, J. (2014). Online student satisfaction: An examination of preference, asynchronous course elements and collaboration among online students. Current Issues in Education, 17(3).

MarylandOnline, Inc. (2011). Quality Matters Rubric Standards 2011-2013 edition. Retrieved from http://www.elo.iastate.edu/files/2014/03/Quality_Matters_Rubric.pdf

Means, T. B., Jonassen, D. H., \& Dwyer, F. M. (1997). Enhancing relevance: Embedded ARCS strategies vs. purpose. Educational Technology Research and Development, 45(1), 5-17.

Moore, J. C. (2005). The Sloan consortium quality framework and the five pillars. The Sloan Consortium. Retrieved July, 15, 2007.

O'Neill, M. A., \& Palmer, A. (2004). Importance-performance analysis: a useful tool for directing continuous quality improvement in higher education. Quality Assurance in Education, 12(1), 39-52.Online Learning Consortium. (n.d.) Retrieved from http://onlinelearningconsortium.org/

Online Learning Consortium [OLC]. (2015a). About the OLC. Retrieved from http://onlinelearningconsortium.org/about/olc-2/

Online Learning Consortium [OLC]. (2015b). Quality Framework. Retrieved from http://onlinelearningconsortium.org/about/quality-framework-five-pillars/

Online Learning Consortium [OLC]. (2015c). A Quality Scorecard for the Administration of Online Education Programs. Retrieved from 
http://olc.onlinelearningconsortium.org/effective_practices/quality-scorecardadministration-online-education-programs

Ozdemir, D., \& Loose, R. (2014). Implementation of a Quality Assurance Review System for the Scalable Development of Online Courses. Online Journal of Distance Learning Administration, 17(1).

Pappas, Christopher. (2015). Instructional Design Models and Theories: Keller’s ARCS Model of Motivation. Retrieved from https://elearningindustry.com/arcs-model-of-motivation

Pintrich, P. R. (2002). The role of metacognitive knowledge in learning, teaching, and assessing. Theory Into Practice, 41(4), 219-225.

Quality Matters. (2014a). About Us. Retrieved from https://www.qualitymatters.org/about Quality Matters. (2014b). 2014/2015 Research Agenda on Student Impact. Retrieved from https://www.qualitymatters.org/20142015-research-agenda-student-impact

Quality Matters. (2014c). What We're Learning from QM-Focused Research. Retrieved from https://www.qualitymatters.org/whaht-were-learning-focused-research

Quality Matters. (2014d). Preparing for a Quality Matters Course Review. Retrieved from https://www.qualitymatters.org/reviews/preparing

Quality Matters. (2015a). Subscriber Institutions by Country - Higher Education. Retrieved from https://www.qmprogram.org/qmresources/subscriptions/subscribers.cfm?program=2

Quality Matters. (2015b). 2015 QM Recognized Courses - Higher Education. Retrieved from https://www.qmprogram.org/qmresources/courses/index.cfm?program=2

Qualtrics. (2015). Factor analysis. Retrieved from http://www.qualtrics.com/university/researchsuite/research-resources/data-analysisguides/advanced-analysis-methods/factor-analysis/ 
Ralston-Berg, P., \& Nath, L. (2011). What makes a quality online course? The student perspective. In 3rd Annual Quality Matters Conference, Baltimore, MD.

Sarwar, M., \& Ashrafi, G. M. (2014). Students' Commitment, Engagement and Locus of Control as Predictor of Academic Achievement at Higher Education Level. Current Issues in Education, 17(3).

Schmidt L, Lebreton M, Cléry-Melin M-L, Daunizeau J, Pessiglione M (2012). Neural Mechanisms Underlying Motivation of Mental Versus Physical Effort. PLoS Biol 10(2): e1001266. doi:10.1371/journal.pbio.1001266

Schunk, D. H. (1991). Self-efficacy and academic motivation. Educational Psychologist, 26(34), 207-231.

Shattuck, K. (2012). What we're learning from Quality Matters-focused research: Research, practice, continuous improvement. Annapolis: MarylandOnline.

Shattuck, K. (2013). Results of Review of the 2011-2913 Research Literature. Retrieved from https://www.qualitymatters.org/2013-lit-review-summary-report-11-25-13-revised-kspdf/

Shea, P., Li, C. S., Swan, K., \& Pickett, A. (2005). Developing learning community in online asynchronous college courses: The role of teaching presence. Journal of Asynchronous Learning Networks, 9(4), 59-82.

Smith, M. K. (2002) 'Malcolm Knowles, informal adult education, self-direction and andragogy', The Encyclopedia of Informal Education. Retrieved from www.infed.org/thinkers/etknowl.htm.

Smyth, R. (2014). Daniel, J. \& Uvalić-Trumbić, S., ed. (2013) A guide to quality in online learning. British Journal of Educational Technology, 45: E1. Retrieved from http://www.contactnorth.ca/tips-tools/guide-quality-online-learning. 
Swan, K., Matthews, D., Bogle, L., Boles, E., \& Day, S. (2012). Linking online course design and implementation to learning outcomes: A design experiment. Internet \& Higher Education, 15(2), 81-88. doi:10.1016/j.iheduc.2011.07.002

Sweller, J. (1988). Cognitive load during problem solving: Effects on learning. Cognitive Science, 12(2), 257-285.

Sweller, J. (1994). Cognitive load theory, learning difficulty, and instructional design. Learning and Instruction, 4(4), 295-312.

Sweller, J., Van Merrienboer, J. J., \& Paas, F. G. (1998). Cognitive architecture and instructional design. Educational Psychology Review, 10(3), 251-296.

Syllabus A. (2015). Morgantown, WV

Syllabus B. (2015). Morgantown, WV

Syllabus C. (2015). Morgantown, WV

Syllabus D. (2015). Morgantown, WV

Tyler, S. W., Hertel, P. T., McCallum, M. C., \& Ellis, H. C. (1979). Cognitive effort and memory. Journal of Experimental Psychology: Human Learning and Memory, 5(6), 607.

U.S. Department of Education, National Center for Education Statistics. (2011). Condition of Education 2011 in Brief. Retrieved from http://nces.ed.gov/pubsearch/pubsinfo.asp?pubid=2011034

“Value.” (2015). In Merriam-Webster.com. Retrieved May 2, 2015, from http://www.merriamwebster.com/dictionary/value

West, R. E. (2010). A student's guide to strengthening an online community. TechTrends, 54(5), 69-75. 
Westbrook A, Kester D, Braver T.S. (2013). What is the subjective cost of cognitive effort? Load, trait, and aging effects revealed by economic preference. PLoS ONE 8(7): e68210. doi:10.1371/journal.pone.0068210

Wigfield, A., \& Eccles, J. S. (2000). Expectancy-value theory of achievement motivation. Contemporary Educational Psychology, 25(1), 68-81.

“Worth.” (2015). In Merriam-Webster.com. Retrieved May 2, 2015, from http://www.merriamwebster.com/dictionary/worth

Youger, R.E. \& Ahern, T.C. (2015). Is a quality course a worthy course? Designing for value and worth in online courses. Online Journal of Distance Learning Administration, 18(1). 


\section{Appendix A: Course Interest Survey}

Instructions

There are 34 statements in this survey. Please think about each statement in relation to the class you are taking and indicate how true it is.

Use the following values to indicate your response to each item:

1. Not true

2. Slightly true

3. Moderately true

4. Mostly true

5. Very true

Think about each statement by itself and indicate how true it is. Do not be influenced by your answers to other statements. Give the answer that truly applies to you, and not what you would like to be true, or what you think others want to hear. Thank you.

1. The instructor knows how to make us feel enthusiastic about the subject matter of this course.

2. The things I am learning in this course will be useful to me.

3. I feel confident that I will do well in this course.

4. This class has very little in it that captures my attention.

5. The instructor makes the subject matter of this course seem important.

6. You have to be lucky to get good grades in this course.

7. I have to work too hard in this course.

8. I do NOT see how the content of this course relates to anything I already know.

9. Whether or not I succeed in this course is up to me.

10. The instructor creates suspense when building up to a point. 
11. The subject matter of this course is just too difficult for me.

12. I feel this course gives me a lot of satisfaction.

13. In this class, I try to set and achieve high standards of excellence.

14. I feel that the grades or other recognition I receive are fair compared to other students.

15. The students in this class seem curios about the subject matter.

16. I enjoy working for this course.

17. It is difficult to predict what grade the instructor will give my assignments.

18. I am pleased with the instructor's evaluation of my work compared to how well I think I have done.

19. I feel satisfied with what I am getting from this course.

20. The content of this course relates to my expectations and goals.

21. The instructor does unusual or surprising things that are interesting.

22. The students actively participate in this class.

23. To accomplish my goals, it is important that I do well in this course.

24. The instructor uses an interesting variety of teaching techniques.

25. I do NOT think I will benefit much from this course.

26. I often daydream while in this class.

27. As I am taking this class, I believe that I can succeed if I try hard enough.

28. The personal benefits of this course are clear to me.

29. My curiosity is often stimulated by the questions asked or the problems given on the subject matter in this class.

30. I feel the challenge level of this course to be about right: neither too easy nor too hard.

31. I feel rather disappointed with this course. 
32. I feel I get enough recognition of my work in this course by means of grades, comments or other feedback.

33. The amount of work I have to do is appropriate for this type of course.

34. I get enough feedback to know how well I am doing. 


\section{Appendix B: Instructional Materials Motivation Scale}

Instructions

There are 36 statements in this survey. Please think about each statement in relation to the instructional materials you are studying and indicate how true it is.

Use the following values to indicate your response to each item:

1. Not true

2. Slightly true

3. Moderately true

4. Mostly true

5. Very true

Think about each statement by itself and indicate how true it is. Do not be influenced by your answers to other statements. Give the answer that truly applies to you, and not what you would like to be true, or what you think others want to hear. Thank you.

1. When I first looked at this course, I had the impression that it would be easy for me.

2. There is something interesting at the beginning of each lesson that gets my attention.

3. This course material was more difficult to understand than I would like it to be.

4. After reading the introductory information, I felt confident that I knew what I was supposed to learn from each lesson in this course.

5. Completing the exercises in each lesson gave me a satisfying feeling of accomplishment.

6. It is clear to me how the content of this course is related to things I already know.

7. Many of the resources have so much information that it is hard to pick out and remember the important points. 
8. The materials are eye-catching.

9. There were stories, pictures, or examples that showed me how this material could be important to some people.

10. Completing this course successfully is important to me.

11. The quality of the writing helped to hold my attention.

12. This course lessons were so abstract that it was hard to keep my attention on them.

13. As I worked on each lesson, I was confident I could learn the content.

14. I enjoyed this course so much that I would like to know more about this topic.

15. The resources for this course look dry and unappealing.

16. The content of this course is relevant to my interests.

17. The way the information is arranged helped keep my attention.

18. There are examples or explanations of how people can use the knowledge from this course.

19. The exercises in this course are too difficult.

20. This course has things that stimulate my curiosity.

21. I really enjoyed studying the lessons in this course.

22. The amount of repetition in course lessons caused me to get bored sometimes.

23. The content and style of writing in the lessons convey the impression that its content is worth knowing.

24. I learned some things that were surprising or unexpected.

25. After working on the lessons, I was confident that I would be able to pass the course.

26. This course is not relevant to my needs because I already knew most of the material.

27. The wording of feedback after the exercises, or other comments on the lessons, helped me feel rewarded for my efforts. 
28. The variety of readings, exercises, illustrations, etc., helped keep my attention on the lessons.

29. The style of writing used in the course resources is boring.

30. I could relate the content of this course to things I have seen, done, or thought about in my own life.

31. There were so many words on each page of reading that it was irritating.

32. It felt good to successfully complete the lessons.

33. The content of the lessons will be useful to me.

34. I could not really understand quite a bit of material in this course.

35. The good organization of content helped me be confident that I would learn the material.

36. It was a pleasure to work on such a well-designed course. 
Table 1: ARCS Model Categories, Definitions, and Process Questions

\begin{tabular}{|cll}
\hline Table 1 & & \\
ARCS Model Categories, Definitions, and Process & Questions \\
\hline Attention & $\begin{array}{l}\text { Capturing the interest of learners; } \\
\text { stimulating the curiosity to learn }\end{array}$ & $\begin{array}{l}\text { How can I make this learning } \\
\text { experience stimulating and interesting? }\end{array}$ \\
Relevance & $\begin{array}{l}\text { Meeting the personal needs/goals } \\
\text { of the learner to effect a positive } \\
\text { attitude }\end{array}$ & $\begin{array}{l}\text { In what ways will this learning } \\
\text { experience be valuable to my students? }\end{array}$ \\
Confidence & $\begin{array}{l}\text { Helping learners believe/feel they } \\
\text { will succeed and control their } \\
\text { success }\end{array}$ & $\begin{array}{l}\text { How can I via instruction help the } \\
\text { students succeed and allow them to } \\
\text { control their success? }\end{array}$ \\
Satisfaction & $\begin{array}{l}\text { Reinforcing accomplishment with } \\
\text { rewards (internal and external) }\end{array}$ & $\begin{array}{l}\text { What can I do to help the students feel } \\
\text { good about their experience and desire } \\
\text { to continue learning? }\end{array}$ \\
\hline & & \\
\hline
\end{tabular}


Table 2: Study Matrix: Course Analysis

\begin{tabular}{|c|c|c|c|c|c|}
\hline \multicolumn{6}{|c|}{$\begin{array}{l}\text { Study Matrix: Course Analysis } \\
\text { RQ: Do Instructional design decisions influence student motivation in online courses? } \\
\text { Sub-question \#1: What motivational elements are present in QM vs non-QM designed courses? } \\
\text { Sub-question \#2: Do motivational elements differ in QM vs non-QM designed courses? }\end{array}$} \\
\hline \multicolumn{5}{|c|}{ INSTRUCTIONAL DESIGN } & $\begin{array}{c}\text { STUDENT } \\
\text { MOTIVATION }\end{array}$ \\
\hline Online & Course & Course & Instructor & Observation & Student \\
\hline Courses & Syllabi & Design & Interviews & Research & Survey Data \\
\hline A & $\begin{array}{c}\text { ARCS } \\
\text { elements and }\end{array}$ & ID & $\begin{array}{l}\text { Teaching and } \\
\text { instructional }\end{array}$ & $\begin{array}{l}\text { How does actual } \\
\text { course experience }\end{array}$ & $\begin{array}{l}\text { Keller's Course } \\
\text { Interest Survev }\end{array}$ \\
\hline B & $\begin{array}{l}\text { strategies } \\
\text { as reflected by }\end{array}$ & ID & $\begin{array}{c}\text { design } \\
\text { experience; }\end{array}$ & $\begin{array}{l}\text { reflect syllabus } \\
\text { description for }\end{array}$ & $\begin{array}{c}\text { (CIS) \& } \\
\text { Instructional }\end{array}$ \\
\hline C & $\begin{array}{c}\text { Course Syllabus } \\
\text { Comparison }\end{array}$ & QM & $\begin{array}{l}\text { perspective on } \\
\text { course }\end{array}$ & $\begin{array}{l}\text { motivation } \\
\text { elements of }\end{array}$ & $\begin{array}{c}\text { Materials } \\
\text { Motivational }\end{array}$ \\
\hline D & $\begin{array}{c}\text { Chart } \\
\text { (data developed } \\
\text { in Table 5) }\end{array}$ & QM & $\begin{array}{l}\text { importance \& } \\
\text { relevance }\end{array}$ & $\begin{array}{l}\text { attention, } \\
\text { relevance, } \\
\text { confidence, and } \\
\text { satisfaction? }\end{array}$ & Scale (IMMS) \\
\hline
\end{tabular}


Table 3: CIS Reliability Estimate

Table 3

CIS Reliability Estimate

\begin{tabular}{ll}
\hline Scale & Reliability Estimate (Cronbach a) \\
\hline Attention & .84 \\
Relevance & .84 \\
Confidence & .81 \\
Satisfaction & .88 \\
Total Score & .95 \\
\hline
\end{tabular}


Table 4: IMMS Reliability Estimate

Table 4

IMMS Reliability Estimate

Scale Reliability Estimate (Cronbach a)

Attention

.89

Relevance

.81

Confidence

.90

Satisfaction

.92

Total Score

.96 
Table 5: Course Syllabi Comparison Chart

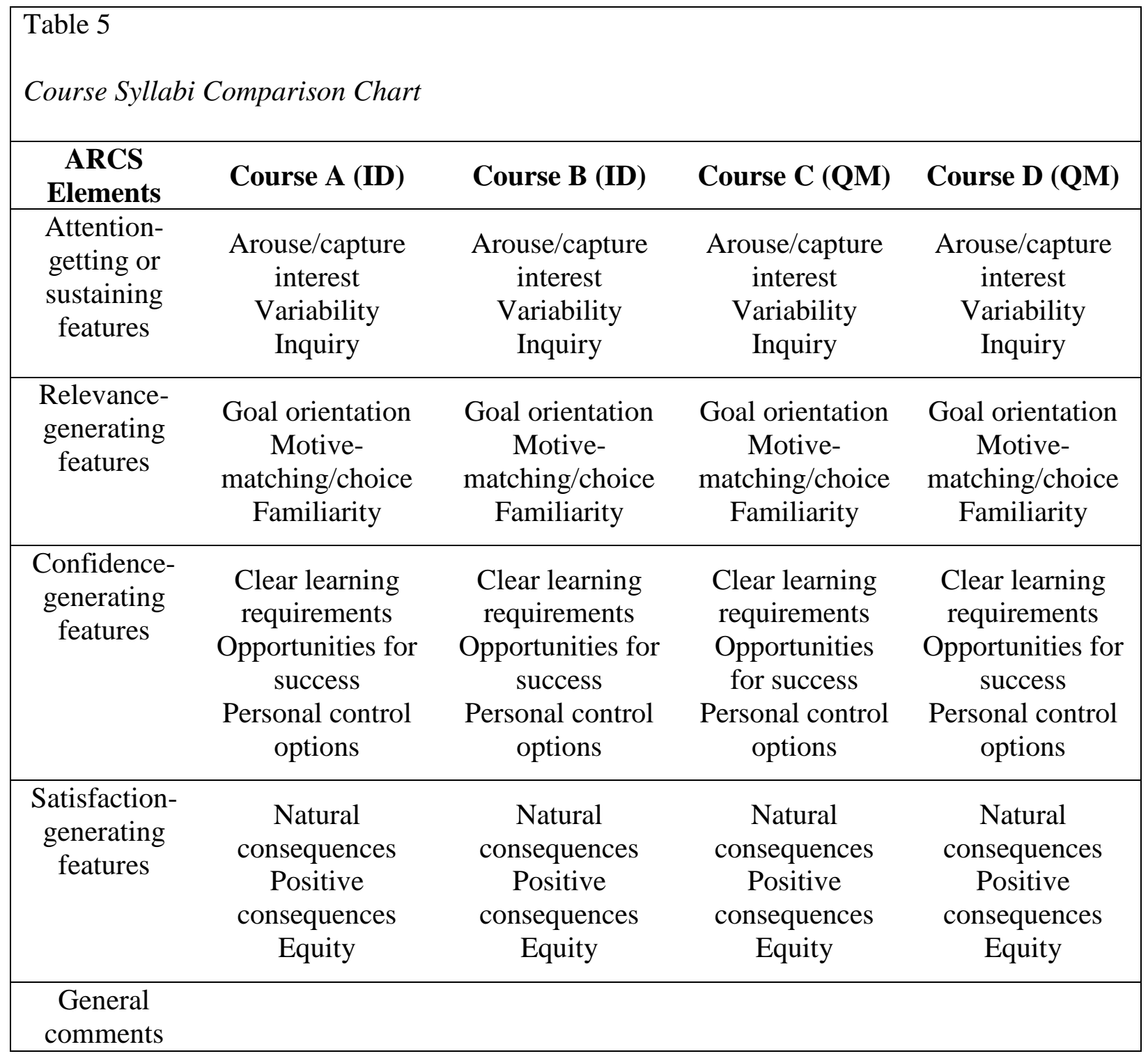


Table 6: Summary of Motivational Design in Relation to Instructional Design

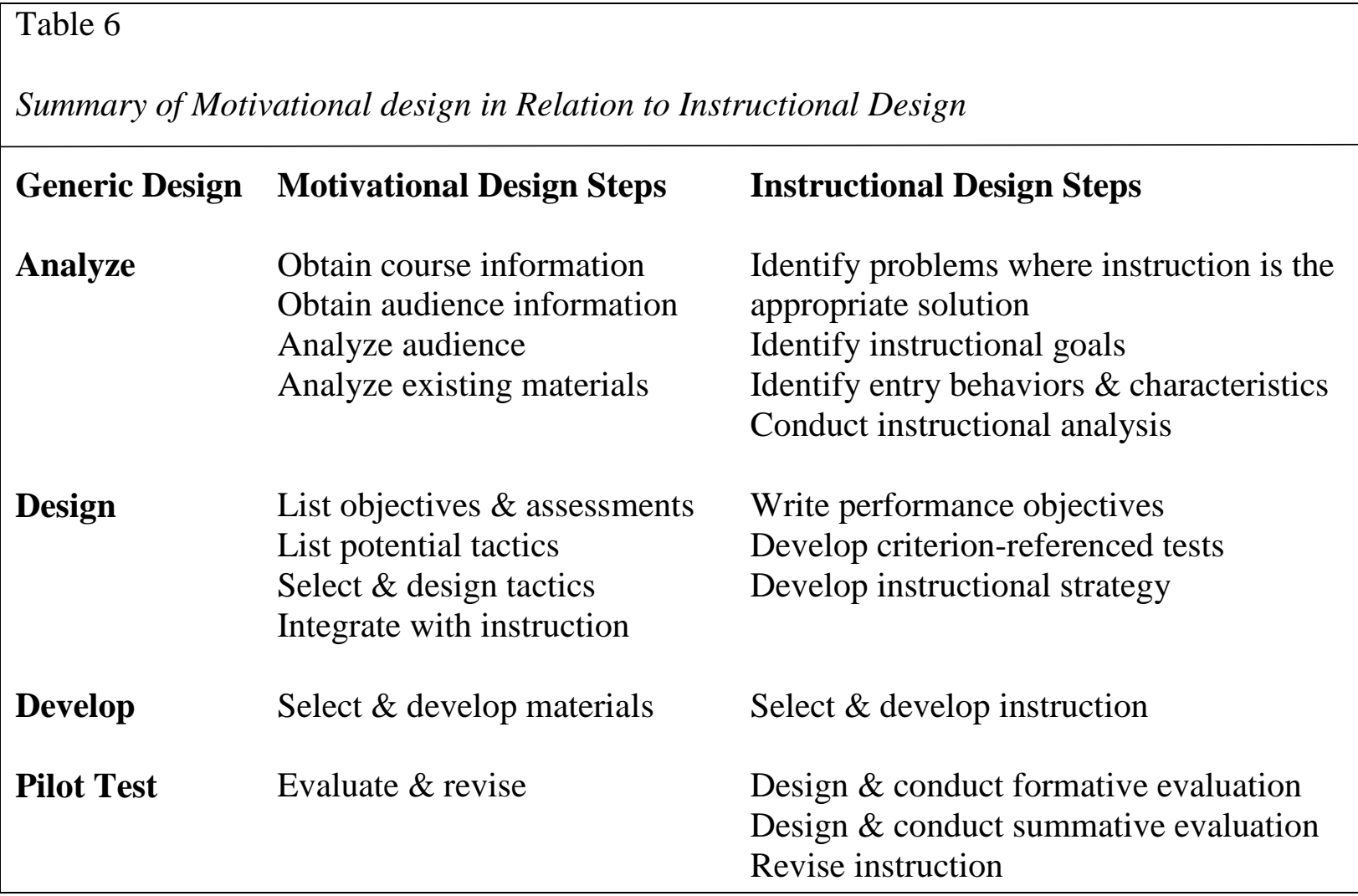


Table 7: Data Sources, Collection, and Analysis Procedures

Table 7

Data Sources, Collection, and Analysis Procedures

Research Question: Does instructional design influence student motivation in online courses?

Data Source(s) Collection Procedures for each data Analysis Procedures for each Data Source source (number each step)

1. Course syllabi 1.1. Design Course Syllabus Comparison (number each step)

Chart* of motivational design elements, based Keller's ARCS framework.

1.2. Gather syllabi from instructors

1.3 Obtain QM higher education rubric

1.4.Content analysis to record ARCS-related keywords and key-ideas on Course Syllabus Comparison Chart*.

1.5.Comparative analysis to determine differences in ARCS motivational design elements between the courses.

1.6.Comparative analysis to determine design elements of QM standards.

2. Qualtrics surveys (Keller's Course Interest [CIS] Survey \& Instruction Materials Motivation Survey [IMMS])

3. * Course Syllabi Comparison Chart

4. Instructor interviews
2.1 Create surveys in Qualtrics.

2.2. Email students invitation to anonymously participate in the surveys.

2.3. Send Qualtrics URL links for instructors to email to course students.

2.4. Gather qualitative results from Qualtrics (ANOVA)

3.1. Completed chart from textual analysis discussed in 1.1 analysis above.
2.1. Analyze survey results to determine student motivation rating in each course.

2.2. Comparison analysis between Qualtrics scores and Course Syllabus Comparison Chart* to seek correlations or differences in overall motivation.

2.3. Comparison analysis between Qualtrics motivation subcategory scores and Course Syllabus Comparison Chart* to seek correlations or differences in each of the four elements of motivation.

3.1. Comparative analysis with Qualtrics survey results to seek correlations or differences in overall student motivation between courses.

3.2. Comparison analysis with Qualtrics motivation subcategory scores to seek correlations or differences in each of the four elements of motivation

4.1. Researcher will use textual analysis to review instructor responses to gain insight into their perspectives about their course and their teaching and instructional design experience. 
Table 7

Data Sources, Collection, and Analysis Procedures

Research Question: Does instructional design influence student motivation in online courses?

Data Source(s) Collection Procedures for each data source (number each step)

4.2. Interview survey link will be emailed to each instructor near the beginning of the semester.

5. Observation

Research
5.1. Researcher will be added as class auditor to each of the four online courses by instructors via learning management system (LMS).
Analysis Procedures for each Data Source (number each step)

4.2 Comparison of textual analysis results with Course Syllabi ARCS data and student rating of motivation in each course will be used to develop case studies on each course.

5.1. Observation research will examine how actual course experience reflects syllabus description for motivation elements of attention, relevance, confidence, and satisfaction.

5.2. Results will complete the study matrix. 
Table 8: Scoring Guide for the Course Interest Survey (CIS)

\begin{tabular}{|llll|}
\hline \multicolumn{4}{|l|}{ Table 8} \\
Scoring Guide for the Course Interest Survey (CIS) & \\
\hline Attention & Relevance & Confidence & Satisfaction \\
\hline 1 & 2 & 3 & 7 (reverse) \\
4 (reverse) & 5 & 6 (reverse) & 12 \\
10 & 8 (reverse) & 9 & 14 \\
15 & 13 & 11 (reverse) & 16 \\
21 & 20 & 17 (reverse) & 18 \\
24 & 22 & 27 & 19 \\
26 (reverse) & 23 & 30 & 31 (reverse) \\
29 & 25 (reverse) & 34 & 32 \\
& 28 & & 33 \\
\hline
\end{tabular}


Table 9: Scoring Guide for the Instructional Materials Motivational Survey (IMMS)

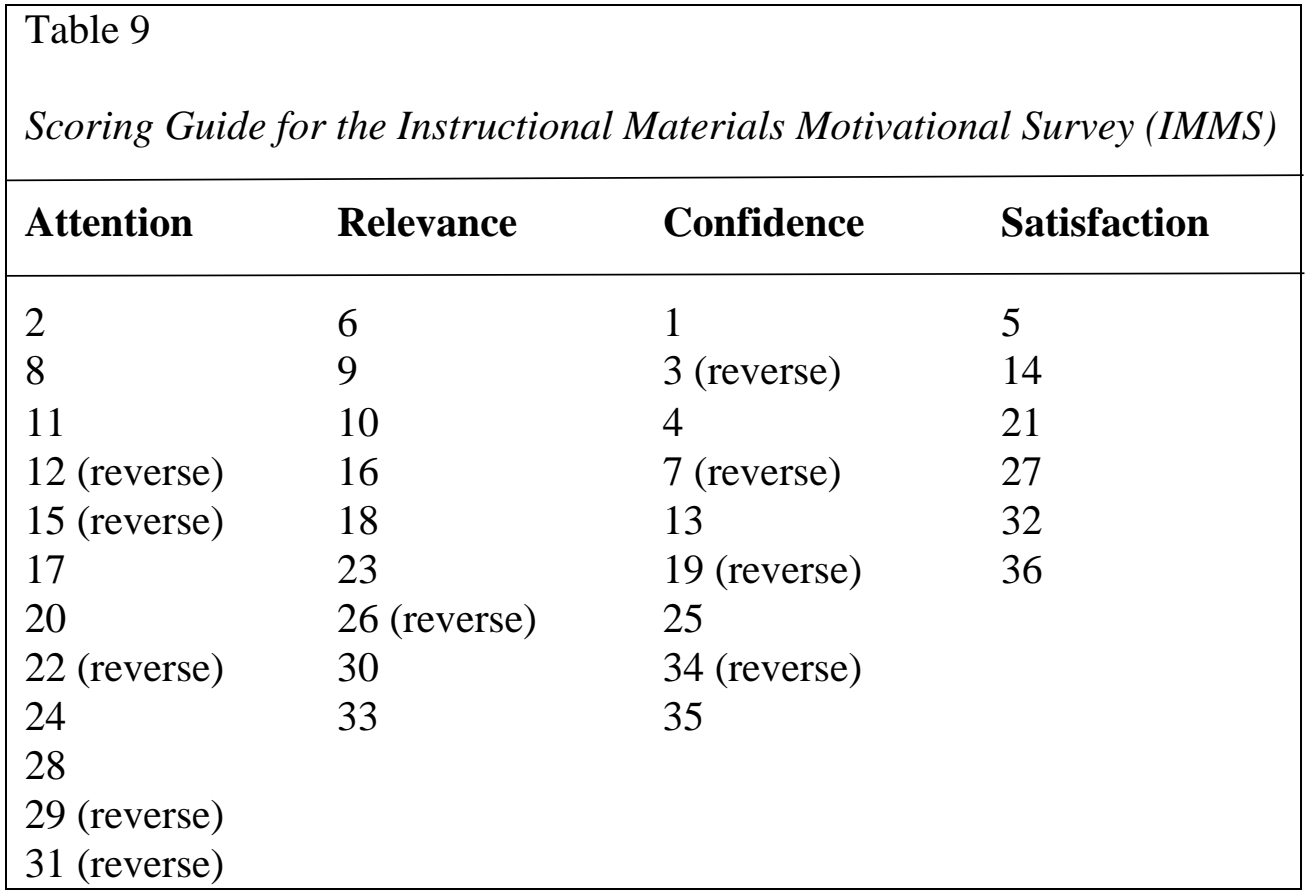


Table 10: Course A Scoring Results of the Course Interest Survey (CIS)

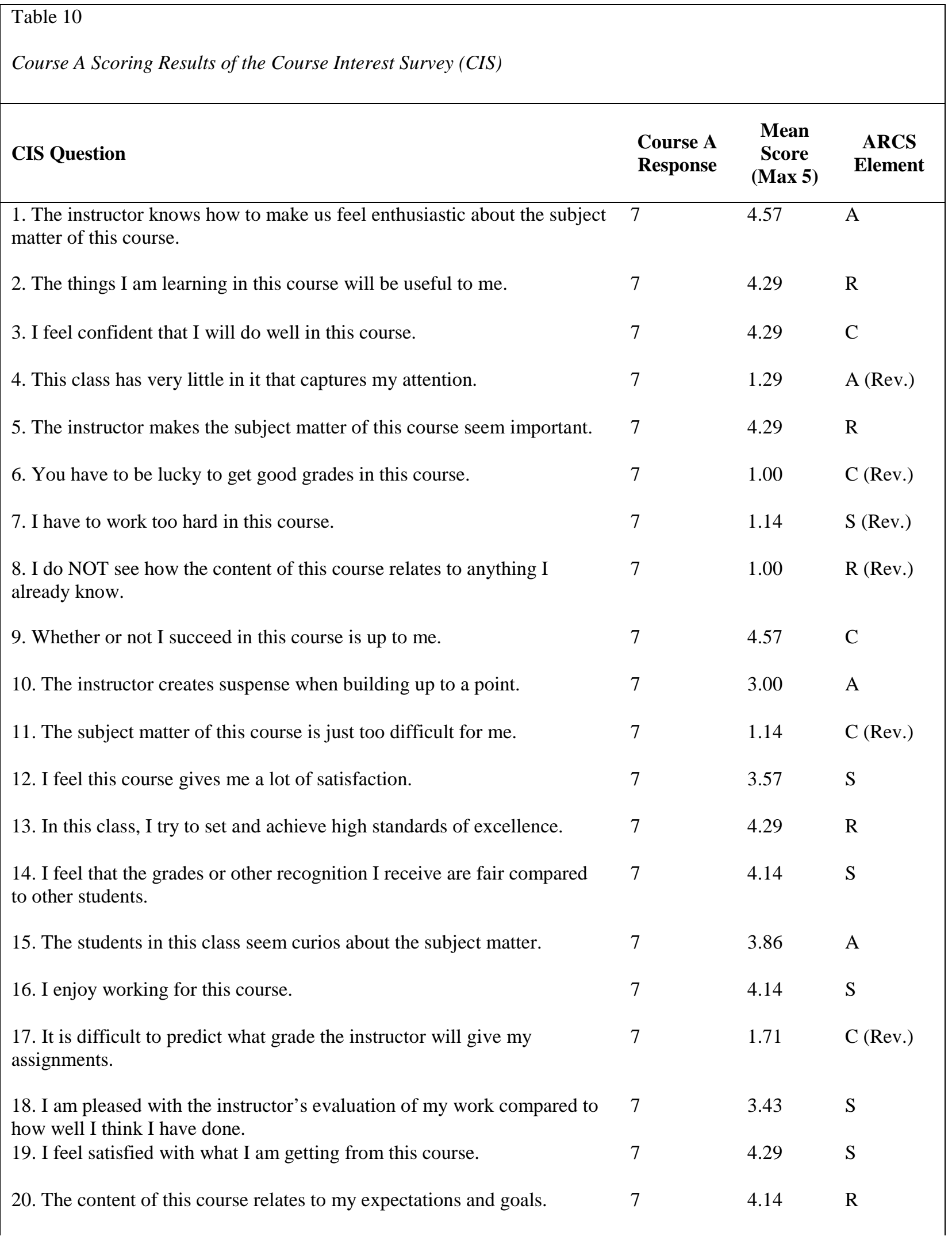




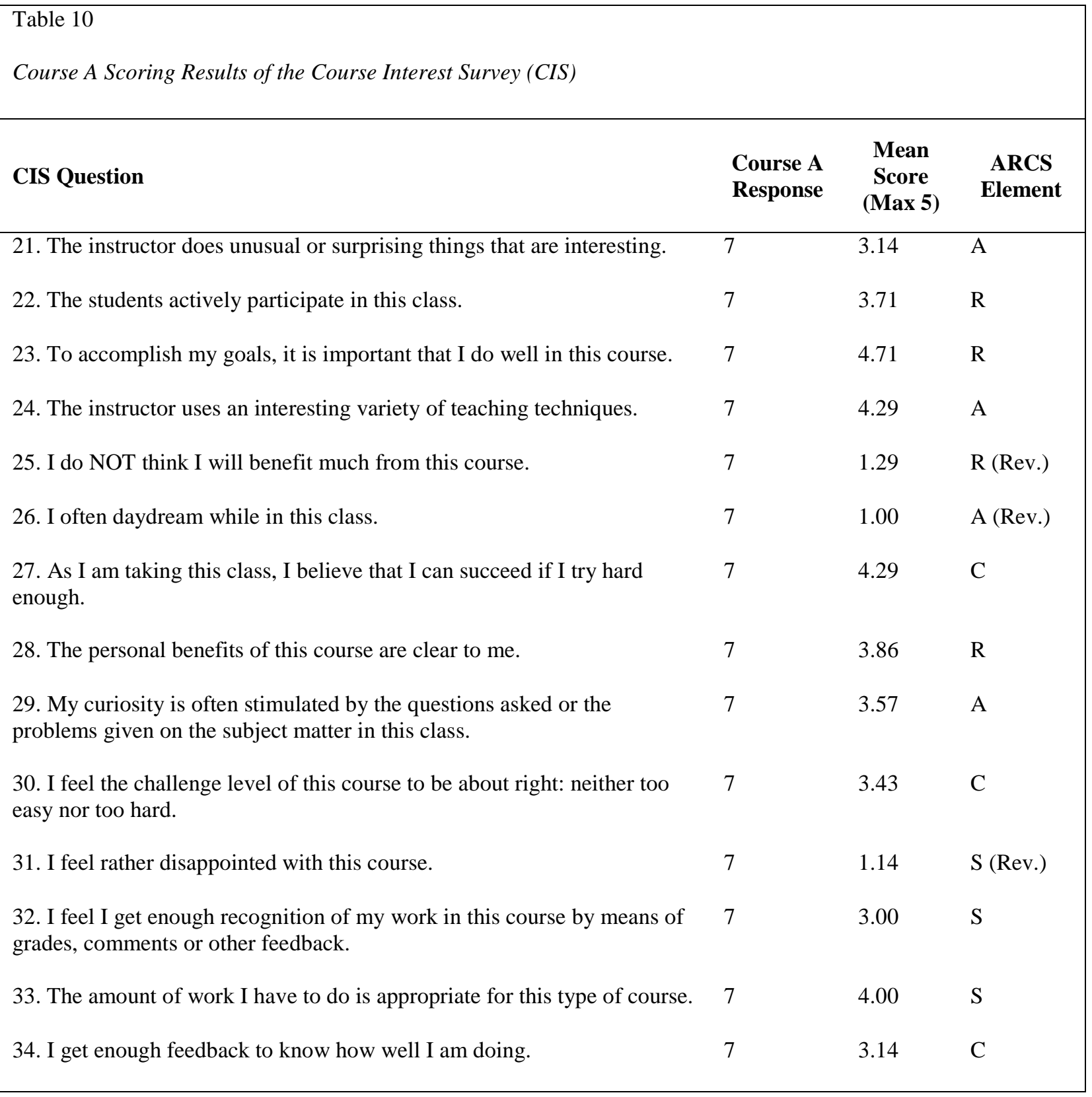


Table 11: Course A CIS Motivational Averages

\begin{tabular}{|c|c|}
\hline Table 11 & \\
Course A CIS Motivational Averages \\
\hline ARCS Element & Course A CIS Avg. \\
\hline Attention & 3.77 \\
Relevance & 4.11 \\
Confidence & 3.89 \\
Satisfaction & 3.81 \\
\hline
\end{tabular}


Table 12: Course A Scoring Results of the Instructional Materials Motivation Scale (IMMS)

\begin{tabular}{|c|c|c|c|}
\hline IMMS Question & $\begin{array}{c}\text { Course } \\
\text { A } \\
\text { Response }\end{array}$ & $\begin{array}{c}\text { Mean } \\
\text { Score } \\
\text { (Max. 5) }\end{array}$ & $\begin{array}{c}\text { ARCS } \\
\text { Element }\end{array}$ \\
\hline $\begin{array}{l}\text { 1. When I first looked at this course, I had the impression that it would be } \\
\text { easy for me. }\end{array}$ & 7 & 2.14 & $\mathrm{C}$ \\
\hline $\begin{array}{l}\text { 2. There is something interesting at the beginning of each lesson that gets } \\
\text { my attention. }\end{array}$ & 7 & 3.29 & A \\
\hline $\begin{array}{l}\text { 3. This course material was more difficult to understand than I would like } \\
\text { it to be. }\end{array}$ & 7 & 1.29 & C (Rev.) \\
\hline $\begin{array}{l}\text { 4. After reading the introductory information, I felt confident that I knew } \\
\text { what I was supposed to learn from each lesson in this course. }\end{array}$ & 7 & 3.71 & $\mathrm{C}$ \\
\hline $\begin{array}{l}\text { 5. Completing the exercises in each lesson gave me a satisfying feeling of } \\
\text { accomplishment. }\end{array}$ & 7 & 4.29 & $\mathrm{~S}$ \\
\hline $\begin{array}{l}\text { 6. It is clear to me how the content of this course is related to things I } \\
\text { already know. }\end{array}$ & 7 & 4.57 & $\mathrm{R}$ \\
\hline $\begin{array}{l}\text { 7. Many of the resources have so much information that it is hard to pick } \\
\text { out and remember the important points. }\end{array}$ & 7 & 1.43 & C (Rev.) \\
\hline 8. The materials are eye-catching. & 7 & 3.71 & A \\
\hline $\begin{array}{l}\text { 9. There were stories, pictures, or examples that showed me how this } \\
\text { material could be important to some people. }\end{array}$ & 7 & 4.14 & $\mathrm{R}$ \\
\hline 10. Completing this course successfully is important to me. & 7 & 4.86 & $\mathrm{R}$ \\
\hline 11. The quality of the writing helped to hold my attention. & 7 & 3.43 & A \\
\hline $\begin{array}{l}\text { 12. This course lessons were so abstract that it was hard to keep my } \\
\text { attention on them. }\end{array}$ & 7 & 1.14 & A (Rev.) \\
\hline 13. As I worked on each lesson, I was confident I could learn the content. & 7 & 4.14 & $\mathrm{C}$ \\
\hline $\begin{array}{l}\text { 14. I enjoyed this course so much that I would like to know more about } \\
\text { this topic. }\end{array}$ & 7 & 4.57 & S \\
\hline 15. The resources for this course look dry and unappealing. & 7 & 1.43 & A (Rev.) \\
\hline 16. The content of this course is relevant to my interests. & 7 & 4.43 & $\mathrm{R}$ \\
\hline 17. The way the information is arranged helped keep my attention. & 7 & 4.29 & A \\
\hline $\begin{array}{l}\text { 18. There are examples or explanations of how people can use the } \\
\text { knowledge from this course. }\end{array}$ & 7 & 4.29 & $\mathrm{R}$ \\
\hline
\end{tabular}




\begin{tabular}{|c|c|c|c|}
\hline IMMS Question & $\begin{array}{c}\text { Course } \\
\text { A } \\
\text { Response } \\
\end{array}$ & $\begin{array}{c}\text { Mean } \\
\text { Score } \\
\text { (Max. 5) }\end{array}$ & $\begin{array}{c}\text { ARCS } \\
\text { Element }\end{array}$ \\
\hline 19. The exercises in this course are too difficult. & 7 & 1.29 & C (Rev.) \\
\hline 20. This course has things that stimulate my curiosity. & 7 & 4.00 & A \\
\hline 21. I really enjoyed studying the lessons in this course. & 7 & 4.00 & $\mathrm{~S}$ \\
\hline $\begin{array}{l}\text { 22. The amount of repetition in course lessons caused me to get bored } \\
\text { sometimes. }\end{array}$ & 7 & 1.14 & A (Rev.) \\
\hline $\begin{array}{l}\text { 23. The content and style of writing in the lessons convey the impression } \\
\text { that its content is worth knowing. }\end{array}$ & 7 & 4.00 & $\mathrm{R}$ \\
\hline 24. I learned some things that were surprising or unexpected. & 7 & 3.71 & A \\
\hline $\begin{array}{l}\text { 25. After working on the lessons, I was confident that I would be able to } \\
\text { pass the course. }\end{array}$ & 7 & 4.29 & $\mathrm{C}$ \\
\hline $\begin{array}{l}\text { 26. This course is not relevant to my needs because I already knew most } \\
\text { of the material. }\end{array}$ & 7 & 1.29 & R (Rev.) \\
\hline $\begin{array}{l}\text { 27. The wording of feedback after the exercises, or other comments on the } \\
\text { lessons, helped me feel rewarded for my efforts. }\end{array}$ & 7 & 3.14 & $\mathrm{~S}$ \\
\hline $\begin{array}{l}\text { 28. The variety of readings, exercises, illustrations, etc., helped keep my } \\
\text { attention on the lessons. }\end{array}$ & 7 & 3.86 & A \\
\hline 29. The style of writing used in the course resources is boring. & 7 & 1.43 & A (Rev.) \\
\hline $\begin{array}{l}\text { 30. I could relate the content of this course to things I have seen, done, or } \\
\text { thought about in my own life. }\end{array}$ & 7 & 4.43 & $\mathrm{R}$ \\
\hline $\begin{array}{l}\text { 31. There were so many words on each page of reading that it was } \\
\text { irritating. }\end{array}$ & 7 & 1.14 & A (Rev.) \\
\hline 32. It felt good to successfully complete the lessons. & 7 & 4.57 & $\mathrm{~S}$ \\
\hline 33. The content of the lessons will be useful to me. & 7 & 4.57 & $\mathrm{R}$ \\
\hline 34. I could not really understand quite a bit of material in this course. & 7 & 1.14 & C (Rev.) \\
\hline $\begin{array}{l}\text { 35. The good organization of content helped me be confident that I would } \\
\text { learn the material. }\end{array}$ & 7 & 4.00 & $\mathrm{C}$ \\
\hline 36. It was a pleasure to work on such a well-designed course. & 7 & 4.29 & $\mathrm{~S}$ \\
\hline
\end{tabular}


Table 13: Course A IMMS Motivational Averages

\begin{tabular}{|c|c|}
\hline ARCS Element & Course A IMMS Avg. \\
\hline Attention & 3.77 \\
\hline Relevance & 4.11 \\
\hline Confidence & 3.89 \\
\hline Satisfaction & 3.81 \\
\hline
\end{tabular}


Table 14: Course B Scoring Results of the Course Interest Survey (CIS)

\begin{tabular}{|c|c|c|c|}
\hline CIS Question & $\begin{array}{l}\text { Course B } \\
\text { Response }\end{array}$ & $\begin{array}{l}\text { Mean } \\
\text { Score } \\
\text { (Max. 5) }\end{array}$ & $\begin{array}{l}\text { ARCS } \\
\text { Element }\end{array}$ \\
\hline $\begin{array}{l}\text { 1. The instructor knows how to make us feel enthusiastic about the } \\
\text { subject matter of this course. }\end{array}$ & 4 & 4.75 & $\mathrm{~A}$ \\
\hline 2. The things I am learning in this course will be useful to me. & 4 & 4.75 & $\mathrm{R}$ \\
\hline 3. I feel confident that I will do well in this course. & 4 & 5.00 & $\mathrm{C}$ \\
\hline 4. This class has very little in it that captures my attention. & 4 & 1.00 & A (Rev.) \\
\hline 5. The instructor makes the subject matter of this course seem important. & 4 & 4.50 & $\mathrm{R}$ \\
\hline 6. You have to be lucky to get good grades in this course. & 4 & 1.00 & C (Rev.) \\
\hline 4. I have to work too hard in this course. & 4 & 1.00 & S (Rev.) \\
\hline $\begin{array}{l}\text { 8. I do NOT see how the content of this course relates to anything I } \\
\text { already know. }\end{array}$ & 4 & 1.00 & R (Rev.) \\
\hline 9. Whether or not I succeed in this course is up to me. & 4 & 4.75 & $\mathrm{C}$ \\
\hline 10. The instructor creates suspense when building up to a point. & 4 & 2.50 & A \\
\hline 11. The subject matter of this course is just too difficult for me. & 4 & 1.00 & C (Rev.) \\
\hline 12. I feel this course gives me a lot of satisfaction. & 4 & 4.00 & $\mathrm{~S}$ \\
\hline 13. In this class, I try to set and achieve high standards of excellence. & 4 & 4.75 & $\mathrm{R}$ \\
\hline $\begin{array}{l}\text { 14. I feel that the grades or other recognition I receive are fair compared } \\
\text { to other students. }\end{array}$ & 4 & 5.00 & $\mathrm{~S}$ \\
\hline 15. The students in this class seem curios about the subject matter. & 4 & 4.50 & A \\
\hline 16. I enjoy working for this course. & 4 & 4.50 & $\mathrm{~S}$ \\
\hline $\begin{array}{l}\text { 17. It is difficult to predict what grade the instructor will give my } \\
\text { assignments. }\end{array}$ & 4 & 1.00 & C (Rev.) \\
\hline $\begin{array}{l}\text { 18. I am pleased with the instructor's evaluation of my work compared } \\
\text { to how well I think I have done. }\end{array}$ & 4 & 5.00 & $\mathrm{~S}$ \\
\hline 19. I feel satisfied with what I am getting from this course. & 4 & 4.75 & $\mathrm{~S}$ \\
\hline
\end{tabular}




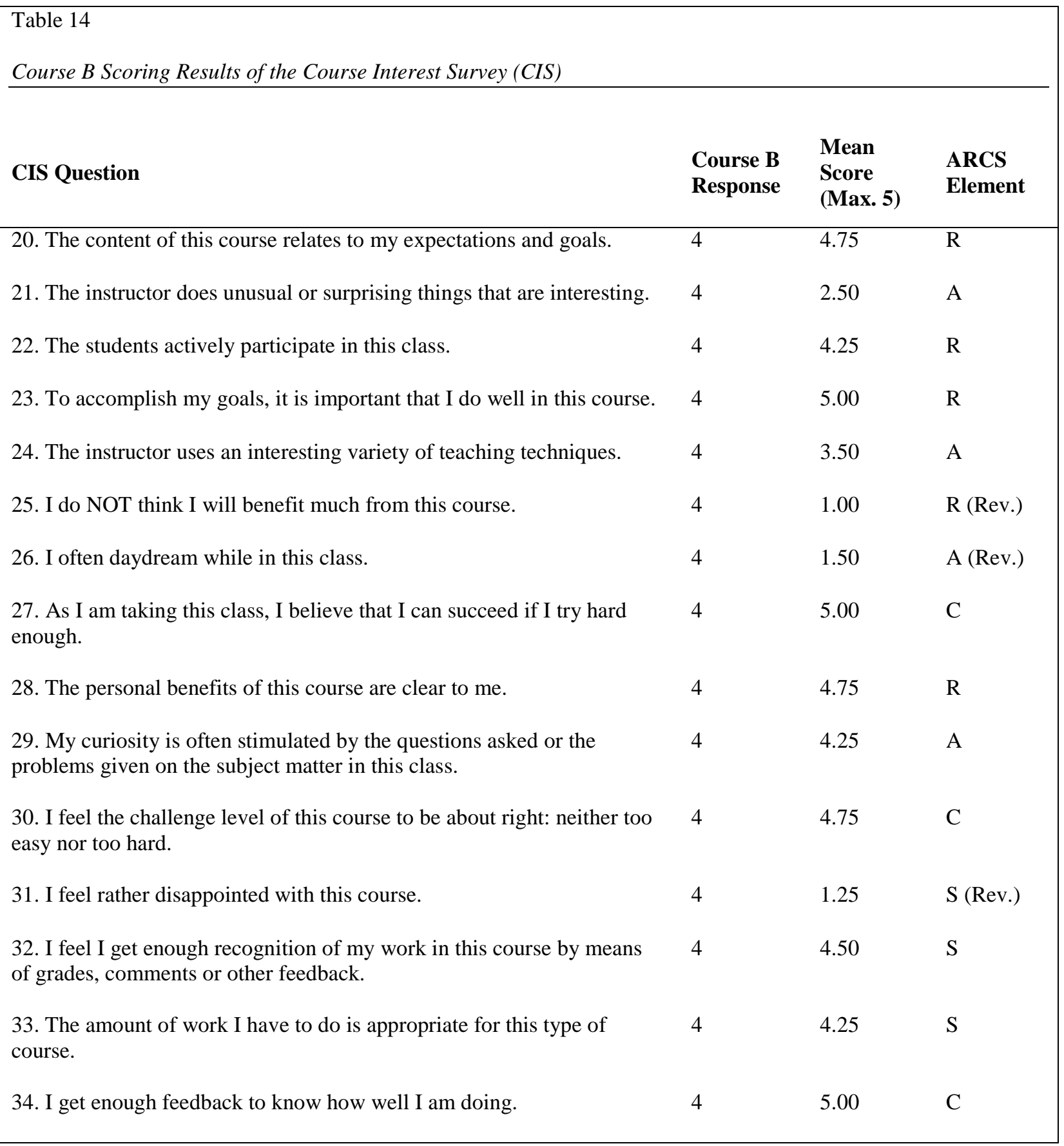


Table 15: Course B CIS Motivational Averages

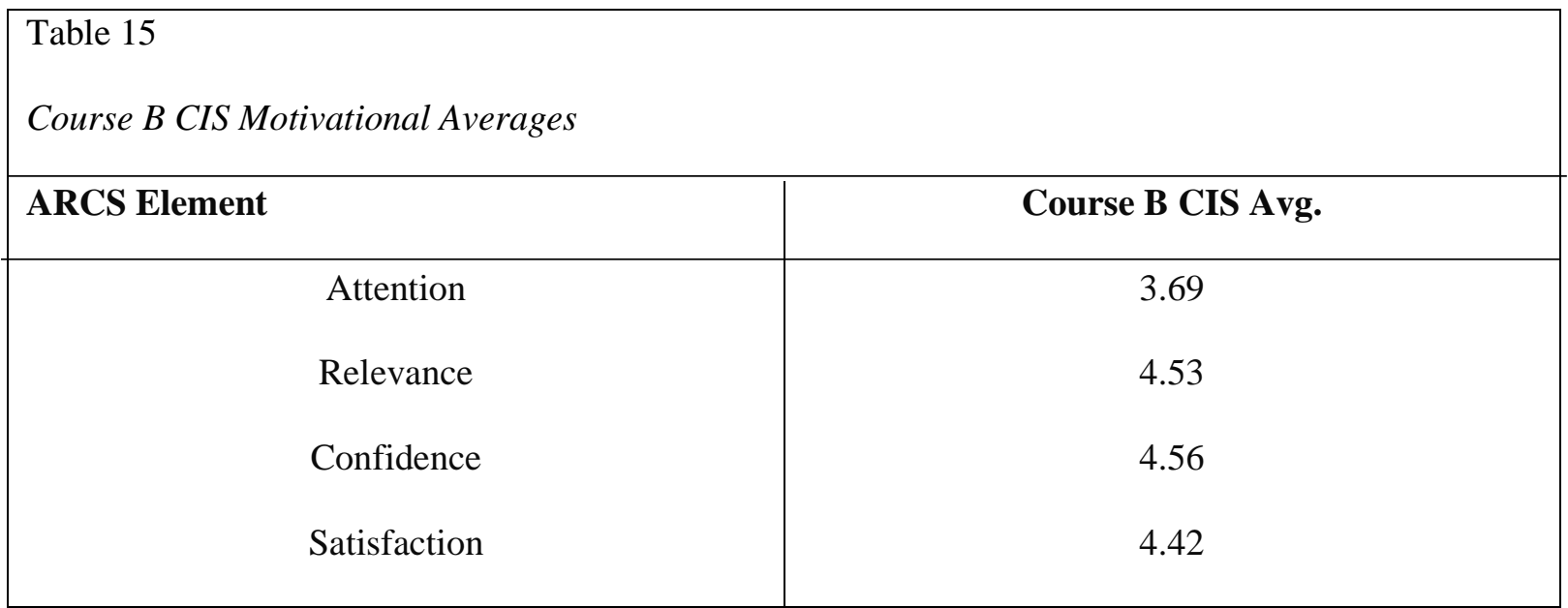


Table 16: Course B Scoring Results of the Instructional Materials Motivation Scale (IMMS)

Table 16

Course B Scoring Results of the Instructional Materials Motivational Scale (IMMS)

\begin{tabular}{|lccc}
\hline IMMS Question & $\begin{array}{c}\text { Course B } \\
\text { Response }\end{array}$ & $\begin{array}{c}\text { Mean } \\
\text { Score } \\
\text { (Max. 5) }\end{array}$ & $\begin{array}{c}\text { ARC } \\
\text { Eleme }\end{array}$ \\
\hline 1. When I first looked at this course, I had the impression that it would be & 2 & 3.50 & C
\end{tabular}
easy for me.

2. There is something interesting at the beginning of each lesson that gets 2 my attention.

A

3. This course material was more difficult to understand than I would like it 2 to be.

4. After reading the introductory information, I felt confident that I knew 2 what I was supposed to learn from each lesson in this course.

5. Completing the exercises in each lesson gave me a satisfying feeling of 2 accomplishment.

6. It is clear to me how the content of this course is related to things I 2 already know.

7. Many of the resources have so much information that it is hard to pick 2 out and remember the important points.

8. The materials are eye-catching.

9. There were stories, pictures, or examples that showed me how this material could be important to some people.

10. Completing this course successfully is important to me.

11. The quality of the writing helped to hold my attention.

12. This course lessons were so abstract that it was hard to keep my attention on them.

13. As I worked on each lesson, I was confident I could learn the content. 2

14. I enjoyed this course so much that I would like to know more about this 2 topic.

15. The resources for this course look dry and unappealing.

2

1.00

C (Rev.)

ARCS

Element 


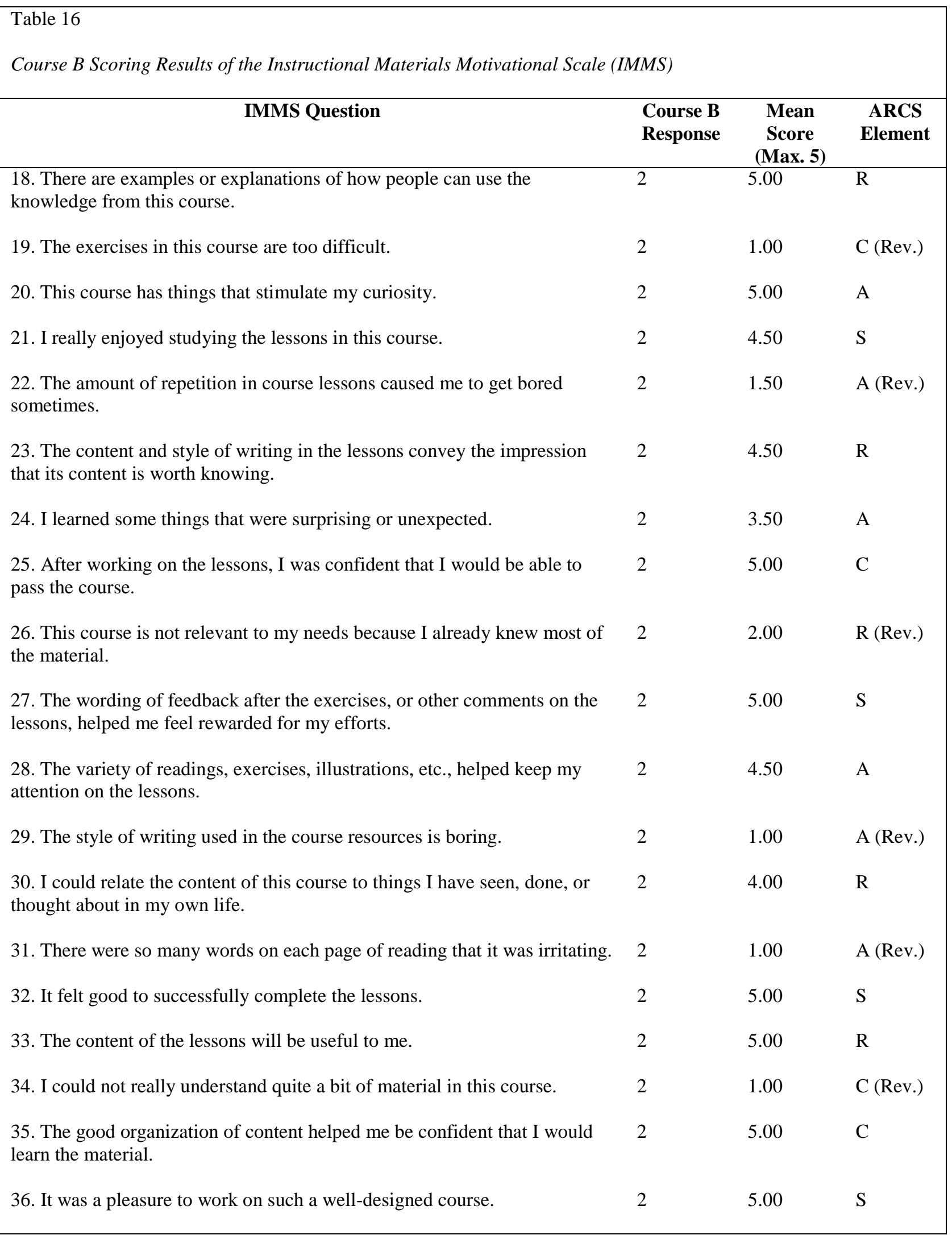


Table 17: Course B IMMS Motivational Averages

Table 17

Course B IMMS Motivational Averages

\begin{tabular}{|c|c|}
\hline ARCS Element & Course B IMMS Avg. \\
\hline Attention & 4.17 \\
Relevance & 4.56 \\
Confidence & 4.28 \\
Satisfaction & 4.70 \\
\hline
\end{tabular}


Table 18: Course C Scoring Results of the Course Interest Survey (CIS)

\begin{tabular}{|c|c|c|c|}
\hline \multicolumn{4}{|l|}{$\begin{array}{l}\text { Table } 18 \\
\text { Course C Scoring Results of the Course Interest Survey (CIS) }\end{array}$} \\
\hline CIS Question & $\begin{array}{l}\text { Course C } \\
\text { Response }\end{array}$ & $\begin{array}{l}\text { Mean } \\
\text { Score } \\
\text { (Max 5) }\end{array}$ & $\begin{array}{l}\text { ARCS } \\
\text { Element }\end{array}$ \\
\hline $\begin{array}{l}\text { 1. The instructor knows how to make us feel enthusiastic about the subject } \\
\text { matter of this course. }\end{array}$ & 7 & 4.29 & A \\
\hline 2. The things I am learning in this course will be useful to me. & 7 & 4.86 & $\mathrm{R}$ \\
\hline 3. I feel confident that I will do well in this course. & 7 & 4.57 & $\mathrm{C}$ \\
\hline 4. This class has very little in it that captures my attention. & 7 & 1.29 & A (Rev.) \\
\hline 5. The instructor makes the subject matter of this course seem important. & 7 & 4.29 & $\mathrm{R}$ \\
\hline 6. You have to be lucky to get good grades in this course. & 7 & 1.00 & C (Rev.) \\
\hline 7. I have to work too hard in this course. & 7 & 2.29 & S (Rev.) \\
\hline $\begin{array}{l}\text { 8. I do NOT see how the content of this course relates to anything I already } \\
\text { know. }\end{array}$ & 7 & 1.00 & R (Rev.) \\
\hline 9. Whether or not I succeed in this course is up to me. & 7 & 5.00 & $\mathrm{C}$ \\
\hline 10. The instructor creates suspense when building up to a point. & 7 & 2.00 & A \\
\hline 11. The subject matter of this course is just too difficult for me. & 7 & 1.00 & C (Rev.) \\
\hline 12. I feel this course gives me a lot of satisfaction. & 7 & 3.71 & S \\
\hline 13. In this class, I try to set and achieve high standards of excellence. & 7 & 4.57 & $\mathrm{R}$ \\
\hline $\begin{array}{l}\text { 14. I feel that the grades or other recognition I receive are fair compared to } \\
\text { other students. }\end{array}$ & 7 & 4.57 & S \\
\hline 15. The students in this class seem curios about the subject matter. & 7 & 4.29 & A \\
\hline 16. I enjoy working for this course. & 7 & 4.00 & S \\
\hline $\begin{array}{l}\text { 17. It is difficult to predict what grade the instructor will give my } \\
\text { assignments. }\end{array}$ & 7 & 1.14 & C (Rev.) \\
\hline $\begin{array}{l}\text { 18. I am pleased with the instructor's evaluation of my work compared to } \\
\text { how well I think I have done. }\end{array}$ & 7 & 4.57 & S \\
\hline 19. I feel satisfied with what I am getting from this course. & 7 & 4.57 & S \\
\hline
\end{tabular}




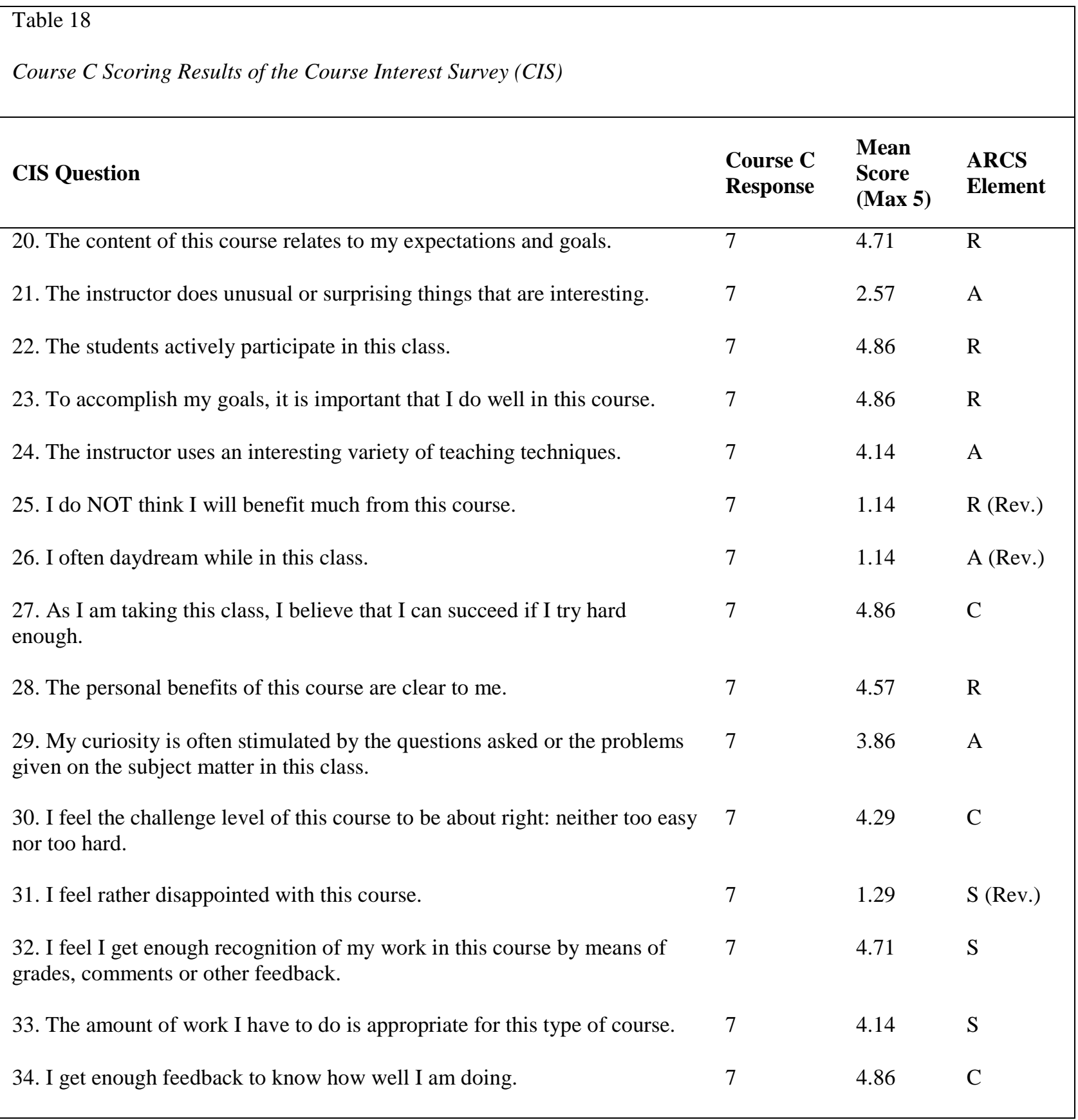


Table 19: Course C CIS Motivational Averages

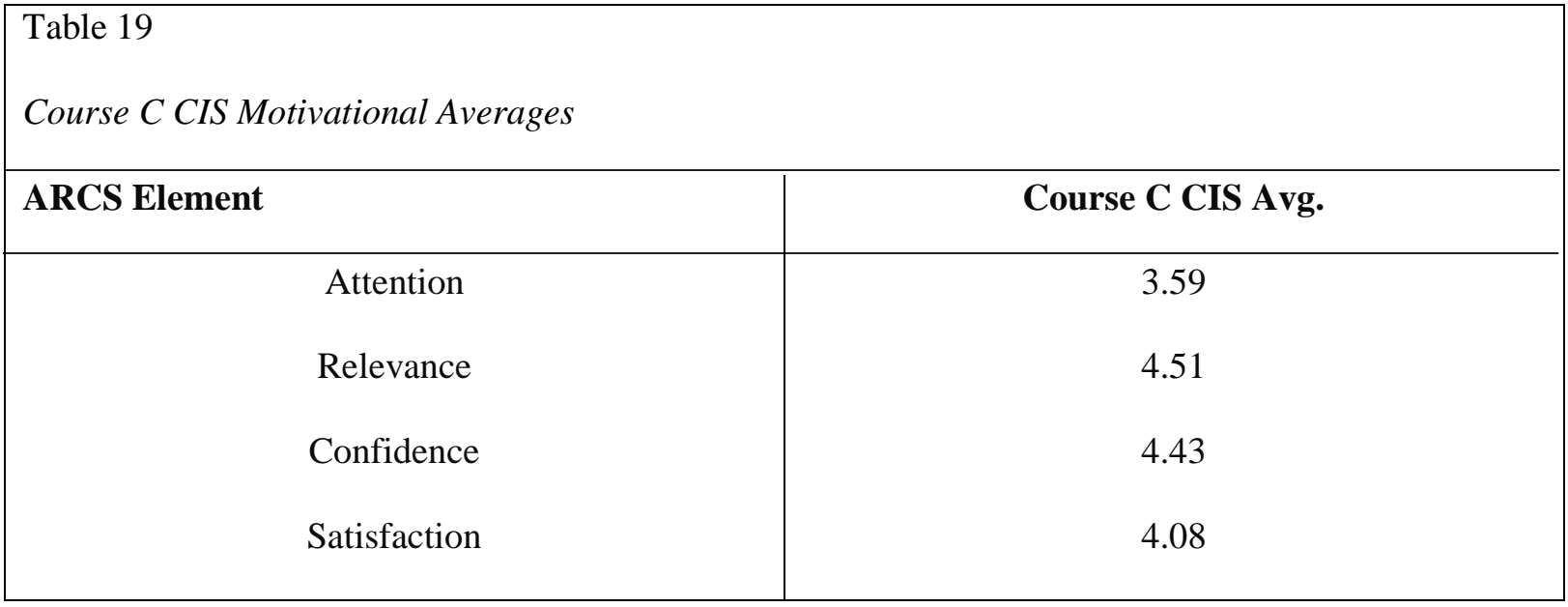


Table 20: Course C Scoring Results of the Instructional Materials Motivation Scale (IMMS)

\begin{tabular}{|c|c|c|c|}
\hline IMMS Question & $\begin{array}{c}\text { Course } \\
\text { C } \\
\text { Response }\end{array}$ & $\begin{array}{c}\text { Mean } \\
\text { Score } \\
\text { (Max. 5) }\end{array}$ & $\begin{array}{c}\text { ARCS } \\
\text { Element }\end{array}$ \\
\hline $\begin{array}{l}\text { 1. When I first looked at this course, I had the impression that it would be } \\
\text { easy for me. }\end{array}$ & 5 & 2.80 & $\mathrm{C}$ \\
\hline $\begin{array}{l}\text { 2. There is something interesting at the beginning of each lesson that gets } \\
\text { my attention. }\end{array}$ & 5 & 3.60 & A \\
\hline $\begin{array}{l}\text { 3. This course material was more difficult to understand than I would like } \\
\text { it to be. }\end{array}$ & 5 & 1.00 & C (Rev.) \\
\hline $\begin{array}{l}\text { 4. After reading the introductory information, I felt confident that I knew } \\
\text { what I was supposed to learn from each lesson in this course. }\end{array}$ & 5 & 4.80 & $\mathrm{C}$ \\
\hline $\begin{array}{l}\text { 5. Completing the exercises in each lesson gave me a satisfying feeling of } \\
\text { accomplishment. }\end{array}$ & 5 & 4.20 & S \\
\hline $\begin{array}{l}\text { 6. It is clear to me how the content of this course is related to things I } \\
\text { already know. }\end{array}$ & 5 & 4.60 & $\mathrm{R}$ \\
\hline $\begin{array}{l}\text { 7. Many of the resources have so much information that it is hard to pick } \\
\text { out and remember the important points. }\end{array}$ & 5 & 1.60 & C (Rev.) \\
\hline 8. The materials are eye-catching. & 5 & 3.80 & A \\
\hline $\begin{array}{l}\text { 9. There were stories, pictures, or examples that showed me how this } \\
\text { material could be important to some people. }\end{array}$ & 5 & 4.80 & $\mathrm{R}$ \\
\hline 10. Completing this course successfully is important to me. & 5 & 5.00 & $\mathrm{R}$ \\
\hline 11. The quality of the writing helped to hold my attention. & 5 & 4.60 & A \\
\hline $\begin{array}{l}\text { 12. This course lessons were so abstract that it was hard to keep my } \\
\text { attention on them. }\end{array}$ & 5 & 1.00 & A (Rev.) \\
\hline 13. As I worked on each lesson, I was confident I could learn the content. & 5 & 4.60 & $\mathrm{C}$ \\
\hline $\begin{array}{l}\text { 14. I enjoyed this course so much that I would like to know more about } \\
\text { this topic. }\end{array}$ & 5 & 4.60 & S \\
\hline 15. The resources for this course look dry and unappealing. & 5 & 1.20 & A (Rev.) \\
\hline 16. The content of this course is relevant to my interests. & 5 & 4.80 & $\mathrm{R}$ \\
\hline 17. The way the information is arranged helped keep my attention. & 5 & 4.20 & A \\
\hline $\begin{array}{l}\text { 18. There are examples or explanations of how people can use the } \\
\text { knowledge from this course. }\end{array}$ & 5 & 4.60 & $\mathrm{R}$ \\
\hline
\end{tabular}




\begin{tabular}{|c|c|c|c|}
\hline IMMS Question & $\begin{array}{c}\text { Course } \\
\text { C } \\
\text { Response }\end{array}$ & $\begin{array}{c}\text { Mean } \\
\text { Score } \\
\text { (Max. 5) }\end{array}$ & $\begin{array}{c}\text { ARCS } \\
\text { Element }\end{array}$ \\
\hline 19. The exercises in this course are too difficult. & 5 & 1.00 & C (Rev.) \\
\hline 20. This course has things that stimulate my curiosity. & 5 & 4.60 & A \\
\hline 21. I really enjoyed studying the lessons in this course. & 5 & 4.20 & $\mathrm{~S}$ \\
\hline $\begin{array}{l}\text { 22. The amount of repetition in course lessons caused me to get bored } \\
\text { sometimes. }\end{array}$ & 5 & 1.40 & A (Rev.) \\
\hline $\begin{array}{l}\text { 23. The content and style of writing in the lessons convey the impression } \\
\text { that its content is worth knowing. }\end{array}$ & 5 & 4.80 & $\mathrm{R}$ \\
\hline 24. I learned some things that were surprising or unexpected. & 5 & 4.40 & A \\
\hline $\begin{array}{l}\text { 25. After working on the lessons, I was confident that I would be able to } \\
\text { pass the course. }\end{array}$ & 5 & 4.80 & $\mathrm{C}$ \\
\hline $\begin{array}{l}\text { 26. This course is not relevant to my needs because I already knew most } \\
\text { of the material. }\end{array}$ & 5 & 1.00 & R (Rev.) \\
\hline $\begin{array}{l}\text { 27. The wording of feedback after the exercises, or other comments on the } \\
\text { lessons, helped me feel rewarded for my efforts. }\end{array}$ & 5 & 4.80 & $\mathrm{~S}$ \\
\hline $\begin{array}{l}\text { 28. The variety of readings, exercises, illustrations, etc., helped keep my } \\
\text { attention on the lessons. }\end{array}$ & 5 & 4.20 & A \\
\hline 29. The style of writing used in the course resources is boring. & 5 & 1.00 & A (Rev.) \\
\hline $\begin{array}{l}\text { 30. I could relate the content of this course to things I have seen, done, or } \\
\text { thought about in my own life. }\end{array}$ & 5 & 4.40 & $\mathrm{R}$ \\
\hline $\begin{array}{l}\text { 31. There were so many words on each page of reading that it was } \\
\text { irritating. }\end{array}$ & 5 & 1.20 & A (Rev.) \\
\hline 32. It felt good to successfully complete the lessons. & 5 & 4.40 & $\mathrm{~S}$ \\
\hline 33. The content of the lessons will be useful to me. & 5 & 5.00 & $\mathrm{R}$ \\
\hline 34. I could not really understand quite a bit of material in this course. & 5 & 1.20 & C (Rev.) \\
\hline $\begin{array}{l}\text { 35. The good organization of content helped me be confident that I would } \\
\text { learn the material. }\end{array}$ & 5 & 4.60 & $\mathrm{C}$ \\
\hline 36. It was a pleasure to work on such a well-designed course. & 5 & 4.40 & $\mathrm{~S}$ \\
\hline
\end{tabular}


Table 21: Course C IMMS Motivational Averages

\begin{tabular}{|c|c|}
\hline ARCS Element & Course C IMMS Avg. \\
\hline Attention & 4.05 \\
\hline Relevance & 4.67 \\
\hline Confidence & 4.09 \\
\hline Satisfaction & 4.43 \\
\hline
\end{tabular}


Table 22: Course D Scoring Results of the Course Interest Survey (CIS)

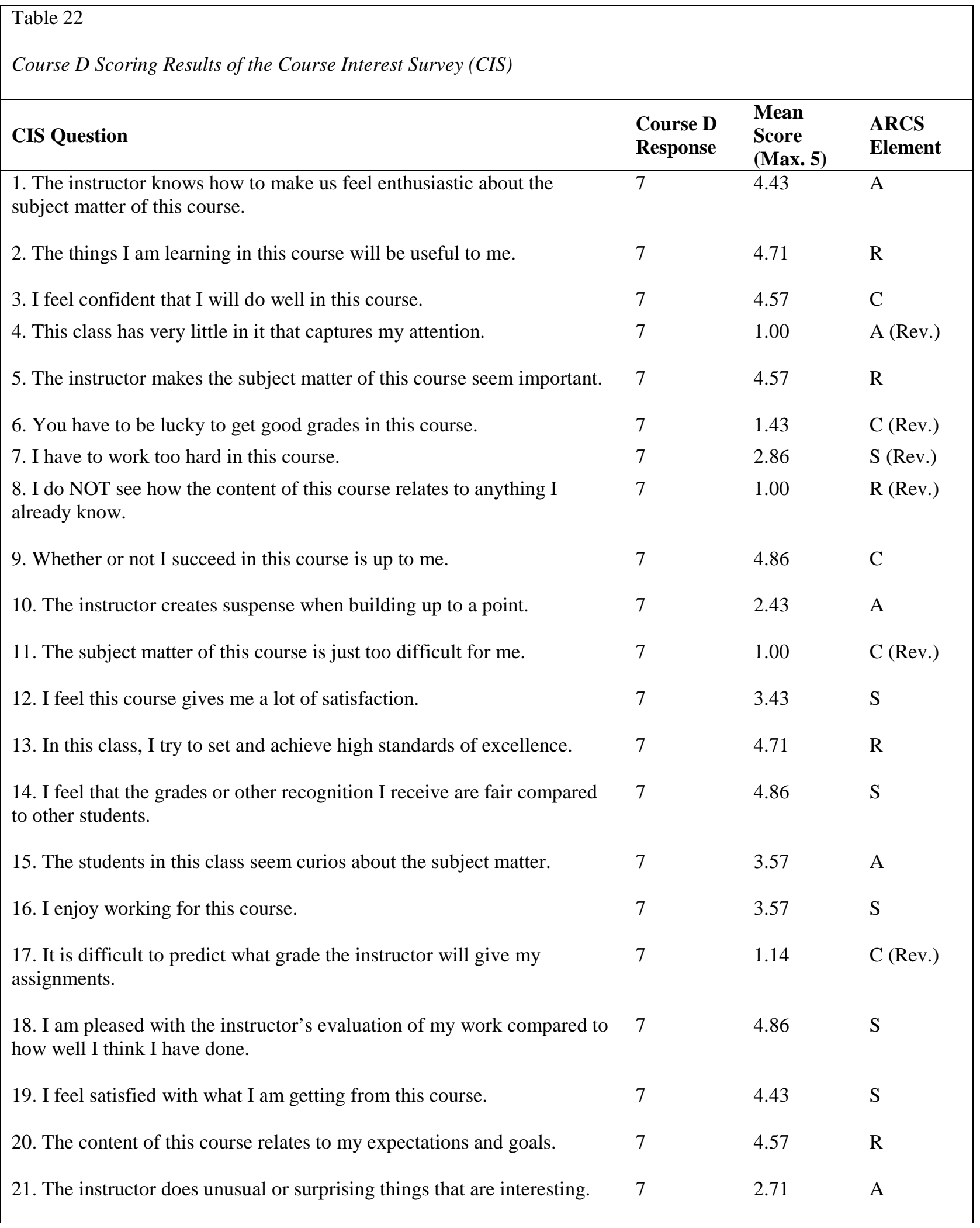




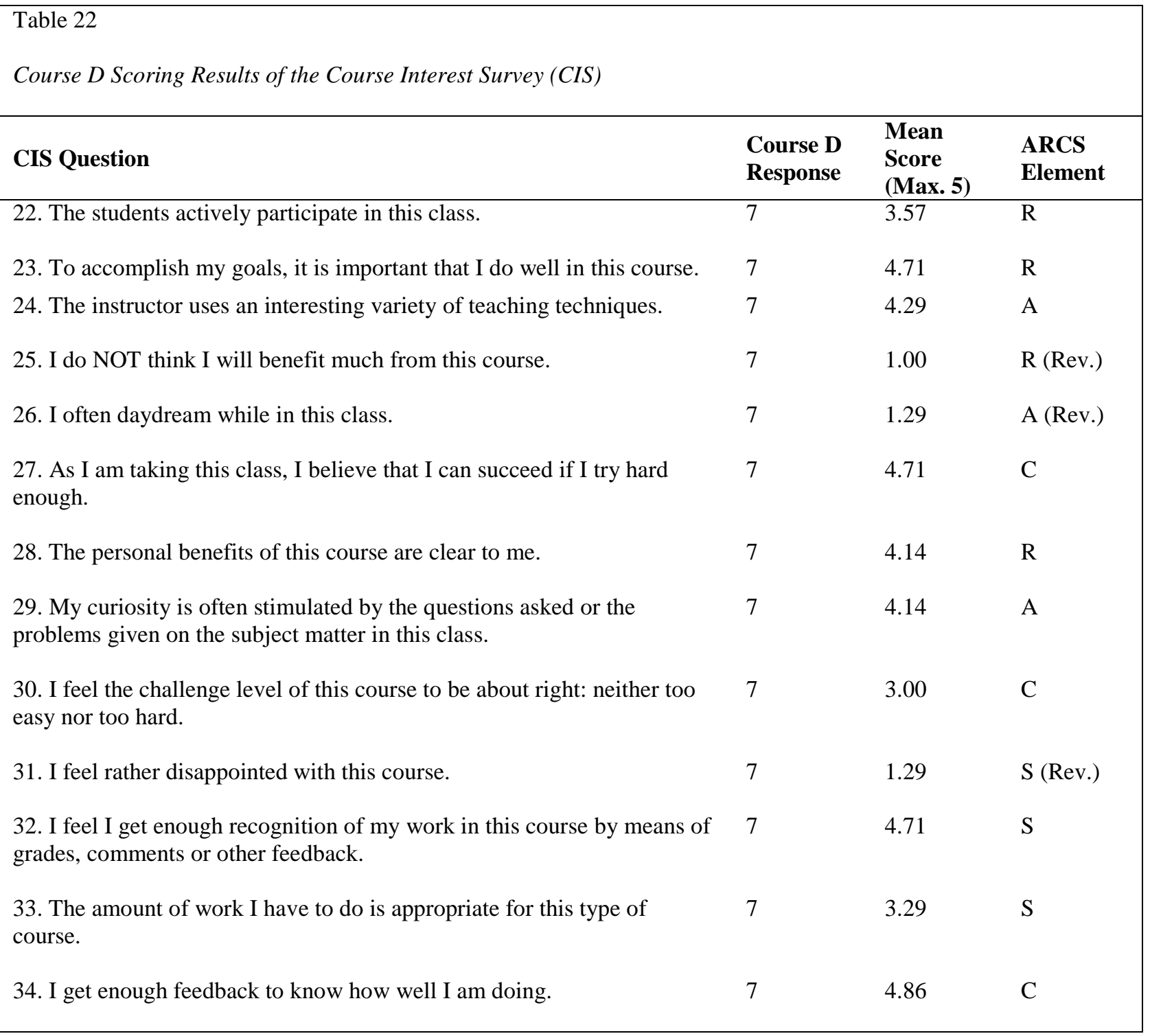


Table 23: Course D CIS Motivational Averages

Table 23

Course D CIS Motivational Averages

\begin{tabular}{|c|c|}
\hline ARCS Element & Course C CIS Avg. \\
\hline Attention & 3.66 \\
Relevance & 4.33 \\
Confidence & 4.18 \\
Satisfaction & 3.89 \\
\hline
\end{tabular}


Table 24: Course D Scoring Results of the Instructional Materials Motivation Scale (IMMS)

\begin{tabular}{|c|c|c|c|}
\hline IMMS Question & $\begin{array}{l}\text { Course D } \\
\text { Response }\end{array}$ & $\begin{array}{c}\text { Mean } \\
\text { Score } \\
\text { (Max. 5) }\end{array}$ & $\begin{array}{c}\text { ARCS } \\
\text { Element }\end{array}$ \\
\hline $\begin{array}{l}\text { 1. When I first looked at this course, I had the impression that it would be easy } \\
\text { for me. }\end{array}$ & 7 & 3.29 & $\mathrm{C}$ \\
\hline $\begin{array}{l}\text { 2. There is something interesting at the beginning of each lesson that gets my } \\
\text { attention. }\end{array}$ & 7 & 3.14 & A \\
\hline $\begin{array}{l}\text { 3. This course material was more difficult to understand than I would like it to } \\
\text { be. }\end{array}$ & 7 & 1.29 & C (Rev.) \\
\hline $\begin{array}{l}\text { 4. After reading the introductory information, I felt confident that I knew what I } \\
\text { was supposed to learn from each lesson in this course. }\end{array}$ & 7 & 3.86 & $\mathrm{C}$ \\
\hline $\begin{array}{l}\text { 5. Completing the exercises in each lesson gave me a satisfying feeling of } \\
\text { accomplishment. }\end{array}$ & 7 & 3.57 & $\mathrm{~S}$ \\
\hline $\begin{array}{l}\text { 6. It is clear to me how the content of this course is related to things I already } \\
\text { know. }\end{array}$ & 7 & 4.57 & $\mathrm{R}$ \\
\hline $\begin{array}{l}\text { 7. Many of the resources have so much information that it is hard to pick out and } \\
\text { remember the important points. }\end{array}$ & 7 & 2.43 & C (Rev.) \\
\hline 8. The materials are eye-catching. & 7 & 3.43 & A \\
\hline $\begin{array}{l}\text { 9. There were stories, pictures, or examples that showed me how this material } \\
\text { could be important to some people. }\end{array}$ & 7 & 4.57 & $\mathrm{R}$ \\
\hline 10. Completing this course successfully is important to me. & 7 & 5.00 & $\mathrm{R}$ \\
\hline 11. The quality of the writing helped to hold my attention. & 7 & 3.43 & A \\
\hline $\begin{array}{l}\text { 12. This course lessons were so abstract that it was hard to keep my attention on } \\
\text { them. }\end{array}$ & 7 & 1.43 & A (Rev.) \\
\hline 13. As I worked on each lesson, I was confident I could learn the content. & 7 & 4.43 & $\mathrm{C}$ \\
\hline $\begin{array}{l}\text { 14. I enjoyed this course so much that I would like to know more about this } \\
\text { topic. }\end{array}$ & 7 & 3.57 & $\mathrm{~S}$ \\
\hline 15. The resources for this course look dry and unappealing. & 7 & 1.43 & A (Rev.) \\
\hline 16. The content of this course is relevant to my interests. & 7 & 4.57 & $\mathrm{R}$ \\
\hline 17. The way the information is arranged helped keep my attention. & 7 & 3.86 & A \\
\hline $\begin{array}{l}\text { 18. There are examples or explanations of how people can use the knowledge } \\
\text { from this course. }\end{array}$ & 7 & 4.71 & $\mathrm{R}$ \\
\hline
\end{tabular}




\begin{tabular}{|c|c|c|c|}
\hline IMMS Question & $\begin{array}{l}\text { Course D } \\
\text { Response }\end{array}$ & $\begin{array}{c}\text { Mean } \\
\text { Score } \\
\text { (Max. 5) }\end{array}$ & $\begin{array}{c}\text { ARCS } \\
\text { Element }\end{array}$ \\
\hline 19. The exercises in this course are too difficult. & 7 & 1.29 & C (Rev.) \\
\hline 20. This course has things that stimulate my curiosity. & 7 & 4.00 & A \\
\hline 21. I really enjoyed studying the lessons in this course. & 7 & 3.57 & S \\
\hline $\begin{array}{l}\text { 22. The amount of repetition in course lessons caused me to get bored } \\
\text { sometimes. }\end{array}$ & 7 & 2.00 & A (Rev.) \\
\hline $\begin{array}{l}\text { 23. The content and style of writing in the lessons convey the impression that its } \\
\text { content is worth knowing. }\end{array}$ & 7 & 4.29 & $\mathrm{R}$ \\
\hline 24. I learned some things that were surprising or unexpected. & 7 & 4.14 & A \\
\hline $\begin{array}{l}\text { 25. After working on the lessons, I was confident that I would be able to pass the } \\
\text { course. }\end{array}$ & 7 & 4.86 & $\mathrm{C}$ \\
\hline $\begin{array}{l}\text { 26. This course is not relevant to my needs because I already knew most of the } \\
\text { material. }\end{array}$ & 7 & 2.00 & R (Rev.) \\
\hline $\begin{array}{l}\text { 27. The wording of feedback after the exercises, or other comments on the } \\
\text { lessons, helped me feel rewarded for my efforts. }\end{array}$ & 7 & 4.71 & S \\
\hline $\begin{array}{l}\text { 28. The variety of readings, exercises, illustrations, etc., helped keep my } \\
\text { attention on the lessons. }\end{array}$ & 7 & 3.71 & A \\
\hline 29. The style of writing used in the course resources is boring. & 7 & 1.71 & A (Rev.) \\
\hline $\begin{array}{l}\text { 30. I could relate the content of this course to things I have seen, done, or } \\
\text { thought about in my own life. }\end{array}$ & 7 & 4.57 & $\mathrm{R}$ \\
\hline 31. There were so many words on each page of reading that it was irritating. & 7 & 2.00 & A (Rev.) \\
\hline 32. It felt good to successfully complete the lessons. & 7 & 4.29 & $\mathrm{~S}$ \\
\hline 33. The content of the lessons will be useful to me. & 7 & 4.29 & $\mathrm{R}$ \\
\hline 34. I could not really understand quite a bit of material in this course. & 7 & 1.00 & C (Rev.) \\
\hline $\begin{array}{l}\text { 35. The good organization of content helped me be confident that I would learn } \\
\text { the material. }\end{array}$ & 7 & 4.57 & $\mathrm{C}$ \\
\hline 36. It was a pleasure to work on such a well-designed course. & 7 & 4.29 & $\mathrm{~S}$ \\
\hline
\end{tabular}


Table 25: Course D IMMS Motivational Averages

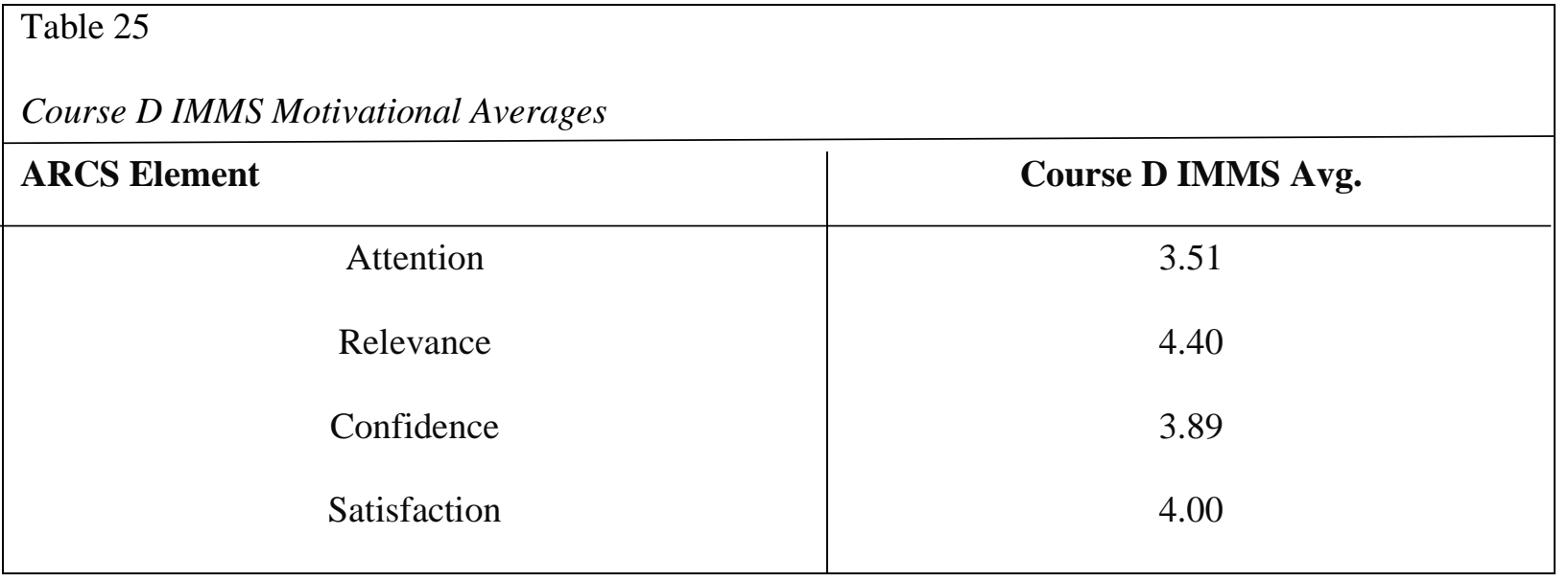


Table 26: Course Syllabus Comparison Chart (completed)

\begin{tabular}{|c|c|c|c|c|}
\hline \multicolumn{5}{|c|}{\begin{tabular}{|l} 
Table 26 \\
Course Syllabi Comparison Chart (completed)
\end{tabular}} \\
\hline $\begin{array}{c}\text { ARCS } \\
\text { Elements }\end{array}$ & Course A (ID) & Course B (ID) & Course C (QM) & Course D (QM) \\
\hline $\begin{array}{l}\text { Attention- } \\
\text { getting or } \\
\text { sustaining } \\
\text { features }\end{array}$ & $\begin{array}{l}\text { Intro is designed to } \\
\text { arouse interest in the } \\
\text { course materials and } \\
\text { activities. } \\
\text { Student choice in } \\
\text { assignment content } \\
\text { provides variability } \\
\text { and promotes inquiry, } \\
\text { which helps to retain } \\
\text { attention or interest. }\end{array}$ & $\begin{array}{l}\text { Intro is designed to } \\
\text { arouse interest in the } \\
\text { course materials and } \\
\text { activities; } \\
\text { Student choice in } \\
\text { assignment content } \\
\text { provides variability } \\
\text { and promotes inquiry, } \\
\text { which helps to retain } \\
\text { attention or interest. }\end{array}$ & $\begin{array}{l}\text { Intro is designed to } \\
\text { arouse interest in the } \\
\text { course materials and } \\
\text { activities; } \\
\text { Student choice in } \\
\text { assignment content } \\
\text { provides variability } \\
\text { and promotes inquiry, } \\
\text { which helps to retain } \\
\text { attention or interest. }\end{array}$ & $\begin{array}{l}\text { Intro is designed to } \\
\text { arouse interest in the } \\
\text { course materials and } \\
\text { activities; } \\
\text { Student choice in } \\
\text { assignment content } \\
\text { provides variability } \\
\text { and promotes } \\
\text { inquiry, which helps } \\
\text { to retain attention or } \\
\text { interest. }\end{array}$ \\
\hline $\begin{array}{l}\text { Relevance- } \\
\text { generating } \\
\text { features }\end{array}$ & $\begin{array}{l}\text { Intro is designed to } \\
\text { prompt goal } \\
\text { orientation and } \\
\text { motive-matching by } \\
\text { allowing student } \\
\text { choice in assignment } \\
\text { content } \\
\end{array}$ & $\begin{array}{l}\text { Intro is designed to } \\
\text { prompt goal } \\
\text { orientation and } \\
\text { motive-matching by } \\
\text { allowing student } \\
\text { choice in assignment } \\
\text { content } \\
\end{array}$ & $\begin{array}{l}\text { Intro is designed to } \\
\text { prompt goal } \\
\text { orientation and } \\
\text { motive-matching by } \\
\text { allowing student } \\
\text { choice in assignment } \\
\text { content } \\
\end{array}$ & $\begin{array}{l}\text { Intro is designed to } \\
\text { prompt goal } \\
\text { orientation and } \\
\text { motive-matching by } \\
\text { allowing student } \\
\text { choice in assignment } \\
\text { content } \\
\end{array}$ \\
\hline $\begin{array}{l}\text { Confidence- } \\
\text { generating } \\
\text { features }\end{array}$ & $\begin{array}{l}\text { Course objectives } \\
\text { provide clear learning } \\
\text { requirements; } \\
\text { Opportunities for } \\
\text { success and personal } \\
\text { control become } \\
\text { present with the design } \\
\text { decision to allow } \\
\text { student choice in } \\
\text { assignment content; } \\
\text { Open access to } \\
\text { professor }\end{array}$ & $\begin{array}{l}\text { Course objectives } \\
\text { provide clear learning } \\
\text { requirements; } \\
\text { Opportunities for } \\
\text { success and personal } \\
\text { control become } \\
\text { present with the design } \\
\text { decision to allow } \\
\text { student choice in } \\
\text { assignment content; } \\
\text { Open access to } \\
\text { professor }\end{array}$ & $\begin{array}{l}\text { Course objectives } \\
\text { provide clear learning } \\
\text { requirements; } \\
\text { Opportunities for } \\
\text { success and personal } \\
\text { control become } \\
\text { present with the } \\
\text { design decision to } \\
\text { allow student choice } \\
\text { in assignment } \\
\text { content; } \\
\text { Open access to } \\
\text { professor }\end{array}$ & $\begin{array}{l}\text { Course objectives } \\
\text { provide clear } \\
\text { learning } \\
\text { requirements; } \\
\text { Opportunities for } \\
\text { success and personal } \\
\text { control become } \\
\text { present with the } \\
\text { design decision to } \\
\text { allow student choice } \\
\text { in assignment } \\
\text { content; } \\
\text { Open access to } \\
\text { professor }\end{array}$ \\
\hline $\begin{array}{l}\text { Satisfaction- } \\
\text { generating } \\
\text { features }\end{array}$ & $\begin{array}{l}\text { Natural consequences } \\
\text { are reflected by each } \\
\text { student’s efforts in } \\
\text { using course- } \\
\text { recommended } \\
\text { technology tools to } \\
\text { create an online } \\
\text { education module; } \\
\text { Positive consequences } \\
\text { occur when the } \\
\text { module works as } \\
\text { planned or when } \\
\text { student learn hard } \\
\text { skills or techniques } \\
\text { useful in their }\end{array}$ & $\begin{array}{l}\text { Natural consequences } \\
\text { are reflected by each } \\
\text { student's efforts in } \\
\text { using course- } \\
\text { recommended } \\
\text { technology tools to } \\
\text { create an online } \\
\text { presentation; Positive } \\
\text { consequences occur } \\
\text { when the presentation } \\
\text { works as planned or } \\
\text { when student learn } \\
\text { hard skills or } \\
\text { techniques useful in } \\
\text { their profession or }\end{array}$ & $\begin{array}{l}\text { Natural consequences } \\
\text { are reflected by each } \\
\text { student's efforts in } \\
\text { using course- } \\
\text { recommended } \\
\text { technology tools to } \\
\text { create an online } \\
\text { assignments. } \\
\text { Positive } \\
\text { consequences occur } \\
\text { as assignment points } \\
\text { are earned while } \\
\text { knowledge is } \\
\text { demonstrated \& } \\
\text { evaluated. }\end{array}$ & $\begin{array}{c}\text { Natural } \\
\text { consequences are } \\
\text { reflected by each } \\
\text { student's efforts in } \\
\text { using course- } \\
\text { recommended } \\
\text { technology tools to } \\
\text { demonstrate } \\
\text { proficiency \& } \\
\text { complete } 5 \text { types of } \\
\text { assessments. } \\
\text { Positive } \\
\text { consequences occur } \\
\text { as assignment points } \\
\text { are earned while }\end{array}$ \\
\hline
\end{tabular}




\begin{tabular}{|c|c|c|c|c|}
\hline $\begin{array}{l}\text { Table } 26 \\
\text { Course Syl }\end{array}$ & i Comparison Chart & ompleted) & & \\
\hline $\begin{array}{c}\text { ARCS } \\
\text { Elements }\end{array}$ & Course A (ID) & Course B (ID) & Course C (QM) & Course D (QM) \\
\hline & $\begin{array}{l}\text { profession or further } \\
\text { studies; Equity exists } \\
\text { because all students } \\
\text { are required to use the } \\
\text { same technology tools } \\
\text { to create an education } \\
\text { module that properly } \\
\text { functions online }\end{array}$ & $\begin{array}{l}\text { further studies; Equity } \\
\text { exists because all } \\
\text { students are required } \\
\text { to use the same } \\
\text { technology tools to } \\
\text { create an online } \\
\text { presentation that } \\
\text { properly functions }\end{array}$ & $\begin{array}{l}\text { Equity exists because } \\
\text { all students are } \\
\text { required to use the } \\
\text { same technology tools } \\
\text { \& assessment } \\
\text { measures. }\end{array}$ & $\begin{array}{c}\text { knowledge is } \\
\text { demonstrated \& } \\
\text { evaluated. } \\
\text { Equity exists because } \\
\text { all students are } \\
\text { required to use the } \\
\text { same technology } \\
\text { tools \& assessment } \\
\text { measures. }\end{array}$ \\
\hline $\begin{array}{l}\text { General } \\
\text { comments }\end{array}$ & $\begin{array}{l}2 \text { pp, discussing only } \\
\text { course objectives and } \\
\text { overview. Other } \\
\text { assignment details, } \\
\text { university policies, } \\
\text { etc. are included on } \\
\text { the course in LMS }\end{array}$ & $\begin{array}{c}4 \text { pp, includes } 2 \\
\text { university policy } \\
\text { statements and an } \\
\text { attached 3-pp detailed } \\
\text { weekly schedule. }\end{array}$ & $\begin{array}{l}12 \mathrm{pp} \text {; includes } \\
\text { University policies } \\
\text { replicated on LMS; } \\
\text { detailed explanation } \\
\text { of all assignments; } \\
\text { numerous } \\
\text { introductory elements } \\
\text { useful to beginning } \\
\text { graduate students }\end{array}$ & $\begin{array}{c}13 \mathrm{pp;} \text { includes } \\
\text { University policies } \\
\text { replicated on LMS; } \\
\text { detailed explanation } \\
\text { of all assignments; } \\
\text { numerous } \\
\text { introductory } \\
\text { elements useful to } \\
\text { beginning graduate } \\
\text { students }\end{array}$ \\
\hline
\end{tabular}


Table 27: Comparison of Course CIS Results

\begin{tabular}{|c|c|c|c|c|c|}
\hline $\begin{array}{l}\text { Table } 27 \\
\text { Comparison of Course CIS Results }\end{array}$ & & & & & \\
\hline CIS Question \# & $\begin{array}{c}\text { ARCS } \\
\text { Element }\end{array}$ & \begin{tabular}{c|} 
Course \\
A
\end{tabular} & $\begin{array}{c}\text { Course } \\
\text { B }\end{array}$ & $\begin{array}{c}\text { Course } \\
\text { C }\end{array}$ & $\begin{array}{c}\text { Course } \\
\text { D }\end{array}$ \\
\hline $\begin{array}{l}\text { 1. The instructor knows how to make us feel } \\
\text { enthusiastic about the subject matter of this course. }\end{array}$ & A & 4.57 & 4.75 & 4.29 & 4.43 \\
\hline $\begin{array}{l}\text { 10. The instructor creates suspense when building up to } \\
\text { a point. }\end{array}$ & A & 3 & 2.5 & 2 & 2.43 \\
\hline $\begin{array}{l}\text { 15. The students in this class seem curious about the } \\
\text { subject matter. }\end{array}$ & A & 3.86 & 4.5 & 4.29 & 3.57 \\
\hline $\begin{array}{l}\text { 21. The instructor does unusual or surprising things that } \\
\text { are interesting. }\end{array}$ & A & 3.14 & 2.5 & 2.57 & 2.71 \\
\hline $\begin{array}{l}\text { 24. The instructor uses an interesting variety of teaching } \\
\text { techniques. }\end{array}$ & A & 4.29 & 3.5 & 4.14 & 4.29 \\
\hline $\begin{array}{l}\text { 29. My curiosity is often stimulated by the questions } \\
\text { asked or the problems given on the subject matter in this } \\
\text { class. }\end{array}$ & A & 3.57 & 4.25 & 3.86 & 4.14 \\
\hline $\begin{array}{l}\text { 4. This class has very little in it that captures my } \\
\text { attention. }\end{array}$ & A (Rev.) & 1.29 & 1 & 1.29 & 1 \\
\hline 26. I often daydream while in this class. & A (Rev.) & 1 & 1.5 & 1.14 & 1.29 \\
\hline 3. I feel confident that I will do well in this course. & $\mathrm{C}$ & 4.29 & 5 & 4.57 & 4.57 \\
\hline 9. Whether or not I succeed in this course is up to me. & $\mathrm{C}$ & 4.57 & 4.75 & 5 & 4.86 \\
\hline $\begin{array}{l}\text { 27. As I am taking this class, I believe that I can succeed } \\
\text { if I try hard enough. }\end{array}$ & $\mathrm{C}$ & 4.29 & 5 & 4.86 & 4.71 \\
\hline $\begin{array}{l}\text { 30. I feel the challenge level of this course to be about } \\
\text { right: neither too easy nor too hard. }\end{array}$ & $\mathrm{C}$ & 3.43 & 4.75 & 4.29 & 3 \\
\hline 34. I get enough feedback to know how well I am doing. & $\mathrm{C}$ & 3.14 & 5 & 4.86 & 4.86 \\
\hline $\begin{array}{l}\text { 6. You have to be lucky to get good grades in this } \\
\text { course. }\end{array}$ & C (Rev.) & 1 & 1 & 1 & 1.43 \\
\hline $\begin{array}{l}\text { 11. The subject matter of this course is just too difficult } \\
\text { for me. }\end{array}$ & C (Rev.) & 1.14 & 1 & 1 & 1 \\
\hline $\begin{array}{l}\text { 17. It is difficult to predict what grade the instructor will } \\
\text { give my assignments. }\end{array}$ & C (Rev.) & 1.71 & 1 & 1.14 & 1.14 \\
\hline $\begin{array}{l}\text { 2. The things I am learning in this course will be useful } \\
\text { to me. }\end{array}$ & $\mathrm{R}$ & 4.29 & 4.75 & 4.86 & 4.71 \\
\hline $\begin{array}{l}\text { 5. The instructor makes the subject matter of this course } \\
\text { seem important. }\end{array}$ & $\mathrm{R}$ & 4.25 & 4.5 & 4.29 & 4.57 \\
\hline $\begin{array}{l}\text { 13. In this class, I try to set and achieve high standards } \\
\text { of excellence. }\end{array}$ & $\mathrm{R}$ & 4.29 & 4.75 & 4.57 & 4.71 \\
\hline $\begin{array}{l}\text { 20. The content of this course relates to my expectations } \\
\text { and goals. }\end{array}$ & $\mathrm{R}$ & 4.14 & 4.75 & 4.71 & 4.57 \\
\hline 22. The students actively participate in this class. & $\mathrm{R}$ & 3.71 & 4.25 & 4.86 & 3.57 \\
\hline $\begin{array}{l}\text { 23. To accomplish my goals, it is important that I do } \\
\text { well in this course. }\end{array}$ & $\mathrm{R}$ & 4.71 & 5 & 4.86 & 4.71 \\
\hline 28. The personal benefits of this course are clear to me. & $\mathrm{R}$ & 3.86 & 4.75 & 4.57 & 4.14 \\
\hline $\begin{array}{l}\text { 8. I do NOT see how the content of this course relates to } \\
\text { anything I already know. }\end{array}$ & R (Rev.) & 1 & 1 & 1 & 1 \\
\hline 25. I do NOT think I will benefit much from this course. & R (Rev.) & 1.29 & 1 & 1.14 & 1 \\
\hline 12. I feel this course gives me a lot of satisfaction. & $\mathrm{S}$ & 3.57 & 4 & 3.71 & 3.43 \\
\hline
\end{tabular}




\begin{tabular}{|c|c|c|c|c|c|}
\hline $\begin{array}{l}\text { Table } 27 \\
\text { Comparison of Course CIS Results }\end{array}$ & & & & & \\
\hline CIS Question \# & $\begin{array}{c}\text { ARCS } \\
\text { Element }\end{array}$ & $\begin{array}{c}\text { Course } \\
\text { A }\end{array}$ & $\begin{array}{c}\text { Course } \\
\text { B }\end{array}$ & $\begin{array}{l}\text { Course } \\
\text { C }\end{array}$ & $\begin{array}{c}\text { Course } \\
\text { D }\end{array}$ \\
\hline $\begin{array}{l}\text { 14. I feel that the grades or other recognition I receive } \\
\text { are fair compared to other students. }\end{array}$ & $\mathrm{S}$ & 4.14 & 5 & 4.57 & 4.86 \\
\hline 16. I enjoy working for this course. & $\mathrm{S}$ & 4.14 & 4.5 & 4 & 3.57 \\
\hline $\begin{array}{l}\text { 18. I am pleased with the instructor's evaluation of my } \\
\text { work compared to how well I think I have done. }\end{array}$ & S & 3.43 & 5 & 4.57 & 4.86 \\
\hline $\begin{array}{l}\text { 19. I feel satisfied with what I am getting from this } \\
\text { course. }\end{array}$ & $\mathrm{S}$ & 4.29 & 4.75 & 4.57 & 4.43 \\
\hline $\begin{array}{l}\text { 32. I feel I get enough recognition of my work in this } \\
\text { course by means of grades, comments or other } \\
\text { feedback. }\end{array}$ & $\mathrm{S}$ & 3 & 4.5 & 4.71 & 4.71 \\
\hline $\begin{array}{l}\text { 33. The amount of work I have to do is appropriate for } \\
\text { this type of course. }\end{array}$ & $\mathrm{S}$ & 4 & 4.25 & 4.14 & 3.29 \\
\hline 7. I have to work too hard in this course. & S (Rev.) & 1.14 & 1 & 2.29 & 2.86 \\
\hline 31. I feel rather disappointed with this course. & S (Rev.) & 1.14 & 1.25 & 1.29 & 1.29 \\
\hline Survey Responses & & 7 & 4 & 7 & 7 \\
\hline
\end{tabular}


Table 28: Comparison of Course IMMS Results

Table 28

Comparison of Course IMMS Results

\begin{tabular}{|c|c|c|c|c|c|}
\hline IMMS Question \# & $\begin{array}{c}\text { ARCS } \\
\text { Element }\end{array}$ & Course A & $\begin{array}{c}\text { Course } \\
\text { B }\end{array}$ & $\begin{array}{c}\text { Course } \\
\text { C }\end{array}$ & $\begin{array}{c}\text { Course } \\
\text { D }\end{array}$ \\
\hline $\begin{array}{l}\text { 2. There is something interesting at the beginning of } \\
\text { each lesson that gets my attention. }\end{array}$ & A & 3.29 & 4.5 & 3.6 & 3.14 \\
\hline 8. The materials are eye-catching. & A & 3.71 & 4.5 & 3.8 & 3.43 \\
\hline $\begin{array}{l}\text { 11. The quality of the writing helped to hold my } \\
\text { attention. }\end{array}$ & A & 3.43 & 4 & 4.6 & 3.43 \\
\hline $\begin{array}{l}\text { 17. The way the information is arranged helped keep my } \\
\text { attention. }\end{array}$ & A & 4.29 & 4.5 & 4.2 & 3.86 \\
\hline 20. This course has things that stimulate my curiosity. & A & 4 & 5 & 4.6 & 4 \\
\hline $\begin{array}{l}\text { 24. I learned some things that were surprising or } \\
\text { unexpected. }\end{array}$ & A & 3.71 & 3.5 & 4.4 & 4.14 \\
\hline $\begin{array}{l}\text { 28. The variety of readings, exercises, illustrations, etc., } \\
\text { helped keep my attention on the lessons. }\end{array}$ & A & 3.86 & 4.5 & 4.2 & 3.71 \\
\hline $\begin{array}{l}\text { 12. This course lessons were so abstract that it was hard } \\
\text { to keep my attention on them. }\end{array}$ & A (Rev.) & 1.14 & 1 & 1 & 1.43 \\
\hline $\begin{array}{l}\text { 15. The resources for this course look dry and } \\
\text { unappealing. }\end{array}$ & A (Rev.) & 1.43 & 1 & 1.2 & 1.43 \\
\hline $\begin{array}{l}\text { 22. The amount of repetition in course lessons caused } \\
\text { me to get bored sometimes. }\end{array}$ & A (Rev.) & 1.14 & 1.5 & 1.4 & 2 \\
\hline $\begin{array}{l}\text { 29. The style of writing used in the course resources is } \\
\text { boring. }\end{array}$ & A (Rev.) & 1.43 & 1 & 1 & 1.71 \\
\hline $\begin{array}{l}\text { 31. There were so many words on each page of reading } \\
\text { that it was irritating. }\end{array}$ & A (Rev.) & 1.14 & 1 & 1.2 & 2 \\
\hline $\begin{array}{l}\text { 1. When I first looked at this course, I had the } \\
\text { impression that it would be easy for me. }\end{array}$ & C & 2.14 & 3.5 & 2.8 & 3.29 \\
\hline $\begin{array}{l}\text { 4. After reading the introductory information, I felt } \\
\text { confident that I knew what I was supposed to learn from } \\
\text { each lesson in this course. }\end{array}$ & $\mathrm{C}$ & 3.71 & 4.5 & 4.8 & 3.86 \\
\hline $\begin{array}{l}\text { 13. As I worked on each lesson, I was confident I could } \\
\text { learn the content. }\end{array}$ & $\mathrm{C}$ & 4.14 & 5 & 4.6 & 4.43 \\
\hline $\begin{array}{l}\text { 25. After working on the lessons, I was confident that I } \\
\text { would be able to pass the course. }\end{array}$ & $\mathrm{C}$ & 4.29 & 5 & 4.8 & 4.86 \\
\hline $\begin{array}{l}\text { 35. The good organization of content helped me be } \\
\text { confident that I would learn the material. }\end{array}$ & $\mathrm{C}$ & 4 & 5 & 4.6 & 4.57 \\
\hline $\begin{array}{l}\text { 3. This course material was more difficult to understand } \\
\text { than I would like it to be. }\end{array}$ & C (Rev.) & 1.29 & 1 & 1 & 1.29 \\
\hline $\begin{array}{l}\text { 7. Many of the resources have so much information that } \\
\text { it is hard to pick out and remember the important points. }\end{array}$ & C (Rev.) & 1.43 & 1.5 & 1.6 & 2.43 \\
\hline 19. The exercises in this course are too difficult. & C (Rev.) & 1.29 & 1 & 1 & 1.29 \\
\hline $\begin{array}{l}\text { 34. I could not really understand quite a bit of material } \\
\text { in this course. }\end{array}$ & C (Rev.) & 1.14 & 1 & 1.2 & 1 \\
\hline $\begin{array}{l}\text { 6. It is clear to me how the content of this course is } \\
\text { related to things I already know. }\end{array}$ & $\mathrm{R}$ & 4.57 & 5 & 4.6 & 4.57 \\
\hline
\end{tabular}




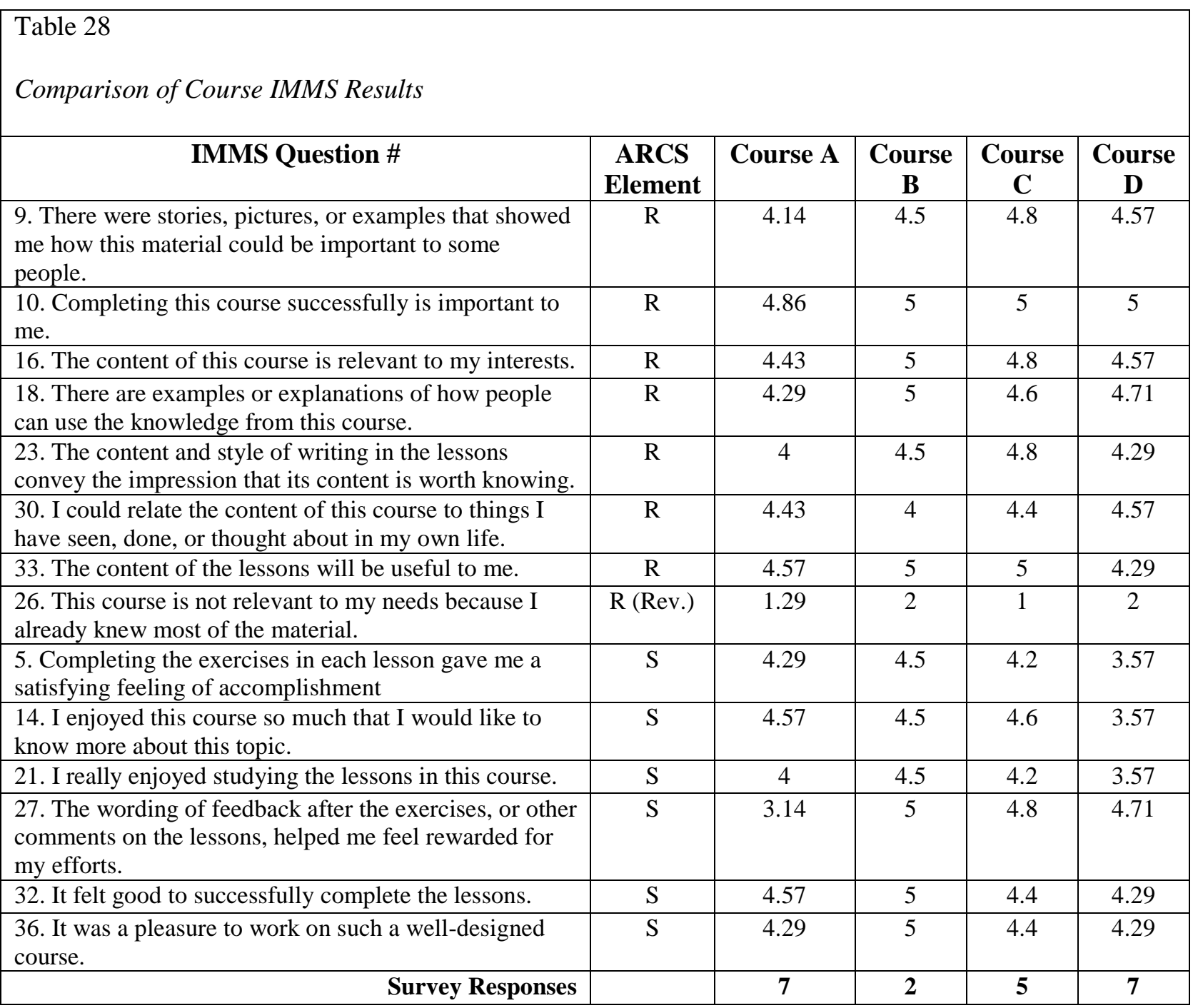


Table 29: Analysis of Course Interest Survey (CIS) Results

\begin{tabular}{|c|c|c|c|c|}
\hline $\begin{array}{l}\text { Table } 29 \\
\text { Analysis of } C\end{array}$ & Interest & ey (CIS) & & \\
\hline & $\begin{array}{c}\text { Course A } \\
\text { ID }\end{array}$ & $\begin{array}{c}\text { Course B } \\
\text { ID }\end{array}$ & $\begin{array}{c}\text { Course C } \\
\text { QM }\end{array}$ & $\begin{array}{c}\text { Course D } \\
\text { QM }\end{array}$ \\
\hline Attention & 3.77 & 3.69 & 3.59 & 3.66 \\
\hline Relevance & 4.11 & 4.53 & 4.51 & 4.33 \\
\hline Confidence & 3.89 & 4.56 & 4.43 & 4.18 \\
\hline Satisfaction & 3.81 & 4.42 & 4.08 & 3.89 \\
\hline $\begin{array}{c}\text { Motivational } \\
\text { Average }\end{array}$ & 3.89 & 4.30 & 4.15 & 4.01 \\
\hline
\end{tabular}


Table 30: Analysis of Instructional Materials Motivational Scale (IMMS) Results

\begin{tabular}{|c|c|c|c|c|}
\hline $\begin{array}{l}\text { Table } 30 \\
\text { Analysis of In }\end{array}$ & ctional Ma & als Motiva & Il Scale (In & ) Results \\
\hline & $\begin{array}{c}\text { Course A } \\
\text { ID }\end{array}$ & $\begin{array}{c}\text { Course B } \\
\text { ID }\end{array}$ & $\begin{array}{c}\text { Course C } \\
\text { QM }\end{array}$ & $\begin{array}{c}\text { Course D } \\
\text { OM }\end{array}$ \\
\hline Attention & 3.75 & 4.17 & 4.05 & 3.51 \\
\hline Relevance & 4.33 & 4.56 & 4.67 & 4.40 \\
\hline Confidence & 3.68 & 4.28 & 4.09 & 3.89 \\
\hline Satisfaction & 4.14 & 4.70 & 4.43 & 4.00 \\
\hline \multicolumn{5}{|l|}{ Motivational } \\
\hline Average & 3.98 & 4.44 & 4.31 & 3.95 \\
\hline
\end{tabular}

